University of Tennessee Health Science Center

UTHSC Digital Commons

\title{
Inhibition of Breast Cancer Angiogenesis and Metastasis ay Targeting Hypoxia-Inducible Factor-1 $\alpha$
}

Chikezie O. Madu

University of Tennessee Health Science Center

Follow this and additional works at: https://dc.uthsc.edu/dissertations

Part of the Medicinal and Pharmaceutical Chemistry Commons, and the Neoplasms Commons

\section{Recommended Citation}

Madu, Chikezie O. , "Inhibition of Breast Cancer Angiogenesis and Metastasis ay Targeting HypoxiaInducible Factor-1 $\alpha$ " (2012). Theses and Dissertations (ETD). Paper 170. http://dx.doi.org/10.21007/ etd.cghs.2012.0192.

This Dissertation is brought to you for free and open access by the College of Graduate Health Sciences at UTHSC Digital Commons. It has been accepted for inclusion in Theses and Dissertations (ETD) by an authorized administrator of UTHSC Digital Commons. For more information, please contact jwelch30@uthsc.edu. 


\title{
Inhibition of Breast Cancer Angiogenesis and Metastasis ay Targeting Hypoxia- Inducible Factor-1 $\alpha$
}

\begin{abstract}
The current clinical chemotherapy agents are not ideal for breast cancer as they are not curative, but only provide a modest extension of survival with sometimes a severely adverse effect on the patient's quality of life. There is, therefore, an urgent need to search for new and more effective anti-breast cancer drugs. However, the existing screening system is inefficient and time-consuming despite the extremely large amount of small molecule compounds in database currently available, and thereby hindering the effort for selecting new and effective anti-cancer drugs.

The majority of locally advanced solid tumors contain regions of reduced oxygen availability. Hypoxia has been identified as a major negative prognostic factor for tumor progression and resistance to anti-cancer therapies. Hypoxia promotes cell proliferation, immortalization, genetic instability, and induces cells to switch their methods of glucose metabolism, a normal response to proliferation. In animal models, HIF-1 (a heterodimer composed of one of the three alpha subunits-HIF-1 $\alpha$, HIF- $2 \alpha$ or HIF-3 $\alpha$ - and one constitutively expressed HIF-1 $\beta$ subunit) overexpression is associated with increased tumor growth, vascularization, and metastasis. The goal of this project, therefore, is to identify a novel compound with anti-HIF- $1 \alpha$ activity, using an efficient high-throughput screening system that has the capability to screen large numbers of potential anti-cancer drugs.
\end{abstract}

Because HIF- $1 \alpha$ is the transcriptional regulator for a group of malignant-pathway related genes (including VEGF) and it promotes the tumor progression and metastasis, identification of novel anti-HIF-1 $\alpha$ agents will lead to effectively blocking of HIF-1 $\alpha$-mediated "switch-on" function for those malignant-pathway related genes, and thus the suppression of VEGF signaling pathway and breast cancer progression and metastasis.

To screen for effective anti-HIF-1 $\alpha$ compounds, human breast cancer cells treated with or without candidate compounds were transfected with a chimeric construct containing a VEGF promoter fused to a reporter gene luciferase (pVEGF-Luc), followed by incubation in the hypoxic conditions. As the HIF-1 $\alpha$ mediated VEGF transactivation was reflected by increased luciferase activity, the potential anti-HIF-1 $\alpha$ effect of the compound were identified by its significant reduction of luciferase activity compared to the untreated control.

Given its potential for systemic administration and targeting, an anti HIF- $1 \alpha$ compound could prove useful as a therapy against breast carcinoma growth and invasion. We propose that down regulation of HIF- $1 \alpha$ by anti HIF-1 $\alpha$ drug will lead to a decrease in the level of hypoxiainduced genes including VEGF, subsequently resulting in the inhibition of tumor growth, decrease metastasis to surrounding organs, block tumor metastasis and increase survival in breast carcinoma animal model.

\section{Document Type}

Dissertation

Degree Name

Doctor of Philosophy (PhD)

\section{Program}

Biomedical Sciences 


\section{Research Advisor}

Yi Lu, Ph.D.

\section{Keywords}

Angiogenesis, Breast Cancer, Hypoxia Inducible Factor $1 \alpha$, Metastasis

\section{Subject Categories}

Diseases | Medicinal and Pharmaceutical Chemistry | Medicine and Health Sciences | Neoplasms 


\title{
INHIBITION OF BREAST CANCER ANGIOGENESIS AND METASTASIS BY \\ TARGETING HYPOXIA-INDUCIBLE FACTOR-1 $\alpha$
}

\author{
A Dissertation \\ Presented for \\ The Graduate Studies Council \\ The University of Tennessee \\ Health Science Center
}

\begin{abstract}
In Partial Fulfillment
Of the Requirements for the Degree

Doctor of Philosophy

From The University of Tennessee
\end{abstract}

By

Chikezie O. Madu

August 2012 
Copyright (C 2012 by Chikezie Okoro Madu.

All rights reserved. 


\section{DEDICATION}

"To (God) who is able to do immeasurably more than all we ask or imagine, according to his power that is at work within us"- Ephesians 3:20.

And to my family-my wife, Pamela; and my children, Chinua and Elechi.

For all you did to sustain my choice. Without you, this will not be. 


\section{ACKNOWLEDGEMENTS}

I observe this dissertation today not as a completion of a search, but a celebration of success; symbolizing a temporary end as well as a beginning-signifying an achievement as well as triumph.

This project culminating into this dissertation would not have been possible if it were not for the contributions and assistance I received from several people. In an attempt to express my appreciation, it will be very difficult to find words that have not already been used over again-a situation where statements will seem no longer sufficient and words inadequate. However I still wish to acknowledge the following persons who stood by me and contributed to make this long-nursed dream a reality.

I would like thank my mentor, Dr Yi Lu, for the opportunity to work in his lab, and supervising this project. To my committee members, Dr Wei Li (for providing the compounds used in this project), Dr Leonard Lothstein (for his input, valuable discussions, and accessibility; for listening and reassuring), Dr Ram I Mahato (for his kind words of encouragement and permitting me to use his lab equipment), Dr Andrzej T Slominski (for his wise suggestions). Thank you for accepting to serve as members of this committee, your thoughtful criticism, and involvement during the course of this project. I would like to thank Dr liyuan Li for the lab training. I gratefully acknowledge Dr Pfeffer for his advice, and unending encouragement and support.

My mother merits special thanks for her support and sacrifice through the years. So does my father-in-law, Obong Okon Mkpong, for his prayers and encouragement. Sufficient words fail me in expressing my gratitude to my wife, Eno-Obong Pamela, whose love, dedication, and relentless confidence in me was the driving force behind all of this. You are the bedrock upon which the past twelve years of my life have been built. My ambition was great, but your faith in me was greater. I love you dearly! To my children Chinua and Elechi, for their love, and understanding during the long years of my education, and sacrificially spending three summers with me in the lab-I promise, this is it!

This project would never have been completed without the encouragement and devotion of all of you, and so many other family members and friends. In the words of President John F. Kennedy, "In your hands, more than mine, rest the final success of (my) course". Thank you! 


\begin{abstract}
The current clinical chemotherapy agents are not ideal for breast cancer as they are not curative, but only provide a modest extension of survival with sometimes a severely adverse effect on the patient's quality of life. There is, therefore, an urgent need to search for new and more effective anti-breast cancer drugs. However, the existing screening system is inefficient and time-consuming despite the extremely large amount of small molecule compounds in database currently available, and thereby hindering the effort for selecting new and effective anti-cancer drugs.
\end{abstract}

The majority of locally advanced solid tumors contain regions of reduced oxygen availability. Hypoxia has been identified as a major negative prognostic factor for tumor progression and resistance to anti-cancer therapies. Hypoxia promotes cell proliferation, immortalization, genetic instability, and induces cells to switch their methods of glucose metabolism, a normal response to proliferation. In animal models, HIF-1 (a heterodimer composed of one of the three alpha subunits-HIF-1 $\alpha$, HIF- $2 \alpha$ or HIF- $3 \alpha$ - and one constitutively expressed HIF-1 $\beta$ subunit) overexpression is associated with increased tumor growth, vascularization, and metastasis. The goal of this project, therefore, is to identify a novel compound with anti-HIF-1 $\alpha$ activity, using an efficient high-throughput screening system that has the capability to screen large numbers of potential anti-cancer drugs.

Because HIF-1 $\alpha$ is the transcriptional regulator for a group of malignant-pathway related genes (including VEGF) and it promotes the tumor progression and metastasis, identification of novel anti-HIF-1 $\alpha$ agents will lead to the blocking of HIF-1 $\alpha$-mediated "switch-on" function for those malignant-pathway related genes, and thus the suppression of VEGF signaling pathway and breast cancer progression and metastasis.

To screen for effective anti-HIF-1 $\alpha$ compounds, human breast cancer cells treated with or without candidate compounds were transfected with a chimeric construct containing a VEGF promoter fused to a reporter gene luciferase (pVEGF-Luc), followed by incubation in the hypoxic conditions. As the HIF-1 $\alpha$-mediated VEGF transactivation was reflected by increased luciferase activity, the potential anti-HIF-1 $\alpha$ effect of the compound were identified by its significant reduction of luciferase activity compared to the untreated control.

Given its potential for systemic administration and targeting, an anti HIF-1 $\alpha$ compound could prove useful as a therapy against breast carcinoma growth and invasion. We propose that down regulation of HIF-1 $\alpha$ by anti HIF- $1 \alpha$ drug will lead to a decrease in the level of hypoxia-induced genes including VEGF, subsequently resulting in the inhibition of tumor growth, decrease metastasis to surrounding organs, block tumor metastasis and increase survival in breast carcinoma animal model. 


\section{TABLE OF CONTENTS}

CHAPTER 1. INTRODUCTION .....................................................................................1

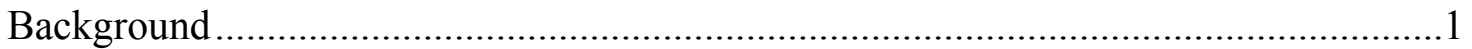

Role of Hypoxia in Human Breast Carcinoma Cell Lines.............................................

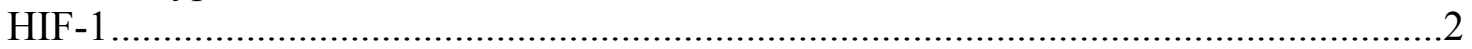

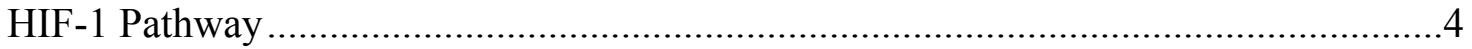

Implications of HIF-1 $\alpha$ Activation in Breast Cancer Cells ....................................6

Research Objective and Specific Aims.................................................................. 7

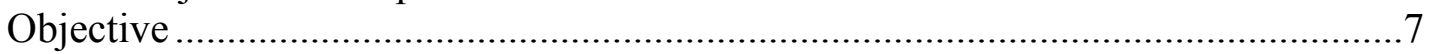

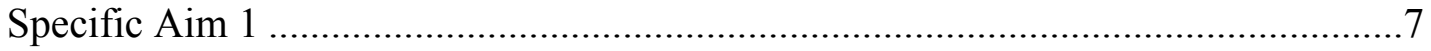

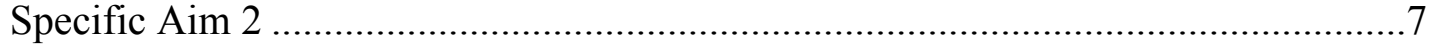

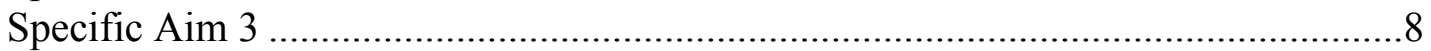

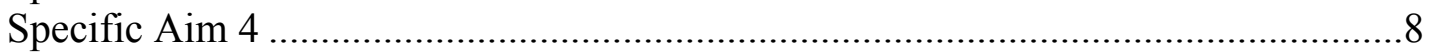

\section{CHAPTER 2. IDENTIFICATION OF NOVEL COMPOUNDS THAT INHIBIT}

VEGF SIGNALING PATHWAY ...................................................................................11

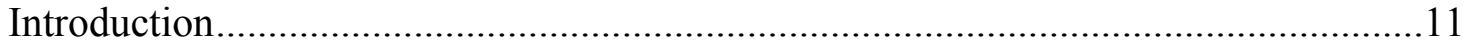

Design and Validation of a High-Throughput Screen System for Potential

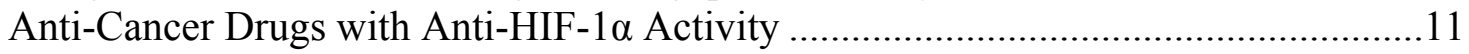

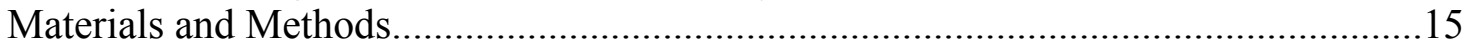

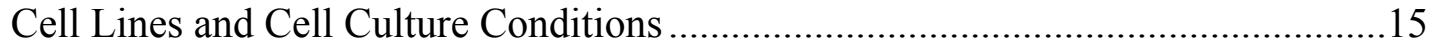

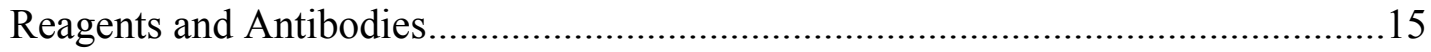

Transfection of VEGF Promoter and Screening for Anti-HIF-1 $\alpha$ Compounds.........15

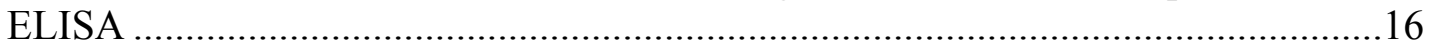

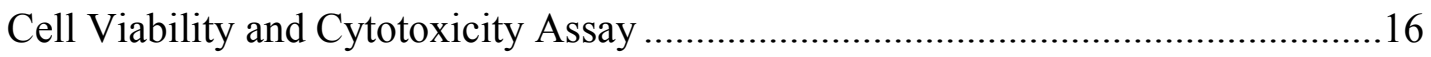

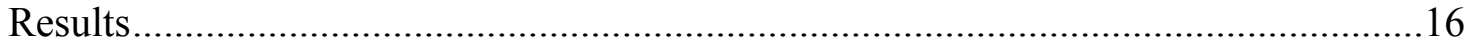

Optimization of Transfection Efficiency in Cell Line ........................................16

Screening for Novel Anti-HIF-1 $\alpha$ Compounds ..................................................18

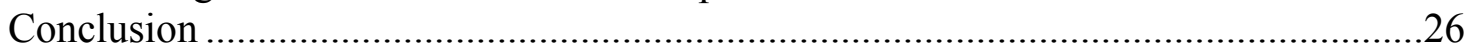

\section{CHAPTER 3. NOVEL THERAPEUTIC COMPOUND INHIBITS HIF-1 $\alpha$} BREAST CANCER CELL GROWTH IN VITRO ....................................................27

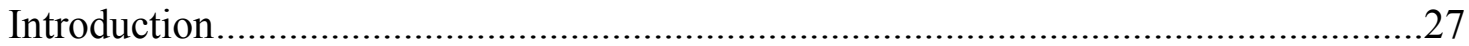

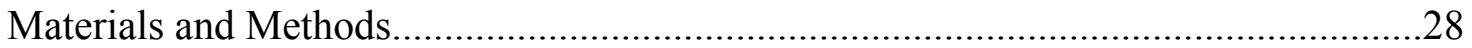

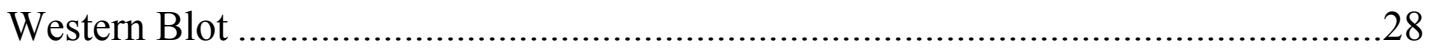

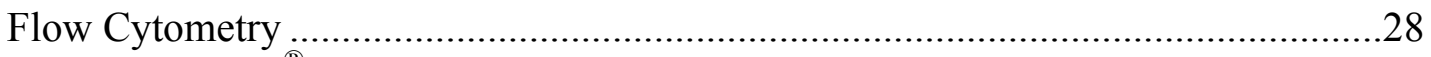

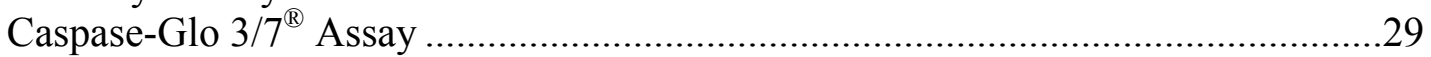

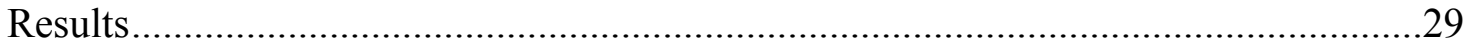

Effects of Compounds on Hypoxia-Mediated HIF-1 $\alpha$ Expression ............................29

Exposure to Compounds Induced Apoptosis in Cells..................................................32

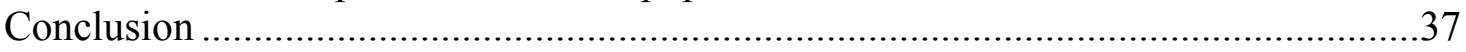




\section{CHAPTER 4. NOVEL THERAPEUTIC COMPOUND INHIBITS TUMOR

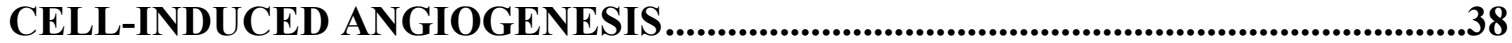

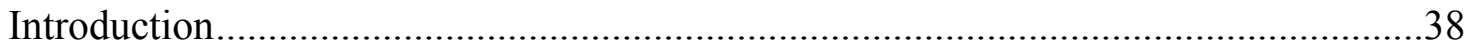

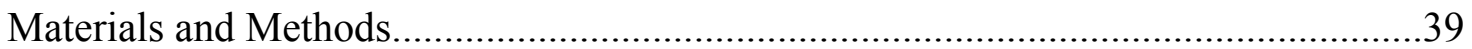

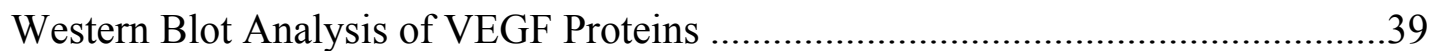

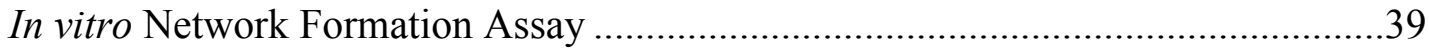

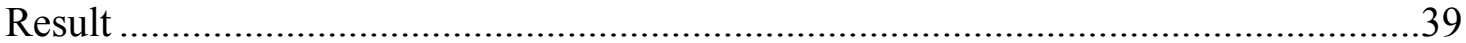

Compounds Inhibit the Induction of VEGF Proteins in MDA-MB-231 Cell Line

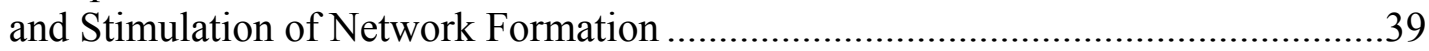

Compounds Inhibit the Stimulation of Network Formation .................................41

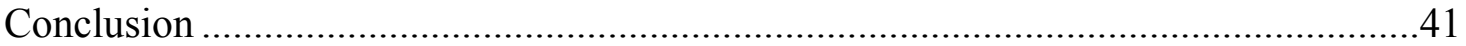

\section{CHAPTER 5. NOVEL THERAPEUTIC COMPOUND SUPPRESSES BREAST}

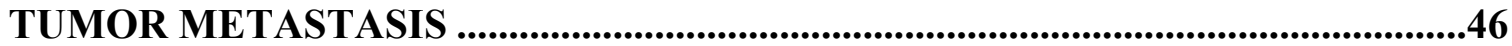

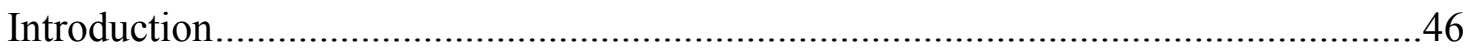

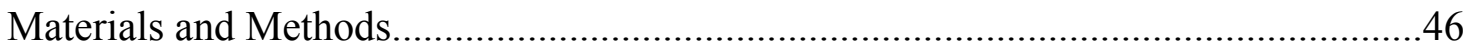

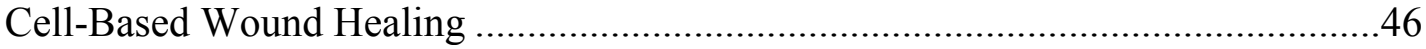

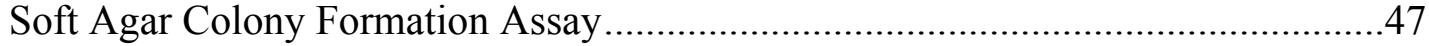

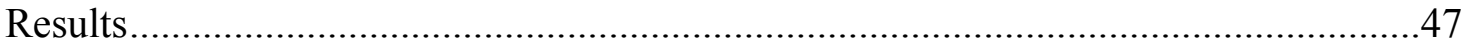

Compounds Inhibit in vitro Migration of MDA-MB-231 and JygMC(A) Cell Lines under Both Normoxia and Hypoxia Conditions ............................................47

CJ-3-60 and G3 Significantly Blocked Colony Formation.....................................50

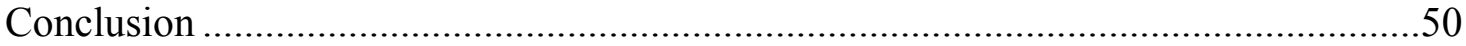

\section{CHAPTER 6. POSSIBLE MECHANISM OF ANTI-HIF-1 $\alpha$ ACTION OF} NOVEL THERAPEUTIC COMPOUND IN VITRO .......................................54

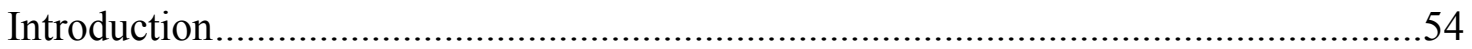

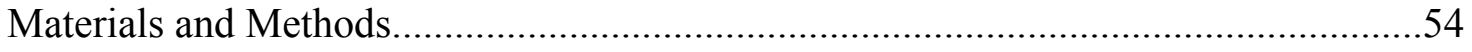

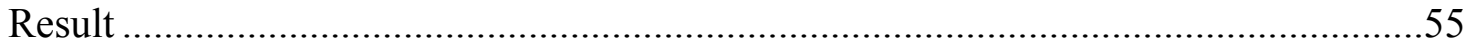

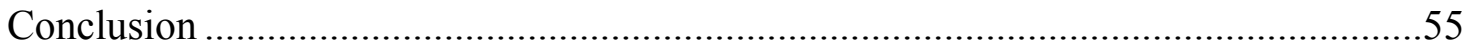

\section{CHAPTER 7. POSSIBLE MECHANISM OF ANTI-METASTATIC ACTION}

OF NOVEL THERAPEUTIC COMPOUND IN VITRO .........................................59

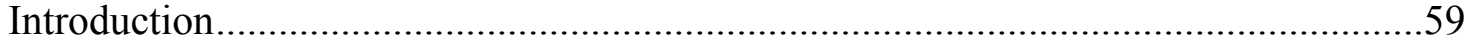

Effect of Compounds on the Expression of Hypoxia-Induced HEF1 Expression .....59

Effect of Compounds on the Expression of MMP-9 in MDA-MB-231 Cells ...........59

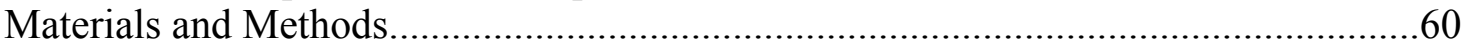

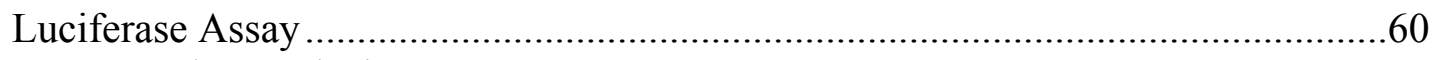

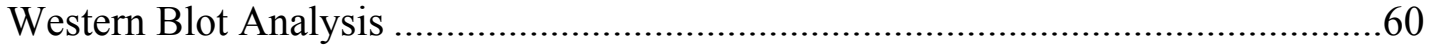

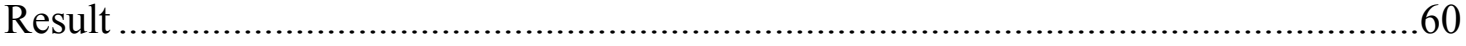

Novel Compound Inhibits Hypoxia-Induced HEF1 Expression .............................60

Compound Suppresses the Activity and Expression of MMP-9 in MDA-MB-231

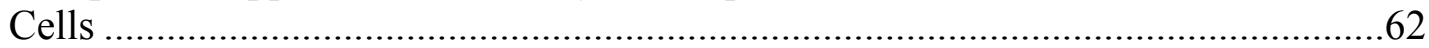

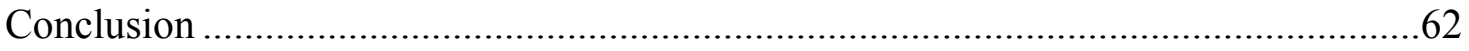


CHAPTER 8. FUTURE PRECLINICAL STUDIES ......................................................64

LIST OF REFERENCES......................................................................................66

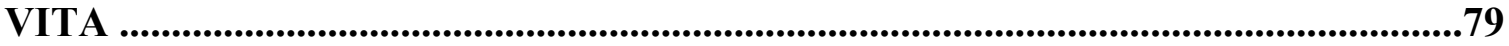




\section{LIST OF FIGURES}

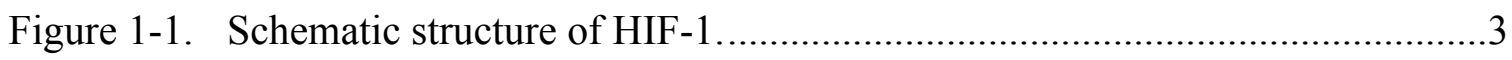

Figure 1-2. Schematic of HIF-1 $\alpha$ pathways and downstream activity. ...........................5

Figure 1-3. Hypoxia is associated with an increased expression of HIF-1 1 . .................

Figure 1-4. Hypoxia is associated with an increased expression of HIF-1 $\alpha$ inducible

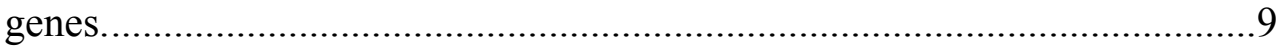

Figure 1-5. HIF-1 $\alpha$ degrades under normoxia condition in a time dependent manner. ..10

Figure 2-1. A simplified algorithm for validation of compounds through the HTS........13

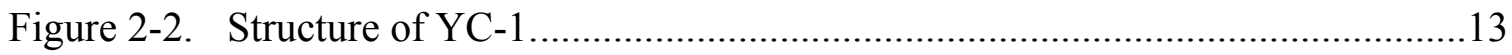

Figure 2-3. A representative sample of YC-1 analogues........................................14

Figure 2-4. Cells expressing $\beta$ galactosidase genes becoming blue after staining.........17

Figure 2-5. Luciferase assay with YC-1 treated MDA-MB-231 cells..........................19

Figure 2-6. VEGF ELISA of YC-1 treated MDA-MB-231 cells. ...............................20

Figure 2-7. MTT assay of YC-1 treated MDA-MB-231 cells...................................21

Figure 2-8. Structure of benzamide, 2-iodo-N-[1-(phenyl methyl)-1H-benzimidazol-2-yl] (G3)..............................................21

Figure 2-9. Throughput screening system for anti-HIF-1 $\alpha$ compounds (YC-1 and G3).

Figure 2-10. MTT assay of YC-1 treated compared with G3 treated MDA-MB-231 cells.

Figure 2-11. Sample analogues of G3 highlighting, in green box, one of the compounds -CJ-3-60- with the most superior anti HIF 1performance........23

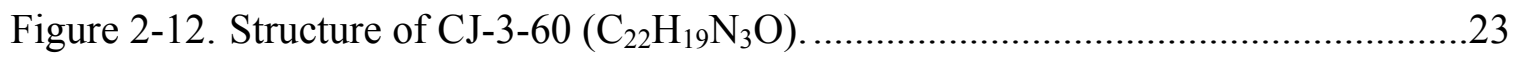

Figure 2-13. Luciferase assay of MDA-MB-231 cells treated with respective drugs......24

Figure 2-14. Determination of MDA-MB-231 cell viability treated with YC-1, G3, or CJ-3-60 by MTT assay.

Figure 2-15. Quantification of VEGF concentrations by ELISA .25 
Figure 3-1. Western blot analysis of HIF-1 $\alpha$ proteins in nuclear extract samples prepared from MDA-MB-231 and JygMC(A) cells.

Figure 3-2. Western blot analysis of HIF-1 $\beta$ proteins in nuclear extract samples prepared from MDA-MB-231.

Figure 3-3. Flow cytometric analysis of apoptosis.

Figure 3-4. Total caspase 3/7 after $72 \mathrm{hr}$ drug treated cells

Figure 3-5. Effects of YC-1, G3, and CJ-3-60 on Bcl-2 in MDA-MB-231 and JygMC(A) cells. .36

Figure 4-1. Compounds inhibit the induction of VEGF proteins in vitro.

Figure 4-2. Compounds inhibit the induction of VEGF proteins and tumor angiogenesis in vitro.

Figure 5-1. Cell migration capability was determined with a wound healing assay......48

Figure 5-2. Effects of YC-1, G3, and CJ-3-60 on soft agar colony formation.

Figure 6-1. Effect of drugs on hypoxia-induced HIF-1 $\alpha$ protein stability by post-translational modification in MDA-MB-231 cells.

Figure 6-2. Inhibitory effect of G3 and CJ-3-60 on HIF-1 $\alpha$ accumulation via prolyl hydroxylation under normoxia.

Figure 7-1. Compounds inhibit hypoxia-induced HEF1 expression.

Figure 7-2. CJ-3-60 reduced the protein levels of MMP 9 in MDA-MB-231 under hypoxic conditions in a dose-dependent manner. 


\section{LIST OF ABBREVIATIONS}

\begin{tabular}{|c|c|}
\hline$\mu$ & Micro \\
\hline$\mu \mathrm{g}$ & Microgram \\
\hline $\mathrm{C}$ & Celsius \\
\hline CHX & Cycloheximide \\
\hline DMOG & Dimethyloxalylglycine \\
\hline HIF-1 & Hypoxia-inducible factor 1 \\
\hline $\mathrm{HIF}-1 \alpha$ & Hypoxia-inducible factor 1 alpha \\
\hline $\mathrm{HIF}-2 \alpha$ & Hypoxia-inducible factor 2 alpha \\
\hline $\mathrm{HIF}-3 \alpha$ & Hypoxia-inducible factor 3 alpha \\
\hline $\mathrm{hr}$ & Hour \\
\hline KDa & Kilodalton \\
\hline L & Liter \\
\hline M & Molar \\
\hline $\min$ & Minute \\
\hline $\mathrm{ml}$ & Milliliter \\
\hline MMP 9 & Matrix Metalloproteinase-9 \\
\hline ng & Nano gram \\
\hline VEGF & Vascular Endothelial Growth Factor \\
\hline
\end{tabular}




\section{CHAPTER 1. INTRODUCTION}

\section{Background}

In 2010, an estimated 210,000 cases of invasive breast carcinoma were diagnosed in the USA [1]. Next to lung cancer, breast cancer is the second most common cancer worldwide, the fifth most common cause of cancer death, the most common malignancies in women, and the number one cause of cancer death in women between 20 and 59 years of age in the United States. An ever-increasing rate of incident cases of breast cancer has also been observed in 2007, where more than 40,000 women died from breast cancer in the United States. In 2008, an estimated 12.5\% women were expected to develop breast cancer during their lifetime, with approximately 54000 new cases of in situ breast carcinoma diagnosed in 2010 in the USA [1,2]. In terms of global burden, no other form of cancer surpasses breast cancer, with the annual cost of treatment for breast cancer patients exceeded $\$ 8$ billion in 2010 [3]. The etiology of breast cancer is somewhat complex-both environmental and genetic factors play a contributory role in its development; an exigent disease to treat due to its heterogeneous characteristic molecularly, clinically, and pathologically [4].

The discovery of molecular changes linked with the different stages of breast cancer progression has been a crucial challenge in breast cancer research for many years. Despite the discovery of new therapies and drug combinations that has led to the improvement in the prognosis of the disease, the cure remains elusive. Latest advances stemming from better understanding of the biology and the molecular transformations in these cells, coupled with improved technologies and techniques however have led to a better understanding of the intricate genetic and molecular biological inter-relationships of the different phases of breast cancer progression. Together, this has led to the design of therapies that target specific aspects of the disease. Some of these agents include angiogenesis inhibitors which targets angiogenesis, a critical step for the progression of breast cancer. The onset of angiogenesis is orchestrated by various physiological and pathological stimuli, chief among these is hypoxia [5-7].

\section{Role of Hypoxia in Human Breast Carcinoma Cell Lines}

For over four decades, researchers have identified the regions of hypoxia within many solid tumors, and over time its role in tumor progression increasingly came to light [8]. The degree of hypoxia is observed to be inversely correlated with prognosis in a number of tumor types $[9,10]$. A prevalent condition in tumors, hypoxia stimulates an extensive range of responses in cells and tissues including metastases, therapeutic resistance, and poor patient survival; hypoxic cells are more invasive, resistant to apoptosis, and genetically unstable. About $50 \%$ of breast cancer cells are hypoxic, and approximately $30 \%$ of the tumors have regions less than $0.3 \%$ median oxygen concentration, while normal breast tissues has been observed to have concentrations 
higher than $9 \%$. Therefore these cells devise physiological and pathophysiological methods of adaptation to hypoxia as a vital step for survival and growth. This phenomenon, a common hallmark of carcinomas, presents breast cancer cells with a high level of resistance to conventional radiation therapy and chemotherapy [10].

As these cells get exposed to repeated periods of hypoxia, they are compelled to adapt to this environmental stress, and this eventually may lead to induced apoptosis in response to hypoxia. Whether cells resort to apoptosis or adapt to hypoxia and survive, largely depends on the severity of hypoxic environment. An absence of nutrients or an insufficient amount will make the cells become necrotic; an alternative to undergoing energy dependent apoptosis if sufficient nutrients were available. Hypoxia inducible factor 1 (HIF-1), a family of transcription factors critically implicated in the response of mammalian cells to low oxygen levels, has been identified as the main regulator of this process. It initiates apoptosis by stimulating the synthesis of high concentrations of proapoptotic proteins, as well as targeting other genes. These resistant cells usually have a more aggressive phenotype and will often demonstrate a diminished response to established treatment [11-13]. This has prompted a search for new treatment protocols targeting hypoxic tumors [14]. The exponential growth of a tumor leads to the rapid depletion of the available nutrients and oxygen. The ultimate survival and progression of the tumor will therefore depend on its ability to instigate new vascularization in order to replenish the levels of nutrients and oxygen [15].

One key outcome arising from these responses and adaptations related to tumor evolution includes: a tilt in the balance between pro and anti-apoptotic factors to promote survival [16]. In the last couple of years, researchers have generated several strategies to target tumor hypoxia [17]. However, it was not until the discovery of Hypoxia Inducible Factors (HIF-1s), one of the primary regulators of hypoxia-responsive pathways, that a molecular target of hypoxia was recognized, which can be exploited for the development of cancer drugs [18-20].

\section{HIF-1}

HIF-1 is a transcription factor, and a heterodimer, consisting of one of the three alpha subunits (HIF-1 $\alpha$, HIF-2 $\alpha$ or HIF-3 $\alpha$ ) and one constitutively expressed HIF-1 $\beta$ subunit [18]. The protein was initially described in 1995 while researchers were investigating the hypoxic induction of the EPO gene. It was purified and revealed to be composed of two basic helix-loop-helix (bHLH) proteins of the PAS family - HIF-1 $\alpha$ and HIF-1 $\beta$ (Figure 1-1). Each exists in various forms with molecular masses of 120-130 $\mathrm{KDa}$ and 91-94 KDa respectively [16]. HIF-1 $\alpha$, recognized as the dimer distinctively associated with the transcription of the hypoxia-inducible genes, is the newly characterized of the two.HIF-1 $\beta$, on the other hand, had previously been known as the aryl hydrocarbon nuclear receptor translocator (ARNT), which is dimerized with the aryl hydrocarbon receptor. Further studies and experiments revealed other members of this family, such as HIF-2 $\alpha$ (also known as endothelial PAS protein-1) $[22,23]$ and HIF-3 $\alpha$ [24]. 


\section{HIF-1a}
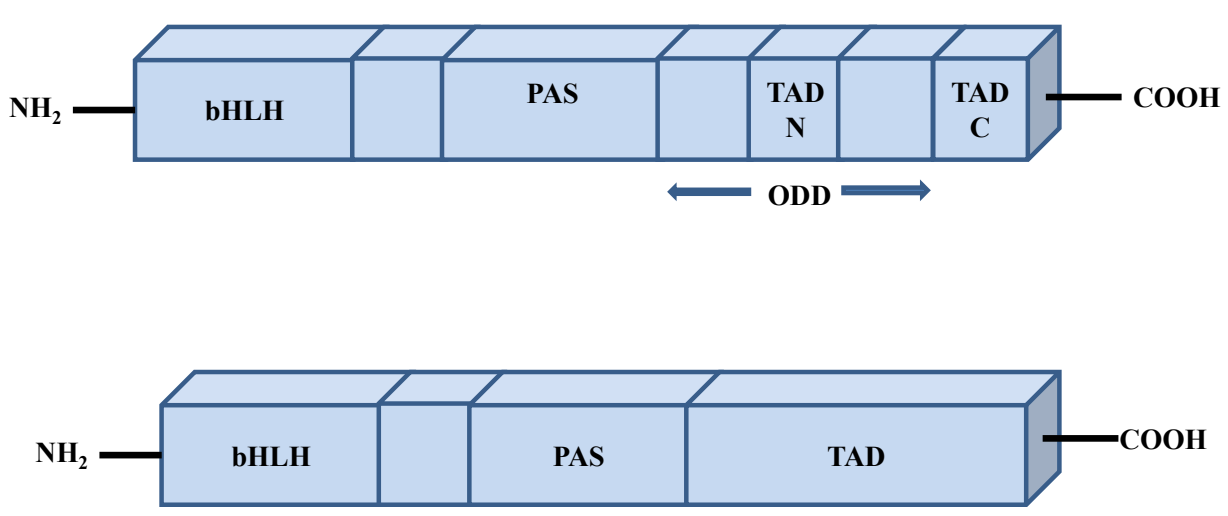

\section{HIF-1及}

\section{Figure 1-1. Schematic structure of HIF-1.}

Both the $\alpha$ and $\beta$ subunits belong to the basic helix-loop-helix (bHLH)-PAS (PER, ARNT, SIM) protein family domains, which are involved in dimerization and DNA binding. The oxygen-dependent degradation domain (ODD) regulates the stability of the $\alpha$ subunit and contains a domain for binding to the von Hippel-Lindau (pVHL) E3 ubiquitin ligase. The $\alpha$ subunit consists of 826 amino acids, and contains two transactivation domains (TAD), the $\mathrm{N}$ - and $\mathrm{C}$-terminus activation domains, while the $\beta$ subunit contains one. Transcriptional activity is regulated via domains, also several co-activators, including p300/CBP, have been identified as interacting with the TAD-C [21]. 
Just like HIF- $1 \alpha$, HIF- $2 \alpha$ is also tightly regulated by low oxygen tension and its complex, but HIF-1 $\alpha$ seems to be party directly implicated in hypoxic gene regulation [24]. Some have suggested that HIF-3 $\alpha$, though homologous to HIF- $1 \alpha$, might act as a negative regulator of hypoxia-inducible gene expression [25].

HIF-1 binds to the HRE DNA center recognition sequence (5'-RCGTG-3'), and plays a central role in tumor progression through the initiation and regulation of the transcription of a number of genes essential for tumor adaptation to hypoxia and has been implicated in major aspects of cancer biology, including immortalization, cellular dedifferentiation, genetic instability, vascularization, etc [21, 26-30], making it a principal target for anti-cancer therapy. It has also been described as unique in its expression and function in various cells of the tumor microenvironment-another feature that makes it an attractive target for therapy [31-33].

Generally, the amount of HIF- $1 \alpha$ determines the formation and transcriptional activity of HIF-1, and its expression is strongly under the control of the cell's oxygen tension [21]. HIF-1 $\alpha$ has a short half-life under normoxic conditions, making it a very unstable protein. The HIF- $1 \alpha$ protein is constantly subjected to strong oxygen-dependent proteasomal degradation in both the cytoplasm and nucleus, while the $\beta$ subunit is relatively unaffected by the oxygen concentration [34]. Additionally, as published by Chun et al, HIF-1 $\alpha$ is also regulated by a range of other stimuli, including transition metals, nitric oxide, reactive oxygen species, growth factors, and mechanical stresses [35, 36].

\section{HIF-1 Pathway}

In the presence of oxygen $\left(\mathrm{O}_{2}\right), \mathrm{HIF}-1 \alpha$ is modified post-translationally by prolyl hydroxylase at specific proline residues (Pro402, Pro564) within the ODD domain, facilitating its interaction with the von Hippel-Lindau (VHL) complex [37]. VHL is a component of a larger complex that consists of a ubiquitin-conjugating enzyme (E2). This complex prompts the ubiquitylation (Ub) of HIF-1 $\alpha$ [38, 39], rendering HIF-1 $\alpha$ a target for degradation. In hypoxia, HIF-1 $\alpha$ cannot be modified by prolyl hydroxylase, leading to the protein being stabilized. The stabilized HIF-1 $\alpha$ is translocated to the nucleus, where, subsequent to dimerization with HIF-1 $\beta$ and recruitment of numerous co activators they both bind to the same hypoxia responsive element (HRE) at the target gene loci and activate transcription of target genes [40] (Figure 1-2).

HIF-1 not only mediates cellular adaptation to hypoxia by regulating biological processes essential for cell survival, it also participates in several cellular processes that take place under normoxic conditions, such as normal tissues growth, death or survival, immune responses, and the adaptation to mechanical stresses. The regulation of HIF-1 in these cases does not rely on oxygen tension, but is coordinated by a range of stimuli. The basal level of HIF-1 $\alpha$ expression in tumor cells is also noticeably increased as a result of somatic mutations that activate oncogene products or inactivate tumor suppressors [17]. 


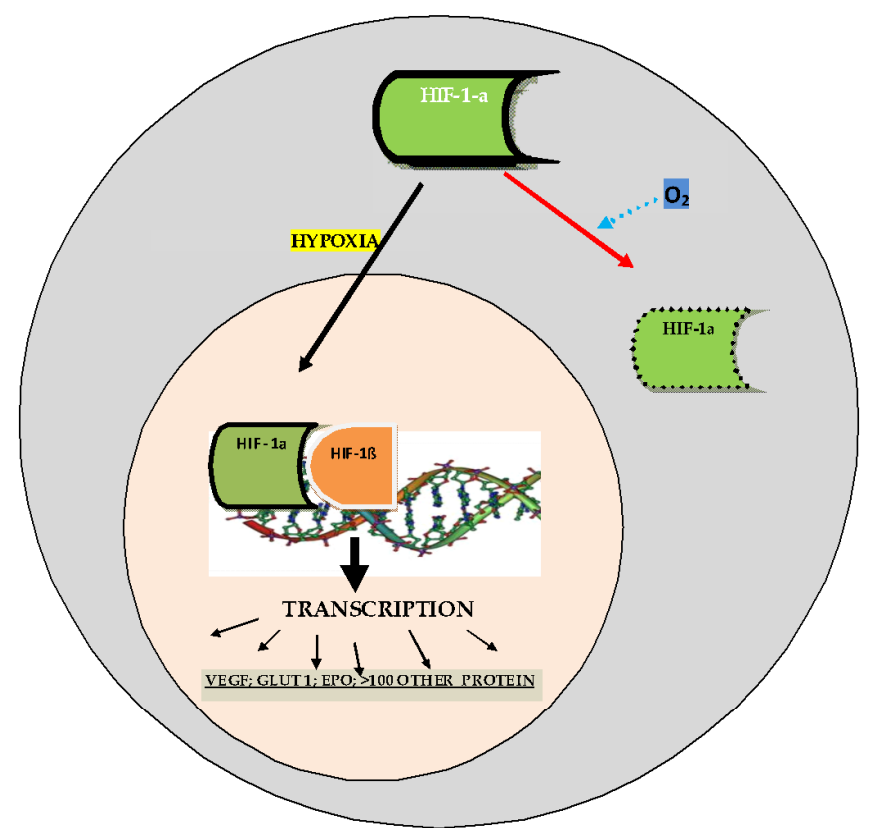

Figure 1-2. Schematic of HIF-1 $\alpha$ pathways and downstream activity.

HIF- $1 \alpha$ is either degraded in the presence of $\mathrm{O}_{2}$ (right pathway) or is stabilized in hypoxia, heterodimerizes with HIF-1 $\beta$, and binds to hypoxia response element domains (left pathway) to transcribe numerous proteins. 


\section{Implications of HIF-1a Activation in Breast Cancer Cells}

HIF-1 has been reported in normoxic tissues, which implies it may be essential for preserving the basal expression of the vital genes it regulates. Furthermore, the extensive accumulation and nuclear targeting of HIF-1 has also been reported in ischemic tissues [41]. Recent studies suggest that different target genes could be affected by HIF-1 $\alpha$ under normoxic conditions with differing physiological roles from those induced by hypoxia [42]. There is a positive correlation between the expression levels of HIF-1 in the biopsies of various solid tumors with tumor aggressiveness, vascularity, treatment failure, and mortality. Furthermore, tumor growth and angiogenesis in grafted tumors rely to a reasonably high degree on the HIF-1 activity or the expression level of HIF-1.

Consequently, HIF-1 enhances the process of angiogenesis during tumor development by inducing the expression of the gene products that promote angiogenesis, such as vascular endothelial growth factor, basic fibroblast growth factor, and angiopoietin 2. [41]. It also supports the survival of tumor cell under hypoxic conditions by means of the expression of gene products that advance anaerobic ATP synthesis, such as glucose transporters [26, $43,44]$.

As stated above several biological pathways like angiogenesis, glycolysis, apoptosis and cell cycle are regulated by HIF-1 $\alpha$. Some of these pathways, including angiogenesis, decreased apoptosis, increased cell cycling, loss of cell cycle arrest, often transform the tumor to a more aggressive phenotype [45]. Angiogenesis is vital for the growth and metastasis of solid tumors, and the inhibition of angiogenesis is seen as a prospective strategy for cancer treatment [46]. Vascular endothelial growth factor (VEGF), an angiogenic factor, plays a pivotal role in tumor angiogenesis $[15,46]$. It is a dimeric glycoprotein secreted by cells that is cable of inducing permeability and angiogenesis in tumor-associated blood vessels [47]. VEGF and its receptors are widely regarded as key targets for antiangiogenic therapy because of the role they play in angiogenesis. A series of investigations have revealed a number of antibodies and soluble proteins that interact with VEGF and its receptors that can come into play as antiangiogenic therapies for solid tumors [48].

Presently, numerous drugs have made it to clinical trials as anticancer agents based on their ability to inhibit angiogenesis [19]. Some researchers have however expressed some reservations about this approach. First of such is the fact that targeting angiogenesis might inadvertently screen for cancer cells that are adapted to hypoxic conditions, since they possess the greatest likelihood to survive a reduction in perfusion [19]. Secondly, besides angiogenesis, another vital adaptation process for cell survival under hypoxia is changes in energy metabolism which may prolong the life span of the tumor beyond its expected death [49]. Therefore, inhibiting angiogenesis directly and specifically will only inhibit one of the arrays of factors that enhance tumor growth. Scientists have proffered that since compromised glucose uptake and metabolic adaptation is also responsible for the reduced tumorigenicity, any anticancer strategy that does not target the metabolic activity of the tumor will not be effective in halting the tumor progression [50]. 
As a result of this, the consequences of inhibiting HIF-1 should be multiple since multiple targets would be hit by inhibiting a variety of genes that work in concert to advance the expansion of the tumor. Therefore, inhibition of HIF-1 activity, rather than angiogenic factors directly, could represent an important and better strategy of anti-angiogenesis therapies. In fact many novel therapeutic agents that target signal-transduction pathways that have antiangiogenic effects, may be due in part to the fact that inhibition of that signal-transduction pathways results in decreased levels of HIF-1 $\alpha[19]$.

Ryan, et al. were the first to demonstrate in studies that genetic deletion of HIF-1 can retard tumor growth. It has since then been shown that inhibition of HIF-1 will lead to inhibition of tumor expansion by decreasing pro-angiogenic gene expression [51]. It follows, therefore, that since angiogenesis is often stimulated by hypoxic conditions via VEGF synthesis, and since HIF-1 (which activity is dependent upon the level of available HIF- $1 \alpha$ ) is a hypoxia activated transcription factor that can regulate VEGF synthesis, HIF- $1 \alpha$ can be a potent mechanism for treating a broad range of hypoxia-related pathologies [52].

\section{Research Objective and Specific Aims}

\section{Objective}

The objective of this proposal was to use a synthesized novel inhibitor of HIF-1 $\alpha$ and the downstream target genes to maximally reduce tumor vascularization. Small molecule HIF-1 inhibitors represent potential drug leads that suppress tumor growth and enhance chemotherapy/radiation by inhibiting hypoxia induced gene expression. Our hypothesis is that a pharmacological drug that inhibits VEGF signaling pathway will effectively inhibit angiogenesis, which contributes to tumor growth and metastasis. Towards achieving this goal, we set the following specific aims:

\section{Specific Aim 1}

To identify the novel compounds that effectively inhibits VEGF signaling pathway. Since HIF-1 $\alpha$ is the master regulator which controls VEGF expression, a library of several hundreds of small molecule compounds were screened based on their anti-HIF-1 $\alpha$ activity.

\section{Specific Aim 2}

To determine whether the identified potentially therapeutic compounds inhibit levels of HIF-1 $\alpha$ protein produced by breast cancer cells growth in vitro, and investigate 
the potential growth inhibition of breast cancer cells by the potential therapeutic compounds.

\section{Specific Aim 3}

To determine whether potential therapeutic compounds inhibit tumor cell-induced angiogenesis. The effects of the most potential therapeutic compound on angiogenesis will be evaluated in in vitro angiogenic assays.

\section{Specific Aim 4}

To determine whether the potential therapeutic compounds suppress breast tumor metastasis, and explore their possible mechanism of anti-cancer action in vitro.

For most of the experiments, we used the MDA-MB-231 cell line, which is a human breast cancer cell line, because of its invasive phenotype, high potency of metastasis, and relatively high colony forming efficiency. The other cell line selected was the JygMC(A) cell line, a mammary carcinoma in the fat pads of a female JYG mouse that has the capacity to metastasize efficiently to sites affected in breast cancer.

We initially set out to confirm by western blot that:

a) Hypoxia condition is associated with an increased expression of HIF-1 $\alpha$ by validating HIF-1 $\alpha$ expression in MDA-MB-231 and JygMC(A) cell lines, and the induction of HIF-1 $\alpha$ protein in MDA MB cell line is at its highest level at $18 \mathrm{hr}$ in hypoxia (Figure 1-3).

b) Hypoxia condition is associated with an expression of two of HIF-1 target genes (GLUT-1 and VEGF) in MDA-MB-231 cells (Figure 1-4).

c) HIF-1 $\alpha$ degrades under normoxia condition in a time dependent manner, with a half-life of $\sim 5$ mins (Figure 1-5).

As a result of its role in angiogenesis, VEGF and its receptors have become main targets for antiangiogenic therapy. Since HIF-1 is a hypoxia-activated transcription factor that can regulate VEGF synthesis, and HIF-1 activity is dependent upon the level of available HIF-1 $\alpha$, a rationale is therefore provided for developing a novel agent aimed at targeting the hypoxic fraction of solid tumors and HIF-1-dependent responses. The discovery and development of novel agents targeting hypoxia signaling pathways is a crucial area of developmental therapeutics that continues to grow. 


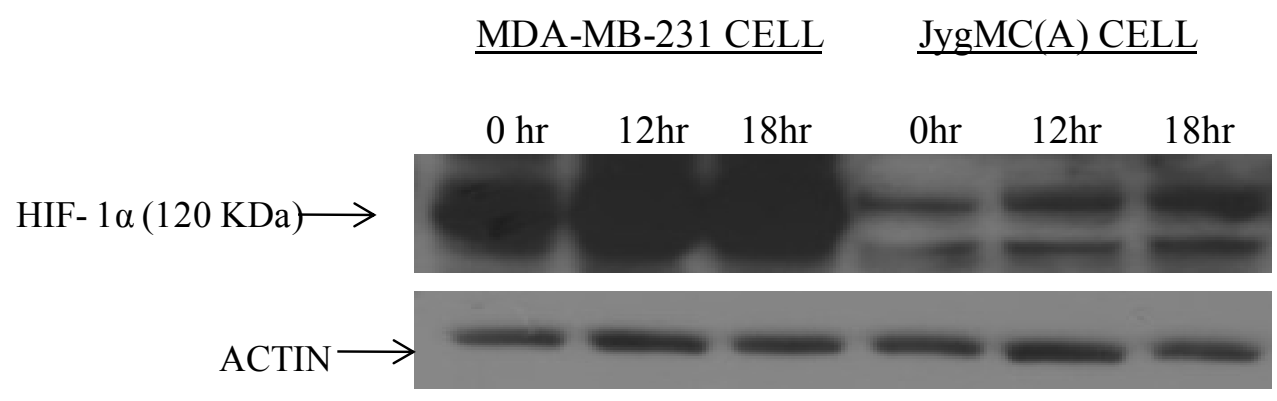

Figure 1-3. Hypoxia is associated with an increased expression of HIF-1 $\alpha$.

Effects of Hypoxia on the protein expressions of HIF-1 $\alpha$ were analyzed by western blotting. At $18 \mathrm{hr}$ hypoxic incubation, levels of HIF-1 $\alpha$ maximally increased in both MDA-MB-231 and JygMC(A) cells.

MDA-MB-231 CELL

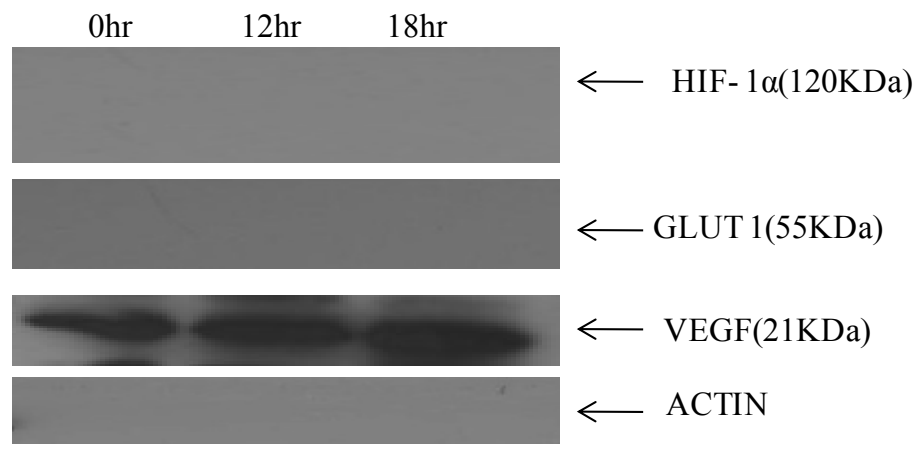

Figure 1-4. Hypoxia is associated with an increased expression of HIF-1 $\alpha$ inducible genes.

Effects of hypoxia on HIF- $1 \alpha$ inducible genes were analyzed by western blotting. At 18 hr hypoxic incubation, levels of HIF-1 $\alpha$ and VEGF protein increased, while levels of Glut 1 protein peaked at $12 \mathrm{hr}$ hypoxic incubation. 


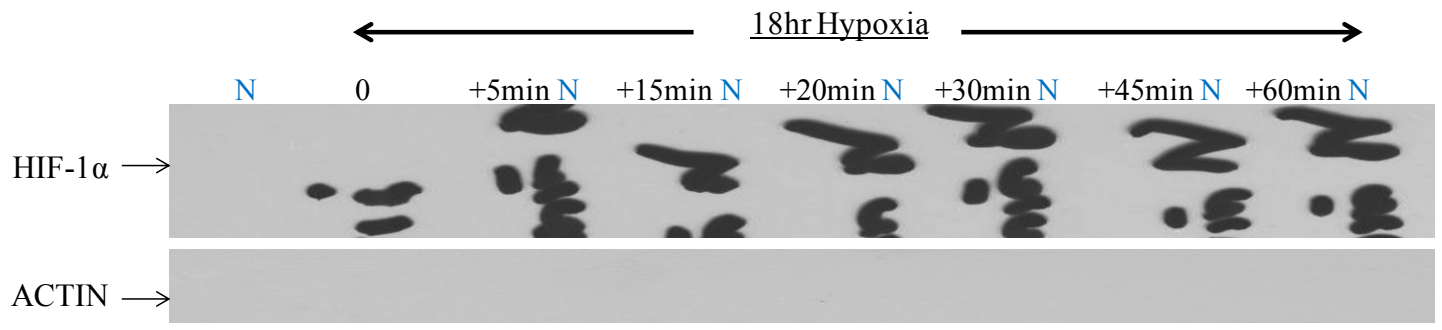

Figure 1-5. HIF-1 $\alpha$ degrades under normoxia condition in a time dependent manner.

After a $1 \mathrm{hr}$ incubation in a hypoxic environment, MDA-MB-231 cells were re oxygenenated (20\%) for different periods of time. 


\section{CHAPTER 2. IDENTIFICATION OF NOVEL COMPOUNDS THAT INHIBIT VEGF SIGNALING PATHWAY}

\section{Introduction}

An increasing number of anticancer agents have been discovered to inhibit HIF-1 activity. The mechanism of action for many of these agents involves the decrease in the rate of HIF-1 $\alpha$ synthesis, increasing the rate of HIF-1 $\alpha$ degradation, or both. These compounds perform this through the reduction of HIF-1 $\alpha$ mRNA or protein levels, modulation of HIF-1 DNA-binding activity, or HIF-1-mediated transactivation of target genes [16]. Already, several nonselective inhibitors, which indirectly target signaling pathways upstream or downstream HIF-1 have been discovered to decrease HIF-1 $\alpha$ protein levels. The prospect of HIF-1 $\alpha$ as a target for cancer therapy depends on such small molecule inhibitors of HIF-1 [19].

\section{Design and Validation of a High-Throughput Screen System for Potential Anti-Cancer Drugs with Anti-HIF-1 $\alpha$ Activity}

For several years, High-Throughput Screening (HTS), a system that expedites the screening of biochemical compound libraries against biological targets, has been extensively employed in stem cell research, drug discovery, and development of new biomaterials [53]. One of the first cell-based High Throughput Screens -targeting HIF-1 to be developed and implemented was at the Developmental Therapeutics Program of the National Cancer Institute (NCI) at Frederick, where several chemical libraries were screened to identify HIF-1 inhibitors [54]. A screen conducted by the NCI comprising of approximately 2000 compounds led to the identification of Topotecan, a camptothecin analog and topoisomerase I inhibitor, as one of the earliest and potent inhibitor of HIF-1 $\alpha$ protein translation [54]. These cell-based HTS take advantage of the ability of HIF-1 to activate transcription of reporter genes either when cells are subjected to hypoxic environment-typically $0.1-1 \% \mathrm{O}_{2}$ - or when treated with HIF-1 $\alpha$ activators, such as Dimethyloxalylglycine (DMOG) - a cell permeable prolyl-4-hydroxylase inhibitor, which upregulates HIF [55].

As reviewed in Melillo, 2006, most of the HIF-1 inhibitors described in several papers have been identified either in cell-based screens or by empirical discoveries during evaluation of HIF-1 activity in cultured cancer cell lines [18]. They rely on the ability of HIF-1 to bind a recognition sequence in the DNA (the hypoxia responsive element (HRE)) and activate transcription in a sequence-specific fashion [56]. One advantage of cell-based HIF-1-targeted HTS is the prospect of discovering small molecules that inhibit unidentified components of the hypoxic cell signaling pathway. However, several extensive mechanistic investigations are frequently required to validate any potential anti HIF-1 compound identified in the primary screen [57]; therefore more experiments are usually expected and routinely performed for the validation purposes. 
Experiments previously conducted using transiently transfecting cancer cell lines with constructs containing reporter genes under control of multiple copies of HRE, have confirmed nearly all mammalian cells respond to hypoxia with induction of HIF-1 transcriptional activity [58]. In the screens, a reliable reporter gene is used, and luciferase is commonly used for screening purposes because it can be easily measured in high throughput assays as well as in animal models by noninvasive imaging of bioluminesce [8]

We designed a high-throughput screening to identify compounds with anti HIF-1 $\alpha$ activity (Figure 2-1). A typically suggested safe guard against false results in such procedure is the inclusion of control cell lines and/or plasmids in which luciferase is constitutively expressed to exclude nonspecific effects, given that HIF-1-targeted HTS depend on synthetic promoters or inhibitors driving or suppressing the expression of a reporter gene [8]. A reporter plasmid was therefore transiently transfected into a human breast cancer cell line -MDA-MB-231 cell line or the mouse mammary carcinomas, JygMC(A). Another safe guard suggested is the inclusion of a known compound that inhibits HIF-1 or/and VEGF [8]. Therefore we carried out trial high-throughput screening assays with a known anti HIF-1 $\alpha$ compound, as a positive control, as we measured the activity of luciferase.

One compound that has been found to have potent antitumor activity is $\mathrm{YC}-1$, 3-(5'-hydroxymethyl-2'-furyl)-1-benzylindazole, a soluble guanylyl-cyclase stimulator (Figure 2-2). Soluble guanylyl cyclase is a receptor for nitric oxide, a molecule that acts in a pleiotropic manner in regulating angiogenesis and haematopoiesis. YC-1 was originally discovered in Teng's laboratory [59], and currently, is used as an inhibitor of HIF- $1 \alpha$ because it has been reported to reduce the protein level of HIF- $1 \alpha$ and inhibit the expression of hypoxia-inducible genes in cultured hepatoma cells. YC-1 was also found to arrest the growth of five xenografted human tumors without inducing noticeable toxicity. Furthermore, tumors from YC-1-treated mice showed fewer blood vessels, reduced HIF-1 $\alpha$ levels, and lower levels of HIF-1-regulated gene transcription. Research conducted by Yeo, et al. shows that it inhibits HIF-1 $\alpha$ protein stability and transactivation of downstream effector genes in cell culture studies [59-60]. It has also been described to halt tumor growth by blocking angiogenesis [61]. However, the potential of YC-1 to increase bleeding time, cause hypotension, and penile erection, limits its clinical applications [62].

With a positive control established, we then sought to find a functional novel inhibitor of HIF-1 $\alpha$ through the high-throughput screen of a library of compounds (Figure 2-3) to identify small molecules inhibiting the HIF-1 pathway (Specific Aim 1). The compounds in the library, which share a structural motif with YC-1, were tested for their ability to inhibit the hypoxic activation of a VEGF reporter gene under the control of hypoxia-responsive elements in breast cancer MDA-MB-231 and JygMC(A) cell lines.

Positive compounds were further validated by a panel of secondary assays. Some of the experiments to explicate the mechanism of action of HIF inhibition included expression of endogenous HIF-1 target genes (specifically VEGF), western blot analysis 


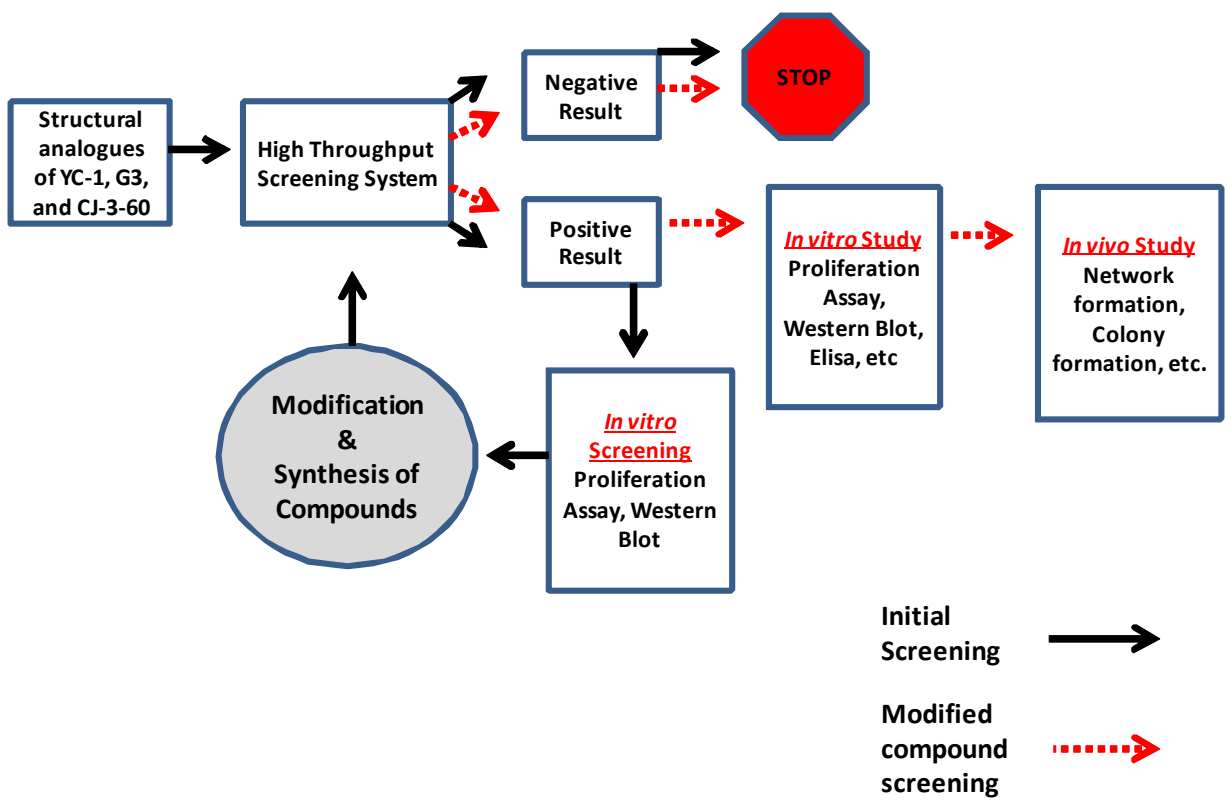

Figure 2-1. A simplified algorithm for validation of compounds through the HTS.

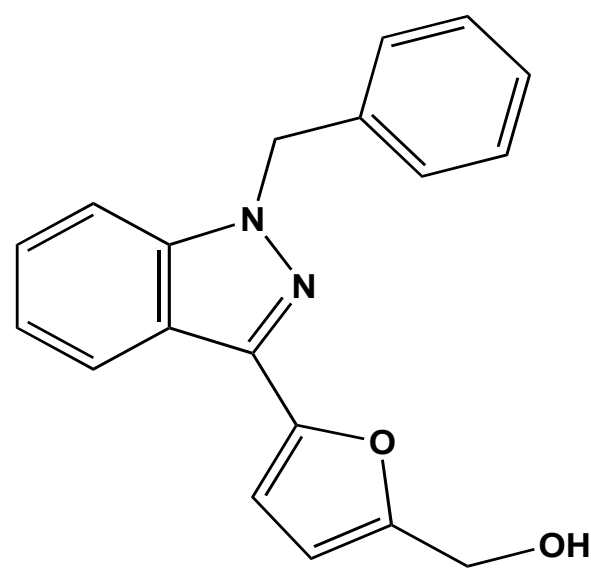

Figure 2-2. Structure of YC-1. 

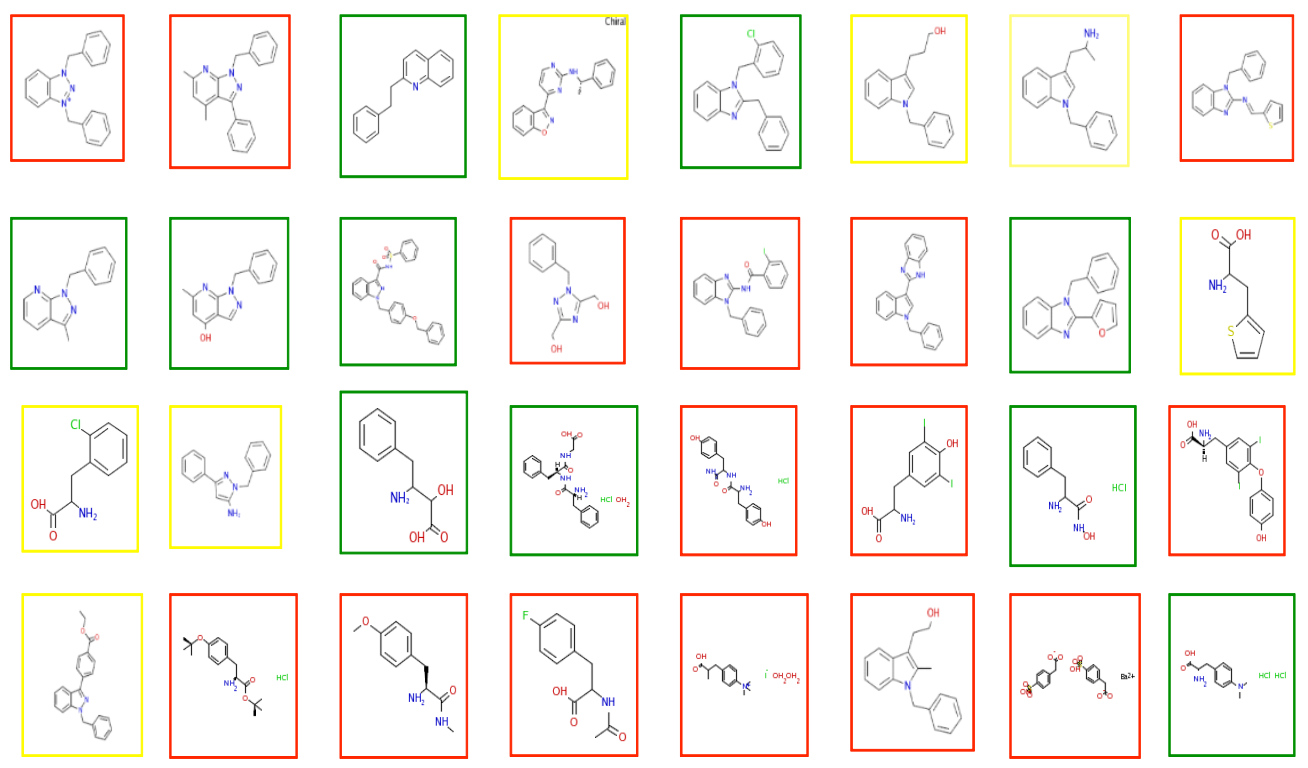

Figure 2-3. A representative sample of YC-1 analogues.

Compounds in red displayed poor outcomes as reported by the result of the HTSS, compounds in yellow displayed good outcomes, while compounds in green displayed superior outcomes. Used with permission from Dr Wei Li, Department of Pharmaceutical Sciences, University of Tennessee Health Science Center, Memphis. Tennessee. 
to measure the levels of HIF-1 $\alpha$ protein in cells, and/or Enzyme-linked immunosorbent assay (ELISA). A decrease in the levels of HIF-1 $\alpha$ protein as confirmed by these validations, revealed an impairment of protein translation or an increase of its degradation.

\section{Materials and Methods}

\section{Cell Lines and Cell Culture Conditions}

RPMI-1640 media was purchased from Gibco BRL (Gaithersburg, MD), and Fetal Bovine Serum (FBS) from Hyclone Human breast cancer cell lines MDA-MB-231 (ATCC) and Murine mammary carcinoma cell line JygMC(A) was grown in RPMI-11995 media purchased also from Gibco BRL (Gaithersburg, MD). All cell lines were grown in medium containing $10 \% \mathrm{FBS}, 100$ units $/ \mathrm{ml}$ penicillin, and $100 \mu \mathrm{g} / \mathrm{ml}$ streptomycin at $37^{\circ} \mathrm{C}$ either under normoxia $\left(5 \% \mathrm{CO}_{2}, 21 \% \mathrm{O}_{2}\right)$ or hypoxia $\left(5 \% \mathrm{CO}_{2}\right.$, $0.5 \% \mathrm{O}_{2}$, balanced with $\mathrm{N}_{2}$ ) conditions.

\section{Reagents and Antibodies}

YC-1 was purchased from AXXORA, LLC. (San Diego, CA), Benzamide, 2-iodo-N-[1-(phenyl methyl)-1H-benzimidazol-2-yl] (G3) was purchased from Ryan Scientific, Inc (Mt. Pleasant, SC.), while CJ-3-60 was synthesized based on its structural similarity to G3 by Dr Wei Li's lab at the University of Tennessee health Science center. All compounds were dissolved in dimethyl sulfoxide (DMSO) to $100 \mathrm{mM}$ stock solution and stored at $-80{ }^{\circ} \mathrm{C}$.

\section{Transfection of VEGF Promoter and Screening for Anti-HIF-1a Compounds}

An expression vector pSV40- $\beta$-gal (Promega), which expresses a $\beta$-galactosidase (LacZ) reporter gene and enables transfected cells to become blue cells after X-gal staining, was used to optimize the conditions. We determined the optimal transfection rate in the cells in 96-well tissue culture plate by the transfection reagent Fugene 6. Subsequently, after determining the correct amount of DNA required, we transiently transfected a chimeric construct containing a 2.4-kb VEGF promoter and a luciferase reporter gene (pVEGF/Luc) into MDA-MB-231 cells by Fugene 6 (Roche, Indianapolis, IN) according to the manufacturer's instructions.

The transfection was carried out in the following way: Cells were seeded in a 96 well plate $\left(5 \times 10^{4}\right.$ cells $/ \mathrm{ml}, 100 \mu \mathrm{l} /$ well $)$. After $4-6 \mathrm{hr}$ they were treated with various concentrations $(0,1,10$, and 100) of the respective anti HIF-1 $\alpha$ compounds throughout the experiment. $48 \mathrm{hr}$ after transfection, the cells in drug treatment were incubated in 
hypoxic condition $\left(37^{\circ} \mathrm{C}\right.$ in $\left.5 \% \mathrm{CO}_{2}, 0.5 \% \mathrm{O}_{2}\right)$ conditions for another $18 \mathrm{hr}$. The cell extracts were then harvested and analyzed for luciferase activity using Luciferase Assay Kit (Promega) according to the manufacturer's instructions. After lysis, $2 \mu 1$ of total $20 \mu 1$ cell extracts per well was used to detect protein concentration for normalization (Coomassie Plus Protein Assay Reagent, Pierce), and the remaining $18 \mu$ l of the cell extract was used to measure luciferase activity (Luciferase Assay System, Promega), and detected by using a 96-well plate luminometer (Synergy HT Multi-Mode Microplate Reader, BioTek, Winooski, VT). At least three independent experiments were done with each performed in triplicates. The known anti-HIF-1 $\alpha$ agent, YC-1, was used as a positive control whenever new or existing candidate compounds were screened.

\section{ELISA}

Cells were plated in six-well plates and cultured to $80-90 \%$ confluence. The medium was replaced and cultures were treated with indicated concentrations of compounds, followed by incubation under normoxic or hypoxic conditions for $24 \mathrm{hr}$ as indicated. Secreted VEGF in extracellular medium was quantified (R\&D Systems, Minneapolis, MN) by comparison with a series of VEGF standard samples included in the assay kit. VEGF level in each experiment was measured twice.

\section{Cell Viability and Cytotoxicity Assay}

Cells were either treated or untreated with compounds in 96-well tissue culture plates $\left(5 \times 10^{3}\right.$ cells per well) for $72 \mathrm{hr}$. For experiments involving a six-day testing period in normoxia, the cells were treated with or without medium that contained test compounds $(0,0.1,1,10,100 \mu \mathrm{M}$ respectively), which were replaced with fresh culture medium that contained the same test compound after three days (results not shown). Following the incubation period, cell viability was determined by MTT [3-(4, 5-dimethylthiazolyl-2)-2, 5-diphenyltetrazolium bromide] kit assay as described by the manufacturers (Sigma). Absorbance at $570 \mathrm{~nm}$ was measured on a BioTek Synergy plate reader with background absorbance at $690 \mathrm{~nm}$.

\section{Results}

\section{Optimization of Transfection Efficiency in Cell Line}

The highest transfection rate (about 40\%) was achieved in the cells in a 96-well tissue culture plate by transfection reagent Fugene 6 and AdRSVlacZ (which expresses an E.coli $\beta$-galactosidase gene, and becomes blue after X-gal staining) (Figure 2-4). 


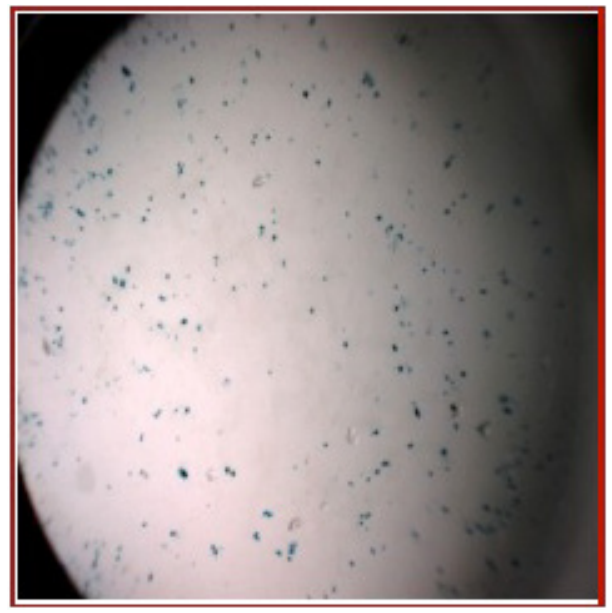

Figure 2-4. Cells expressing $\beta$ galactosidase genes becoming blue after staining.

Using lac $\mathrm{z}$ as a reporter gene in our transfection, we verified that the cells expressed ability to be transfected, and determined the optimal amount of DNA required for transfection. 


\section{Screening for Novel Anti-HIF-1a Compounds}

HIF- $1 \alpha$ is a transcriptional activator VEGF gene promoter [64-67]. We have in previous experiments used a chimeric construct, pVEGF-Luc, fused to a luciferase reporter gene to demonstrate and measure the functional activity of HIF-1 $\alpha$ [68]. Therefore we transfected pVEGF/Luc into treated and untreated MDA-MB-231 cells, and measured the VEGF inhibitory effect of these drugs. This was done to (a) confirm that this screening system had the ability to identify a potential anti-HIF-1 $\alpha$ compound by measuring the quantity of the HIF-1 inducible gene-VEGF (b) screen numerous compounds simultaneously with high efficiency and, (c), identify a potential (either novel or existing) anti-HIF-1 $\alpha$ compound and compare the quantity of the HIF-1 inducible gene-VEGF with a known drug like YC-1. We observed a huge induction of VEGFpromoter transactivity by hypoxia in untreated cells, compared to that in drug treated, indicating an impressive inhibition of VEGF and the transactivator, HIF-1 $\alpha$ by YC-1 (Figures 2-5). VEGF secretion in normoxia and hypoxia condition was measured to further confirm the effect of YC-1 on VEGF proteins secreted by cells compared to untreated. The result indicates that secreted VEGF proteins were reduced under normoxia when compared with hypoxia, and YC-1 induced an inhibition of the protein in both normoxia and hypoxia (Figure 2-6). An MTT assay was also done to investigate the cytotoxic effect of YC-1 on the cells. In the human breast tumor MDA-MB-231, YC-1 decreased cell viability/proliferation by $\sim 60 \%$ at $10 \mu \mathrm{M}$ after $72 \mathrm{hr}$ (Figure 2-7).

Of the hundreds of compounds screened from a defined small molecule library, we identified one compound, a structural analogue of YC-1, G3 (Figure 2-8), that displayed more potent anti-HIF-1 $\alpha$ activity when compared to an established drug like YC-1 (Figure 2-9). The potency of G3 was further tested by MTT assay (Figure 2-10), and the inhibitory activity of G3 against cell proliferation was observed in the different breast cancers cell lines used.

In search of a more potent small-molecule inhibitors of HIF- $1 \alpha$ mediated transcription, we embarked on screening several small molecule compounds synthesized by Dr Wei Li's lab (Department of Pharmaceutical Sciences, University of Tennessee Health Science Center, Memphis.TN), as analogues of G3 (Figure 2-11), with the aim to discover a novel compound using this screening system. These compounds were screened as described above using luciferase, MTT, and ELISA assays sequentially, and the most potent of them -a compound we named CJ-3-60- (Figure 2-12) was singled out for further testing (Figures 2-13, 2-14, 2-15).

The VEGF concentrations were quantified by comparison with a series of VEGF standard samples included in the assay kit. VEGF level in each experiment was measured twice. The level of VEGF protein expression was markedly lower in G3 and CJ-3-60-treated cell than in YC-1-treated cells (Figure 2-12). In addition, these levels were lower in the CJ-3-60 -treated cells than the G3 -treated cells at the same concentration (Figure 2-15). 


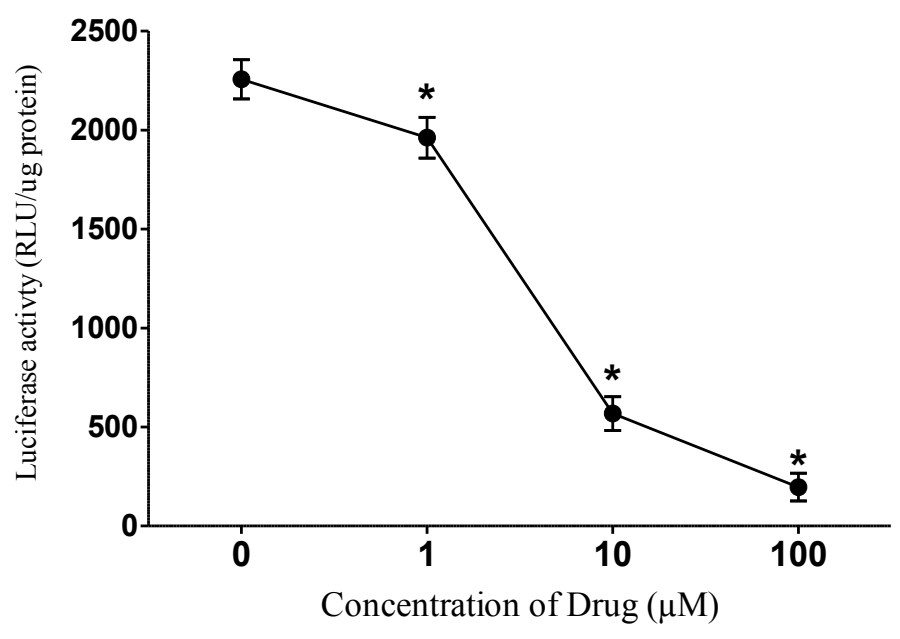

Figure 2-5. Luciferase assay with YC-1 treated MDA-MB-231 cells.

MDA-MB-231 cells were transfected with VEGF reporter that contains the $2.4 \mathrm{~kb}$ human VEGF promoter element inserted upstream of firefly luciferase vector. After transfection, the cells were cultured for $48 \mathrm{hr}$, while being incubated with YC-1 at different concentrations indicated. Cells were incubated in hypoxia for the last $18 \mathrm{hr}$. Protein concentrations from respective wells were used to normalize the luciferase reading. VEGF transcriptional activation was indicated by the relative luciferase activity in the cells. The data indicate that YC-1 inhibited VEGF transcriptional activation in a dosedependent manner. The figure shows mean $\pm \mathrm{SD}$ of relative luciferase activities for each group when compared to that of the control. (* indicates $p<0.05$ when compared to the control). 


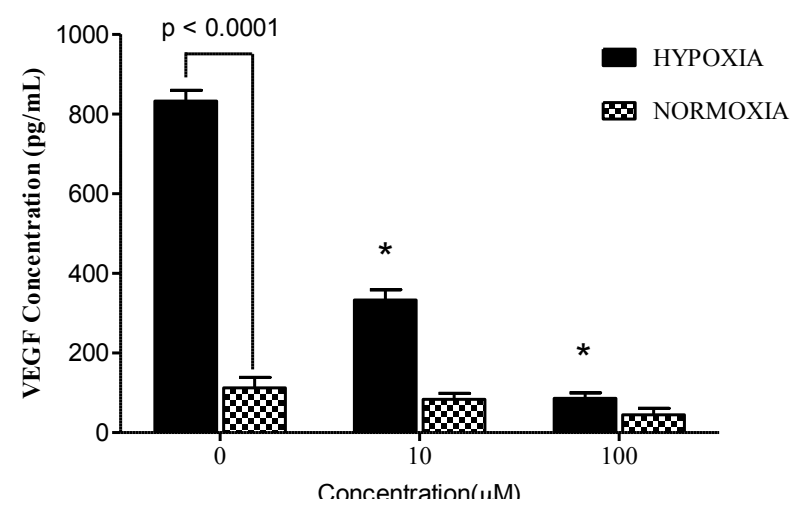

Figure 2-6. VEGF ELISA of YC-1 treated MDA-MB-231 cells.

Conditioned Media and VEGF Enzyme-Linked Immunosorbent Assay.MDA-MB-231 cells were plated in a six-well plate at a density of $3 \times 10^{5}$ cells/well. Cells were treated with YC-1 $(0,10$ and $100 \mu \mathrm{M})$ for $72 \mathrm{hr}$ in normoxia and were then subjected to hypoxia for $24 \mathrm{hr}$. VEGF levels in the conditioned media were quantified by using the Quantikine human VEGF Immunoassay kit (R\&D Systems, Minneapolis, MN) according to the manufacturer's recommended protocol. The VEGF concentrations were quantified by comparison with a series of VEGF standard samples included in the assay kit. Data shown are averages from one representative experiment performed in duplicate and the bars indicate standard deviation. The $\mathrm{p}$ values are provided when there is a statistically significant difference. ( $*$ indicates $p<0.05$ when compared to the hypoxic control). 


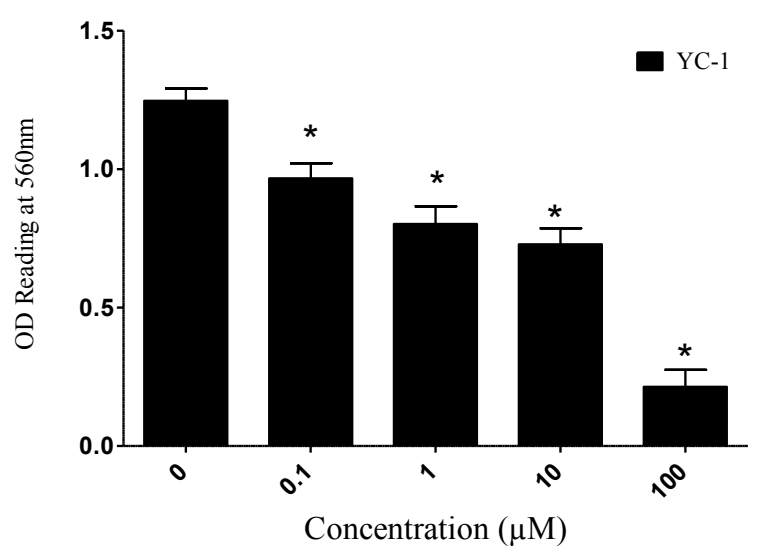

Figure 2-7. MTT assay of YC-1 treated MDA-MB-231 cells.

Proliferation of MDA-MB-231 breast cancer cells is inhibited by YC-1 in a dosedependent manner. The inhibitory effect of YC-1 on the growth of MDA-MB-231 cells were tested using a 3-(4, 5-dimethyl-2-thiazolyl)-2,5-diphenyl-2H-tetrazolium bromide (MTT) assay. MTT assay was determined at $570 \mathrm{~nm}$ and expressed as cell survival relative to control. MDA-MB-231 cells were treated with $0,0.1,1,10$, and $100 \mu \mathrm{M}$ of the drug $72 \mathrm{hr}$. The values are shown as mean S.D. of triplicate wells, and experiment was repeated three times. $*$ indicates $p<0.05$ when compared to the control.

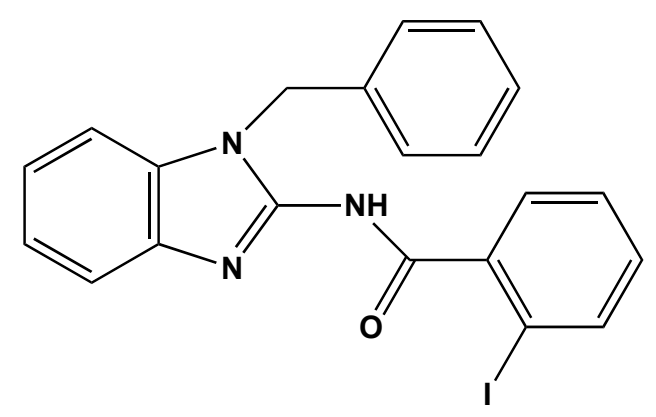

Figure 2-8. Structure of benzamide, 2-iodo-N-[1-(phenyl methyl)-1H-benzimidazol-2-yl] (G3). 


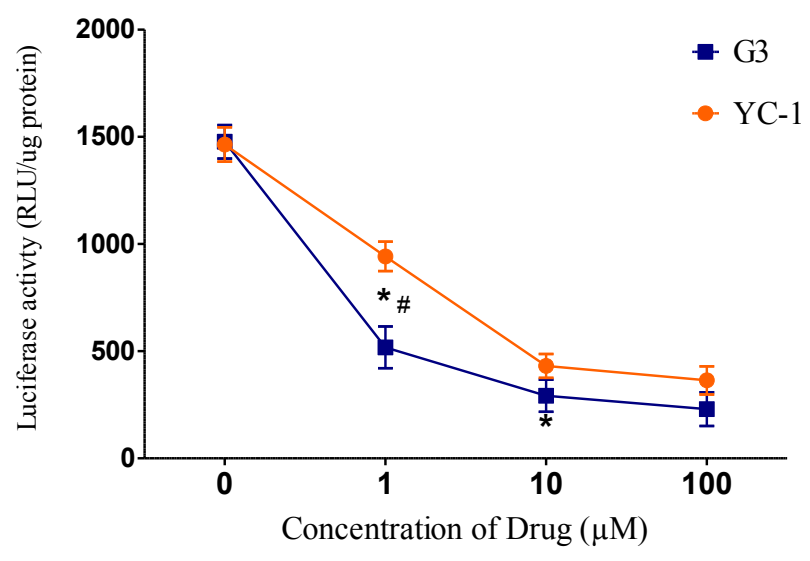

Figure 2-9. Throughput screening system for anti-HIF-1 $\alpha$ compounds (YC-1 and G3).

To identify novel compounds for HIF-1 pathway inhibition, numerous compounds from a library of compounds structurally analogous to YC-1 were screened. MDA-MB-231 cells were plated in 96 well plates and treated with serial dilution of YC-1 and G3 respectively in triplicates. Luciferase assay were conducted similarly to that described in the earlier section. Out of all the compounds screened, G3 displayed more compelling anti HIF-1 effect when compared to YC-1. * indicates $p<0.05$ when compared to the control, \# indicates $p<0.05$ when compared to YC- 1 at the same concentration.

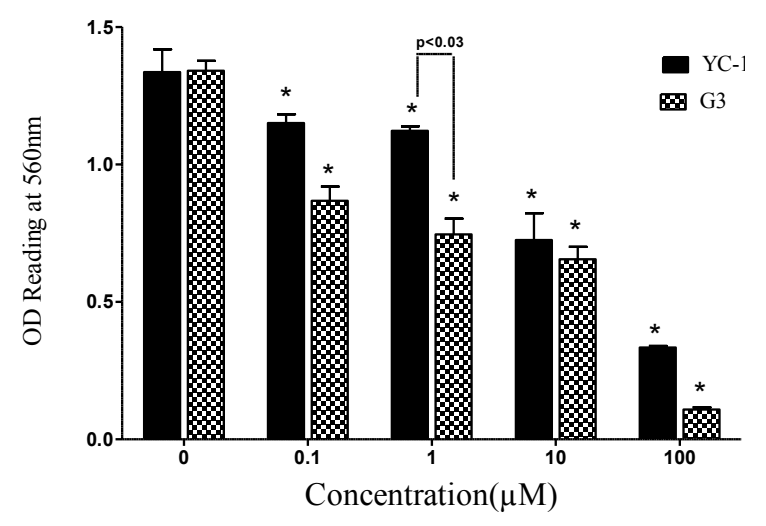

Figure 2-10. MTT assay of YC-1 treated compared with G3 treated MDA-MB-231 cells.

Cells were treated with $\mathrm{YC}-1$ or $\mathrm{G} 3$ as described in the materials and methods section. Each value is presented as mean \pm S.D. of three independent experiments. These data indicated that G3 also inhibited cell proliferation/viability in a dose-dependent manner, and this inhibition is more potent in cells treated with YC-1. (* indicates $p<0.05$ when compared to the control). 

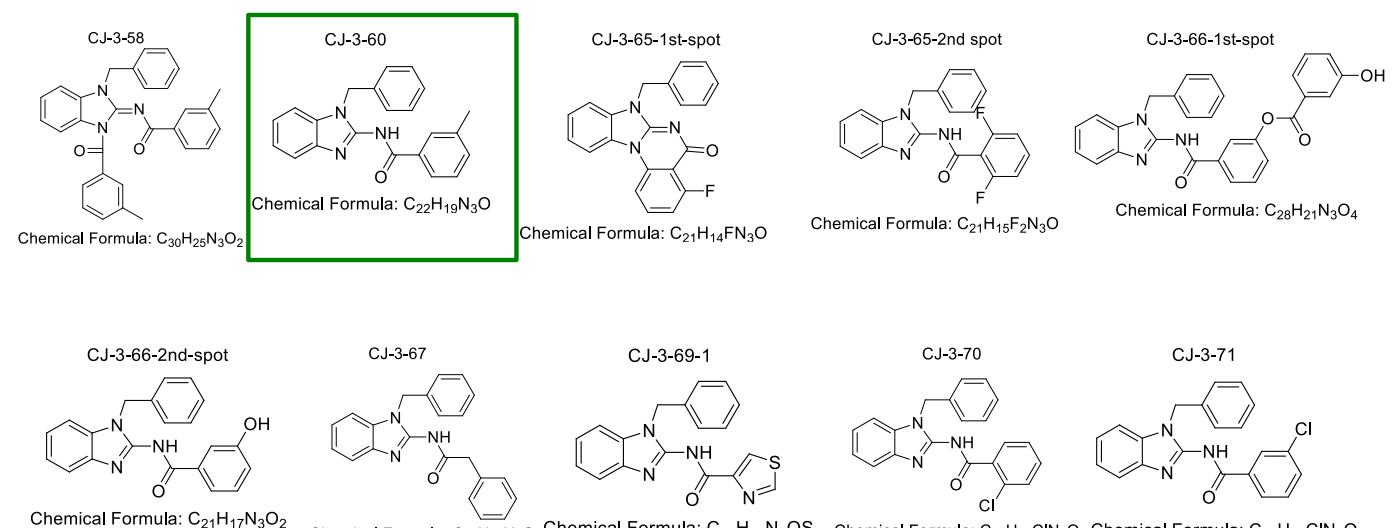

Chemical Formula: $\mathrm{C}_{22} \mathrm{H}_{19} \mathrm{~N}_{3} \mathrm{O}$ Chemical Formula: $\mathrm{C}_{18} \mathrm{H}_{14} \mathrm{~N}_{4} \mathrm{OS}$

Chemical Formula: $\mathrm{C}_{21} \mathrm{H}_{16} \mathrm{CIN}_{3} \mathrm{O}$ Chemical Formula: $\mathrm{C}_{21} \mathrm{H}_{16} \mathrm{CIN}_{3} \mathrm{O}$
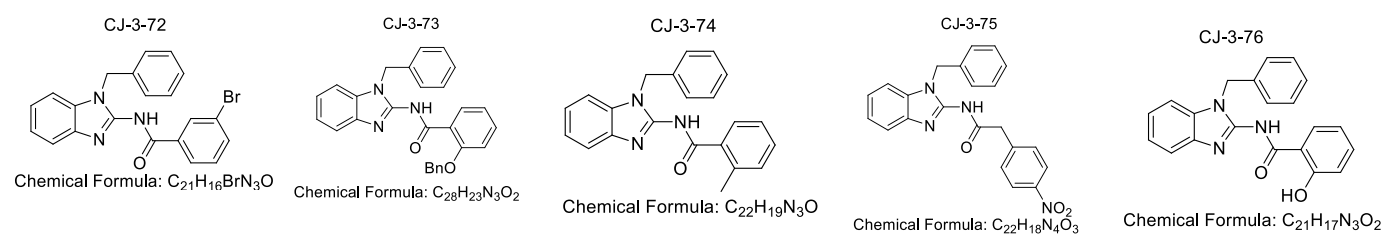

Figure 2-11. Sample analogues of G3 highlighting, in green box, one of the compounds -CJ-3-60- with the most superior anti HIF-1 performance. Used with permission from Dr Wei Li, Department of Pharmaceutical Sciences, University of Tennessee Health Science Center, Memphis. Tennessee.

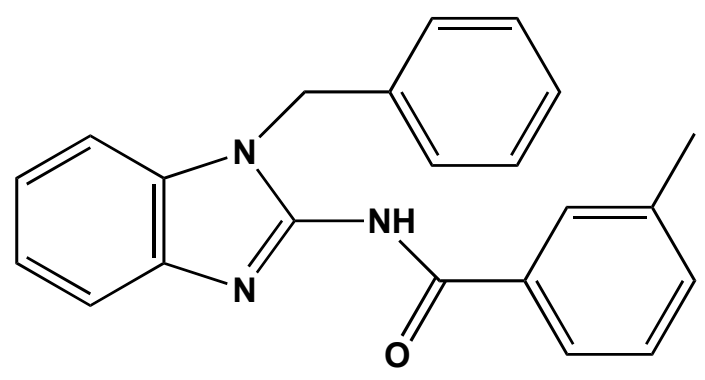

Figure 2-12. Structure of CJ-3-60 $\left(\mathrm{C}_{22} \mathrm{H}_{19} \mathrm{~N}_{3} \mathrm{O}\right)$. 


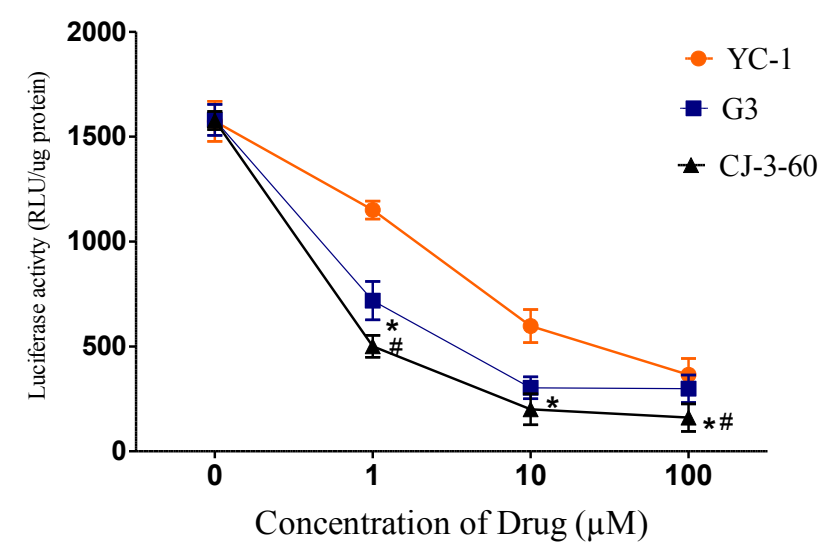

Figure 2-13. Luciferase assay of MDA-MB-231 cells treated with respective drugs.

To identify novel compounds for HIF-1 pathway inhibition, numerous compounds from a library of compounds structurally analogous to $\mathrm{YC}-1$ were screened. Result here shows that CJ-3-60 exhibited the most potent anti HIF-1 effect on the breast cancer cells when compared to $\mathrm{G} 3$ and $\mathrm{YC}-1 .{ }^{*}$ indicates $p<0.05$ when compared to the control; \# indicates $p<0.05$ when compared to $\mathrm{YC}-1$ at the same concentration.

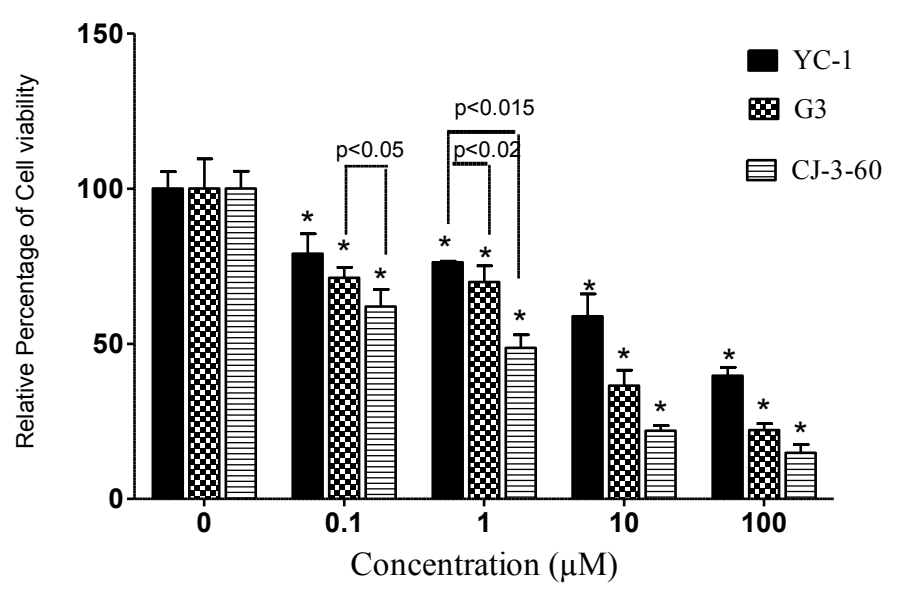

Figure 2-14. Determination of MDA-MB-231 cell viability treated with YC-1, G3, or CJ-3-60 by MTT assay.

Cells were treated with YC-1, G3, or CJ-3-60 as described earlier for $72 \mathrm{hr}$. These data indicated that all drugs inhibited cell proliferation/viability in a dose-dependent manner, and this inhibition is more potent in cells treated with CJ-3-60. * indicates $p<0.05$ when compared to the control. 


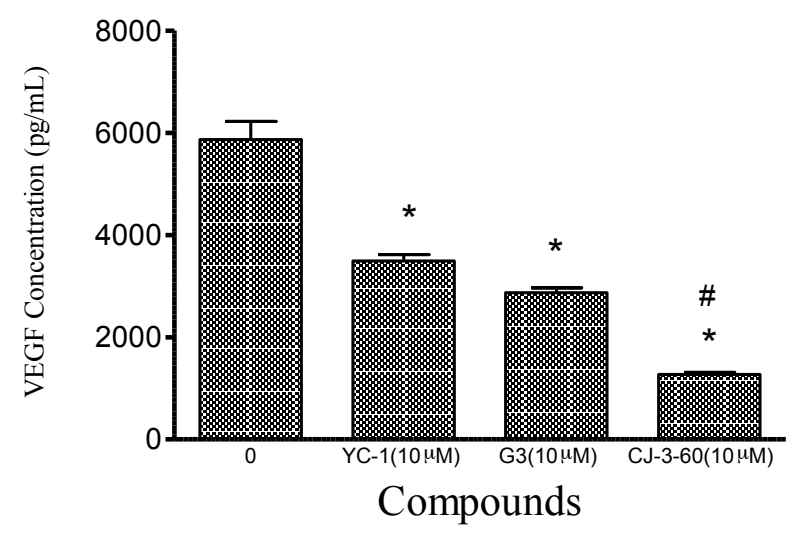

Figure 2-15. Quantification of VEGF concentrations by ELISA.

When compared to the untreated control, VEGF reporter activity was decreased by $\sim 25 \%$ of the control in the cells treated with $10 \mu \mathrm{M} \mathrm{YC}-1, \sim 50 \%$ with $\mathrm{G} 3$, and $\sim 80 \%$ with CJ-3-60. These data indicated that YC-1, G3, and CJ-3-60 inhibited VEGF transcriptional activation in a dose-dependent manner, and this inhibition is more potent in cells treated with CJ-3-60. The figure shows mean $\pm \mathrm{SD}$ of relative luciferase activities for each group when compared to that of the control. * indicates $p<0.05$ when compared to the untreated control and \# indicates $p<0.05$ when compared to $\mathrm{G} 3$ at the same concentration. 
Investigation of the effect of CJ-3-60 and G3 on cell proliferation revealed a strong dose-dependent inhibition in MDA-MB-231 and JygMC(A) cell lines. Compared with controls, and YC-1, the treatment of MDA-MB-231 and JygMC(A) cell lines with CJ-3-60 and G3 for 4 days under normoxia resulted in more reduction in the total number of cells-with greater reduction observed in wells treated with CJ-3-60. An extended cell proliferation/viability study (6 days) suggests that MDA-MB-231 and JygMC(A) cells are more sensitive to the growth inhibitory effects of these compounds (data not shown).

\section{Conclusion}

The high throughput screening system (HTSS) has the ability to identify a potential anti-HIF-1 $\alpha$ compound by measuring the quantity of the HIF-1 inducible gene-VEGF. For initial mechanistic studies, we selected YC-1, an agent previously characterized as a HIF pathway inhibitor as a control. At the outset, using biochemical techniques, we confirmed the inhibitory activity of YC-1 on the HIF pathway by performing experiments with the hypoxia-responsive promoter of the endogenous HIF transcriptional target gene vascular endothelial growth factor (VEGF) in breast cancer MDA-MB-231 cell line.

Having verified that the (HTSS) could detect an anti HIF-1 $\alpha$ compound, we proceeded to screen a large library of compounds with structural similarity to YC-1 in order to identify existing compounds that effectively inhibit VEGF signaling pathway. Over 400 compounds were evaluated in an MDA-MB-231 cell luciferase based reporter assay for HIF-1 inhibitory activities, from which we identified a compound we called G3. Based on the structure of G3, numerous novel compounds were synthesized and screened using the HTSS. One of the compounds (CJ-3-60) was selected based on its superior antiHIF-1 performance when compared with YC-1 and G3. There was a significant inhibition of VEGF and the transactivator, HIF-1 $\alpha$, by YC-1, G3, and CJ-3-60. Compared with YC-1, G3 exhibited a more dramatic inhibition of HIF-1 $\alpha$ than YC-1, and CJ-3-60 exhibited the most (compared to both) in all concentration. 


\section{CHAPTER 3. NOVEL THERAPEUTIC COMPOUND INHIBITS HIF-1 $\alpha$ BREAST CANCER CELL GROWTH IN VITRO}

\section{Introduction}

Several investigations have reported increase levels of HIF-1 $\alpha$ expression in proliferating and/or growth factor-stimulated cells [36]. HIF-1 plays a crucial role in the establishment and progression of common human cancers by activating the transcription of genes encoding proteins that mediate metabolic adaptation, like glucose transporters and glycolytic enzymes, angiogenesis (VEGF), and cell survival (IGF-2). These regulated gene products facilitates in the invasion and metastasis of the cancer cells. Also an increase in HIF-1 $\alpha$ expression possibly contributes extensively to the development of the deadly cancer phenotype. The link between alterations of major signal-transduction pathways and of HIF- $1 \alpha$ expression highlights the fundamental role of HIF-1 in cancer biology. Increased levels of HIF- $1 \alpha$ have been linked with increase proliferation and are potentially associated with more aggressive tumors [69].

Apoptosis, or programmed cell death, is a tightly regulated endogenous process that requires a coordinated activation of signaling pathways. It is regulated by balance of pro and anti-apoptotic proteins; mediated by the caspase proteins. Cellular apoptosis often occurs when cells are exposed to extreme hypoxia, and the adaptive mechanism initiated by HIF-1 that offers some protection is not sufficient, as reviewed in Piret, et al. [70]. One mechanism that has been suggested by which HIF-1 may induce apoptosis is that hypoxia induces the stabilization of $\mathrm{p} 53$ protein, a potent nuclear transcription factor that can trigger a wide array of target genes that initiate cell death in response to stress or DNA damage [71]. The stabilization of p53 in hypoxia corresponds to the increase of HIF- $1 \alpha$ in the cells, and co-immunoprecipitation experiments suggest a direct association between p53 and HIF-1 $\alpha$ in hypoxia cells $[72,73]$. This direct interaction between p53 and HIF-1 $\alpha$ results in both the stabilization of $\mathrm{p} 53$ and an inhibition of HIF-1 dependent transcription. Competitions between p53 and the co activator p300 for the same transactivation domain HIF-1 $\alpha$ may in part explain this effect $[74,75]$.

Conversely, in several experimental conditions, hypoxia has also been reported to repress apoptosis. This effect is preliminarily evidenced at the hypoxia level that leads to the activation of HIF- $1 \alpha$ through the dimerization of HIF- $1 \alpha$ and HIF-1 $\beta$, and adaptive increase in the transcription of genes associated with adaptation and ultimate survival. This anti-apoptotic role of HIF-1 may in part explain why breast tumors (and indeed all tumors) with a high HIF-1 expression are often resistant to chemo and radiation therapy [76]. In breast carcinoma there is a strong positive correlation between tumors expressing both HIF-1 and Bcl-2 (the anti-apoptotic protein) and a worse prognosis [77]. Also, Pidgeon, et al. has demonstrated that VEGF up-regulates Bcl-2 and down-regulates tumor cell apoptosis in human and mammary adenocarcinoma cells [78]. This seemingly conflicting actions of HIF-1 $\alpha$ was summarized by the research conducted by Suzuki, et $a l$. when they suggested that two distinguishable forms of HIF-1 $\alpha$ were responsible these contrasting activities: posphorylated HIF-1 $\alpha$ dimerizes with HIF-1 $\beta$ while 
dephophorylated HIF-1 $\alpha$ links with p53, stabilizes p53 and induces apoptosis through Bax overexpression [79].

\section{Materials and Methods}

\section{Western Blot}

Expression or and inhibition of HIF-1 $\alpha$ and HIF-1 $\beta$ was analyzed by immunoblotting using a monoclonal mouse anti-HIF-1 $\alpha$ and monoclonal rabbit anti-HIF-1 $\beta$ antibody respectively. Corresponding secondary anti body was used and a mouse anti- $\beta$-actin antibody was used for normalization. Cells were treated with $0,1,10$, and $100 \mu \mathrm{M}$ of YC-1, G3, and CJ-3-60 respectively $72 \mathrm{hr}$ before being cultured for the last $18 \mathrm{hr}$ under hypoxic $\left(\mathrm{H}, 0.5 \% \mathrm{O}_{2} \mathrm{v} / \mathrm{v}\right)$ conditions. $\mathrm{G} 3$ and $\mathrm{YC}-1$ served as controls throughout the experiments.

Cells were lysed in lysis buffer containing 10mM Tris- $\mathrm{HCl}(\mathrm{pH} 8.0), 0.25 \mathrm{M}$ Sucrose, $0.05 \mathrm{mM} \mathrm{CaCl}_{2}, 0.02 \%$ Azide, $0.5 \%$ NP-40, 1x protease inhibitor cocktail (Sigma,St. Louis, MO), and 1x phosphatase inhibitor cocktail I and II (Sigma), and processed for gel electrophoresis. Protein concentration was determined by using Coomassie Plus Protein Assay Reagent (Pierce,Rockford, IL). Protein extracts were loaded on a precast $4-12 \%$ gradient polyacrylamide gel (NuPAGE gel, Invitrogen, Carlsbad, CA) (100 $\mu \mathrm{g} /$ per lane) and subject to SDS-gel electrophoresis, followed by transferring to a polyvinylidene fluoride (PVDF) membrane (Immobilon-P Transfer Membrane, Millipore).

The membrane was incubated with blocking solution ( $5 \%$ nonfat milk and $0.02 \%$ sodium azide in phosphate-buffered saline) overnight at $4^{\circ} \mathrm{C}$, followed by an incubation for $16 \mathrm{hr}$ at $4^{\circ} \mathrm{C}$ with these respective antibodies: mouse anti-human HIF-1 $\alpha$ antibody (1:1,000 dilution, cat \# 61958, BD Biosciences); Anti HIF-1 $\beta, 1: 1000$, cat \# H0306 Santa Cruz Biotechnology); Anti-Bcl-2 1:1000 dilution, cat \#2876, Cells Signaling). The membrane were then incubated for $1 \mathrm{hr}$ at room temperature with corresponding secondary antibody coupled to peroxidase, followed by detection with chemiluminescent reagents (ECL kit, Amersham). The blots were quantified using ImageJ (NIH) and the density of the band compared.

\section{Flow Cytometry}

To measure drug-induced apoptosis, annexin- V- phycoerythrin (PE) and SYTOX double assay was performed using the Annexin V-PE Apoptosis Detection Kit Plus (Medical \&Biological Laboratories) according to the manufacturer's instructions. Briefly MDA-MB-231 cells were cultured in 6-well plates at a density of $3 \times 10^{5}$ per well and untreated or treated with different concentrations of YC-1, G3, or CJ-3-60 (0, 0.1, 1, 10 $\mu \mathrm{M}$ ) for $72 \mathrm{hr}$ at $37^{\circ} \mathrm{C}$. Results were calculated as the mean fluorescence intensity and 
expressed as the fold difference from the untreated and control group treated with vehicle alone $(0.04 \%$ DMSO). The cells were trypsinized and washed with PBS. The washed cells were resuspended in $500-\mu \mathrm{L}$ binding buffer and stained with $5 \mu \mathrm{l}$ of Annexin V-PE and $1 \mu \mathrm{l}$ of SYTOX and allowed to incubate at room temperature for 5-10 min in the dark. Flow cytometric analysis was performed immediately after. Experiments were conducted in duplicates and were independently repeated twice.

\section{Caspase-Glo $3 / 7^{\circledR}$ Assay}

The induction of Apoptosis was investigated by measuring the levels of caspase 3/7 using caspase-Glo 3/7® assay (Promega). Briefly, $0.1,1,10$, and $100 \mu \mathrm{M}$ of drug was added to final volume $100 \mu \mathrm{l}$ of media in each well. Three different plates with duplicates of each concentration being investigated were incubated for 24,48 , and $72 \mathrm{hr}$ respectively in hypoxia or normoxia. Following the incubation period, the plates were processed for caspase-3 activity as described by the manufacturers. The fluorescence intensity -a reflection of the caspase-3/7 activity- was measured by a 96-well plate luminometer (Synergy HT Multi-Mode Microplate Reader, BioTek, Winooski, VT). After subtracting the background reading, caspase-3 activity was expressed as a percentage increase compared to untreated control cells.

\section{Results}

\section{Effects of Compounds on Hypoxia-Mediated HIF-1a Expression}

CJ-3-60 inhibits hypoxia-induced HIF-1 $\alpha$ secretion more effectively than YC-1 and G3.We analyzed the effect of $\mathrm{YC}-1, \mathrm{G} 3$, and $\mathrm{CJ}-3-60$ on hypoxic induction of nuclear HIF-1 $\alpha$ protein in MDA-MB-231 and JygMC(A) cells by immunoblotting. MDA-MB-231 were cultured and treated in the absence or presence of YC-1, G3, and CJ-3-60 $(0,1,10$, and100 $\mu \mathrm{M})$ as described earlier. CJ-3-60 specifically inhibited HIF-1 $\alpha$ protein accumulation under hypoxia in a dose dependent manner in these cell lines, and more effectively than YC-1, G3, and CJ-3-60 (Figure 3-1a-d). However, it was found to have no effect on the protein levels of HIF-1 $\beta$ (Figure 3-2).

More than 75\% (in MDA-MB-231 cells) and 50\% (in JygMC(A) cells) protein reduction was observed between the compound treated samples and the control of the HIF- $1 \alpha$ at concentrations that inhibit HIF- $1 \alpha$ activation. CJ-3-60 and G3 inhibited hypoxia $\left(0.5 \% \mathrm{O}_{2}\right)$-induced HIF- $1 \alpha$ activation by $\sim 95 \%$ at the concentration of $1 \mu \mathrm{M}$ compared to $\sim 70$ for $\mathrm{G} 3$ and $\mathrm{YC}-1$ in both cell lines (Figure 3-1c-d). 
a
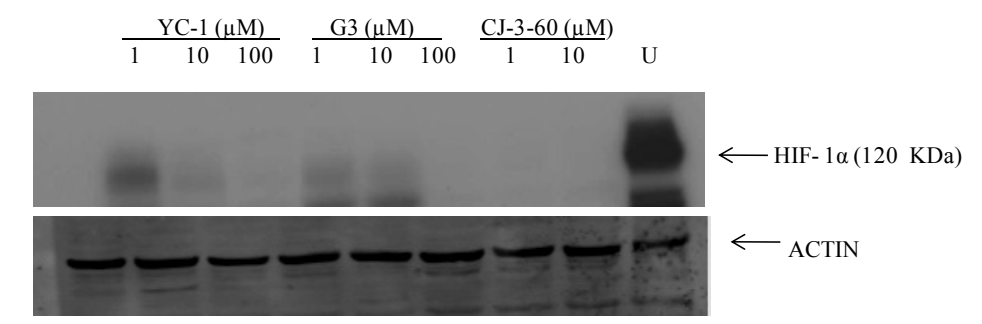

b
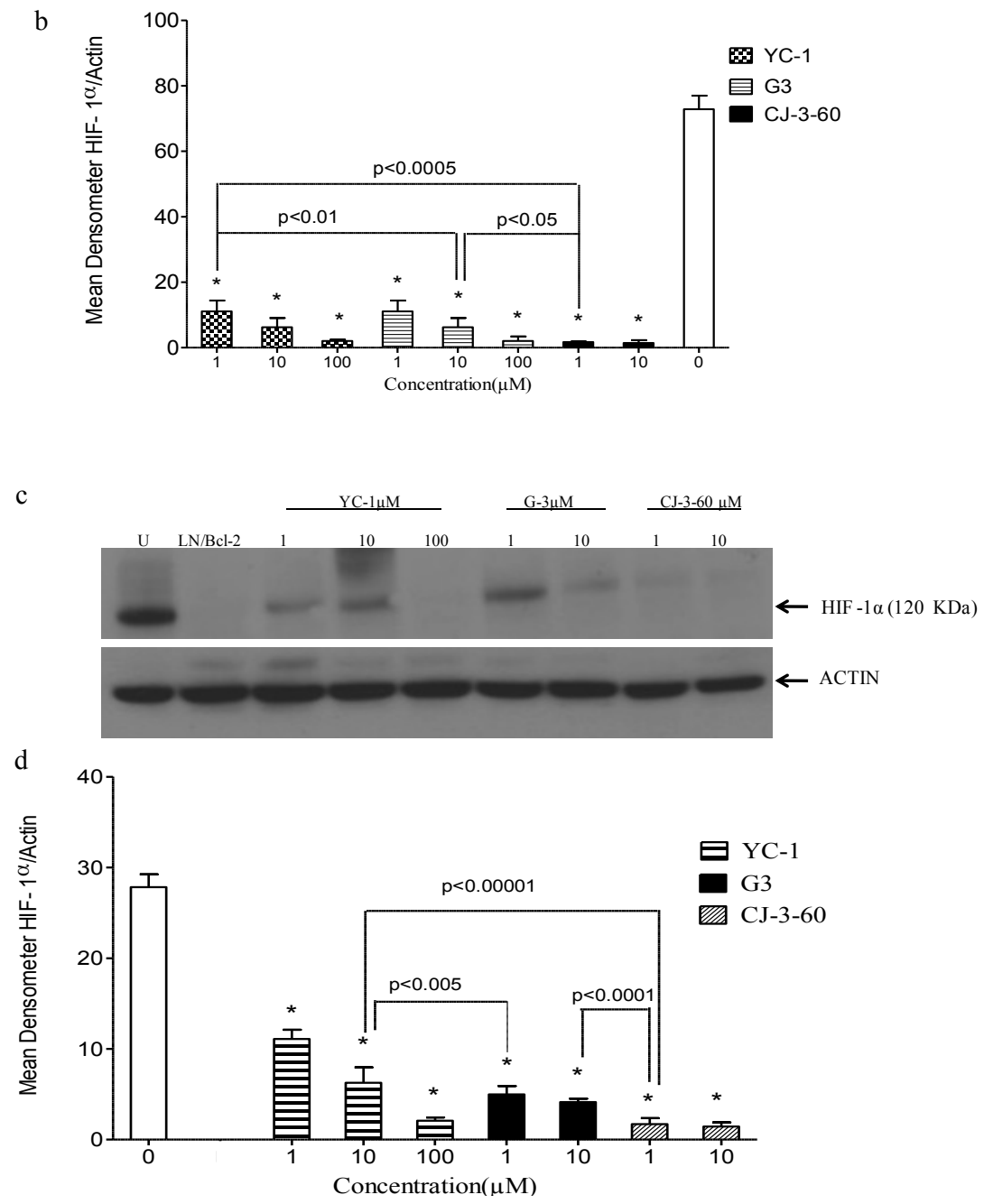

Figure 3-1. Western blot analysis of HIF-1 $\alpha$ proteins in nuclear extract samples prepared from MDA-MB-231 and JygMC(A) cells.

Expression of HIF-1 $\alpha$ and actin proteins was analyzed by immunoblotting with a mouse anti-HIF-1 $\alpha$, mouse anti-actin antibody, respectively. CJ-3-60 specifically inhibited HIF$1 \alpha$ protein accumulation under hypoxia in a dose dependent manner in these cell lines, and more effectively than YC-1 and G3 in MDA-MB-231 cells (a) and JygMC(A) cells (c).Quantified graphs(b and d). Data represent means \pm S.D. from three independent readings $(*$ indicates $p<0.05$ when compared to the control). 
a

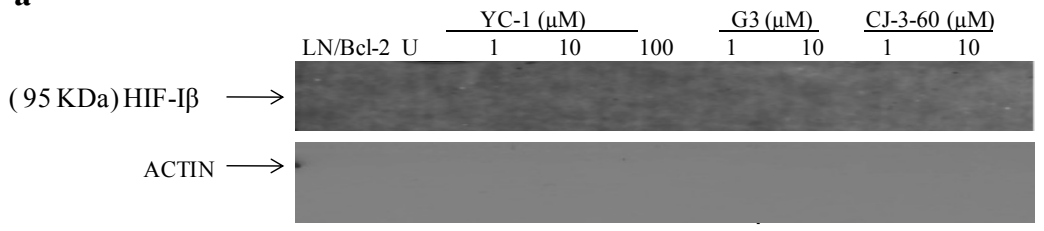

b

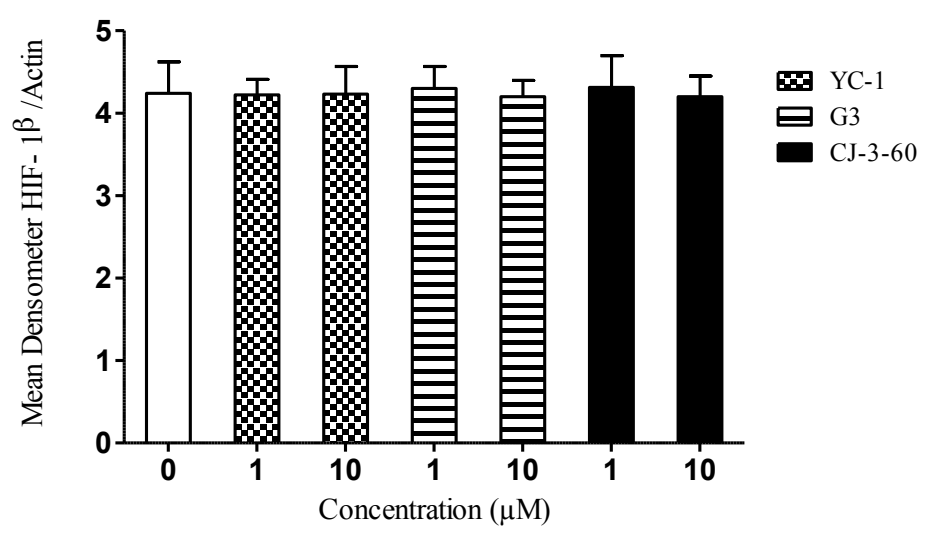

Figure 3-2. Western blot analysis of HIF-1ß proteins in nuclear extract samples prepared from MDA-MB-231.

Levels of HIF-1 $\beta$ protein was not significantly affected in the presence of compounds (a). Quantification of HIF-1 $\beta$ western blot normalized with expression levels of actin (b). 


\section{Exposure to Compounds Induced Apoptosis in Cells}

Flow cytometry with Annexin V-FITC/PI staining showed that the drug treatment significantly increased the proportion of apoptotic cells. Based on staining the cells with Annexin V- PE, flow cytometry was used to quantify the degree of apoptosis (Figure 3-3a-c). The point of lower left quadrant (Q3) in Figure 3-3a represents the life cells with few early apoptotic cells, the point of upper right quadrant $(\mathrm{Q} 2)$ represents the late apoptotic cells, the point of lower right quadrant $(\mathrm{Q} 4)$ represents the necrotic cells. Figure $3-3 \mathrm{~b}$ shows the result from all samples, untreated and treated $(0-10 \mu \mathrm{M})$ of $\mathrm{YC}-1, \mathrm{G} 3$ and CJ-3-60.

As demonstrated in Figure 3-3c, the maximal apoptosis rate was $\sim 60 \%$, observed in cells treated with $10 \mu \mathrm{M}$ of CJ-3-60, which was significantly higher than the other group's lower or equal concentrations. In the vehicle treated cells, $2 \%$ were positive for Annexin. Drug treatment resulted in 20\%, 30\%, and 40\% in apoptosis when cells were treated with $1 \mu \mathrm{M}$ YC-1, G3 and CJ-3-60, respectively. This result confirms the ability of all compounds to induce apoptosis in MDA-MB-231 cells, with the highest percentage seen in cell treated with CJ-3-60 at same concentration.

CJ-3-60 and G3 increases the levels of caspases 3/7. Studies have reported that inhibition of cell proliferation by $\mathrm{YC}-1$ in some cancer cell line might be mediated by apoptosis $[80,81]$. Therefore we examined the apoptosis-inducing capacity of CJ-3-60 and G3 by measuring the activation of caspases 3 and 7. The plating of cells, compound treatment, and exposure to normoxic and hypoxic conditions were similar to those described in the earlier sections. In these cells, the level of caspases 3 and 7 increased up to within $72 \mathrm{hr}$ in response to increasing concentration of drug, compared with the untreated control. We found a direct correlation between impaired cell growth and apoptosis: activation of apoptosis by CJ-3-60 and G3 in these experiments was evident only after $48 \mathrm{hr}$ of treatment (Figure 3-4a and b). A dose-dependent increase in active caspase-3/7 in YC-1, G3, and CJ-3-60-treated cultures was observed in all time period, and CJ-3-60 significantly induced the highest levels of caspase 3/7 at the end of $72 \mathrm{hr}$. Similar trend was observed in cells cultured in normoxia (results not shown).

CJ-3-60 and G3 also inhibits levels of anti- apoptotic Bcl-2 in these cell lines more effectively than YC-1.To determine whether YC-1, G3, and CJ-3-60 apoptosis-inducing activity is through the Bcl-2 pathway, we investigated the level of Bcl-2 protein in MDA-MB-231 and JygMC(A) cell lines by western blot analysis as described above, with $100 \mu \mathrm{g}$ of extracted protein from LNCaP-Bcl-2 cells (a generous gift from Dr Leonard Lothstein, University of Tennessee Health Science Center) serving as a positive control. YC-1, G3, and CJ-3-60 inhibit the accumulation of Bcl-2 protein in a dose-dependent fashion (Figure 3-5a-c). These results demonstrate that $\mathrm{YC}-1, \mathrm{G} 3$, and CJ-3-60 exert an inhibition of hypoxic- induced accumulation of Bcl-2 protein, which was measured after $72 \mathrm{hr}$ of drug treatment and $18 \mathrm{hr}$ in hypoxia.

The changes in the expression of caspase-3/7 and Bcl-2 after YC-1, G3, and CJ-3-60 treatment suggests that apoptosis induced by YC-1, G3, and CJ-3-60 might be 
Figure 3-3. Flow cytometric analysis of apoptosis.

MDA-MB-231cells were incubated with YC-1, G3, or CJ-3-60 at the indicated concentrations for $72 \mathrm{hr}$. (a) Each sample was stained by Annexin V/PE and analyzed by flow cytometry. Figure 3-3a (left panel) shows the total events in untreated sample after the event count was gated, and cell viability was determined using a fixable green reagent. Data in red, broken line box (right panel) shows the statistical percentages of the respective events in the population. Untreated samples exhibited $\sim 5 \%$ apoptotic cells (indicated) and more than $80 \%$ viable cells after processing. (b) Figure shown are a representative of three independent experiments of all samples, and the relative percentage of apoptosis rates of all samples (treated, untreated, and vehicle control) groups are shown in the bar chart (c). Higher percentage of apoptosis cells were detected by Annexin V-FITC and PI staining in CJ-3-60 treated cells than in other groups.

$*$ indicates $\mathrm{P}<0.05$ when compared to vehicle control group. 
a

$\underline{\text { Untreated Sample }}$
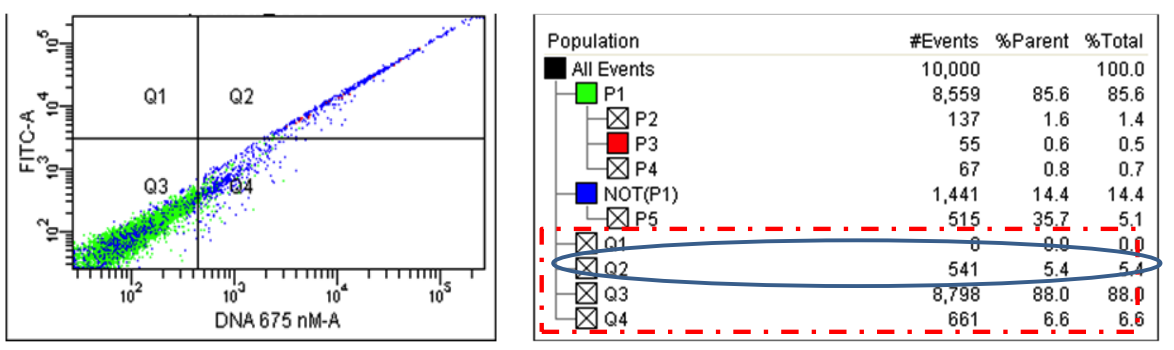

b
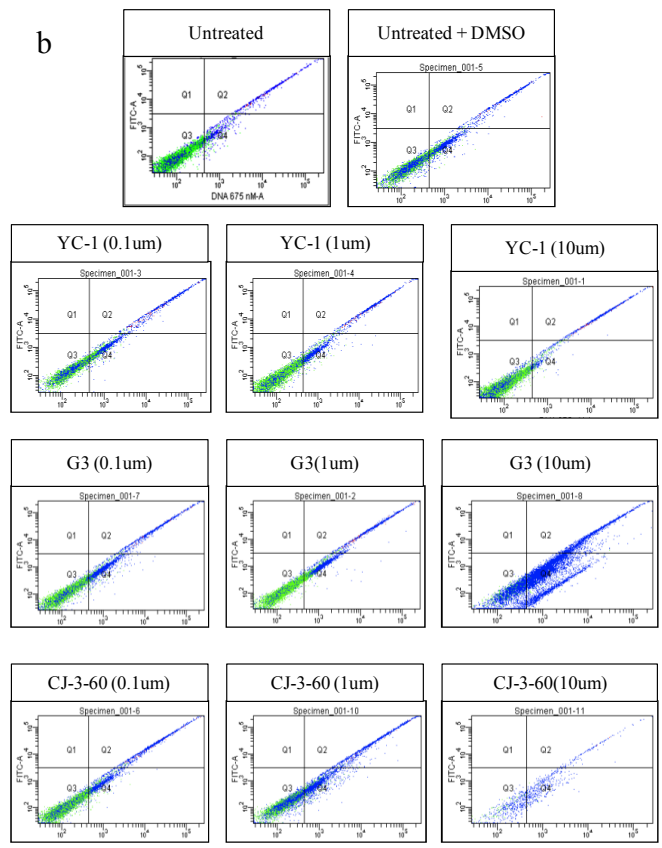

c

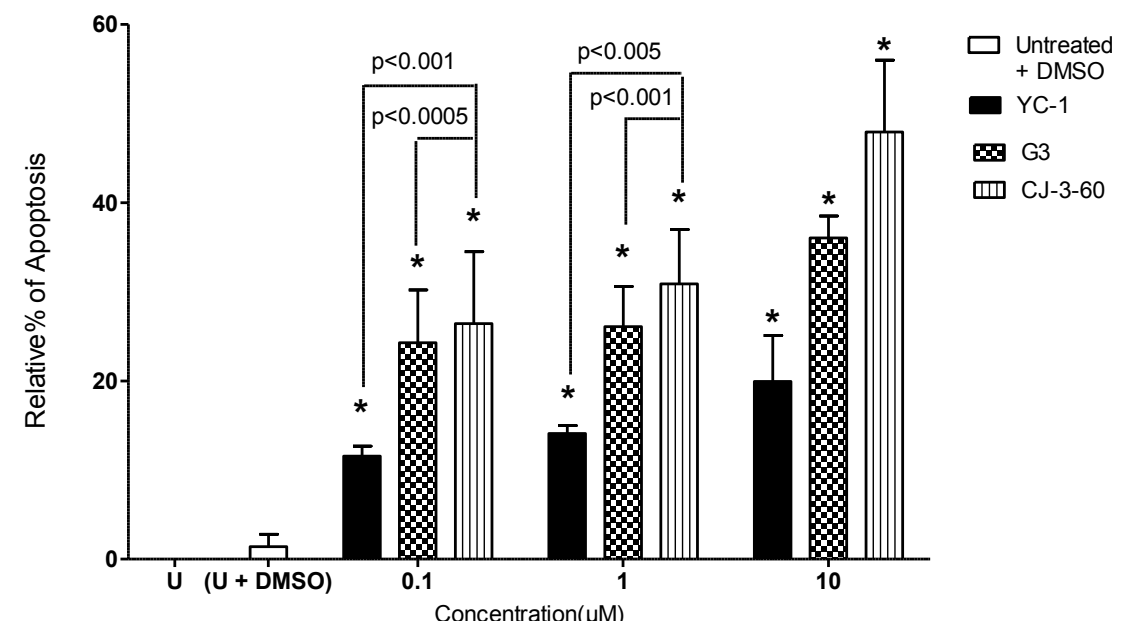




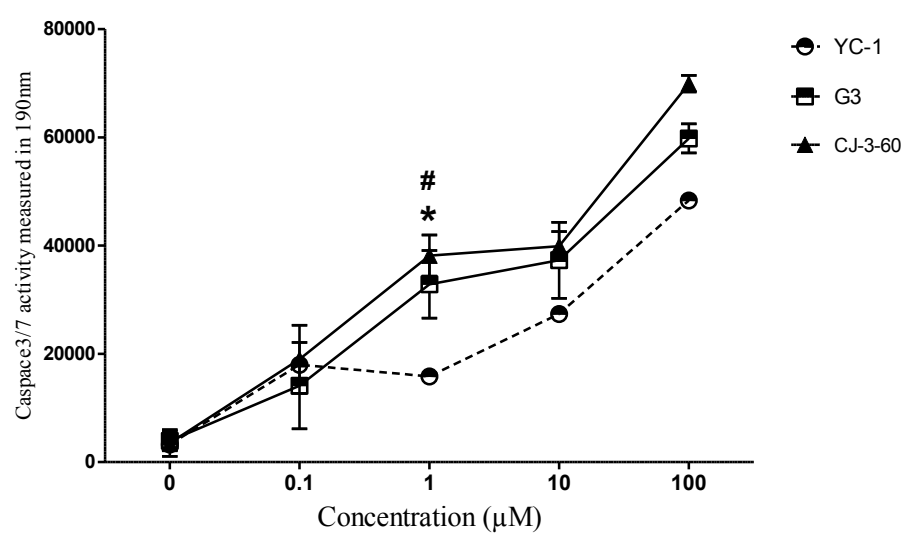

b

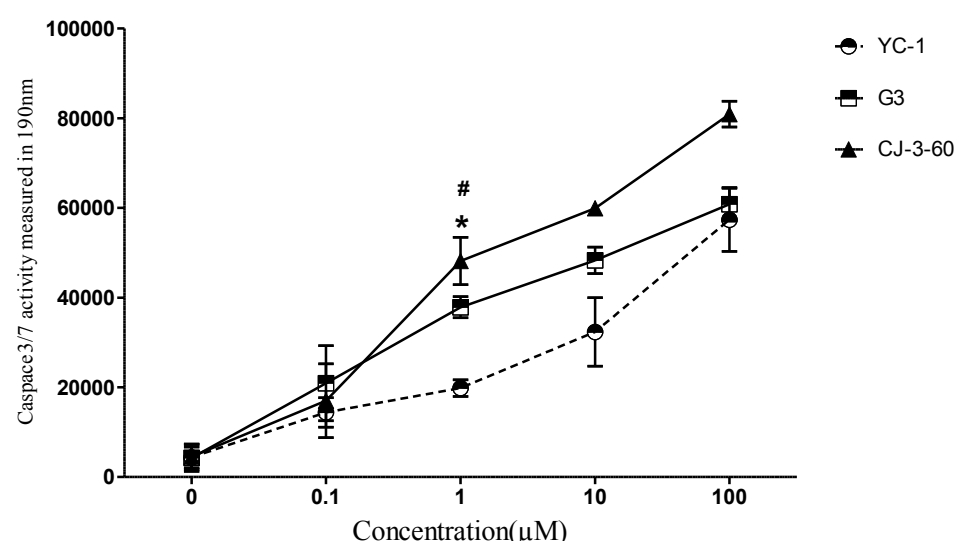

Figure 3-4. Total caspase $3 / 7$ after 72 hr drug treated cells.

Caspase 3/7 activity was assessed at $24 \mathrm{hr}, 48 \mathrm{hr}$ and $72 \mathrm{hr}$ in triplicate wells using MDAMB-231 cells (a) and JygMC(A) cells (b). In this study, caspase-3/7 activities were both increased in a concentration-dependent and time-dependent fashion after treatment. As shown in Figure 3-4a and b, compounds strongly induced the activation of caspase-3/7, and the maximum activity was about 2-8-fold of control at the highest concentration (100 $\mu \mathrm{M})$, with cells treated with CJ-3-60 instigating the greatest increase ( $*$ indicates $p<0.05$ when compared to the control, \# indicates $p<0.05$ when compared to G3 at the same concentration). 
a
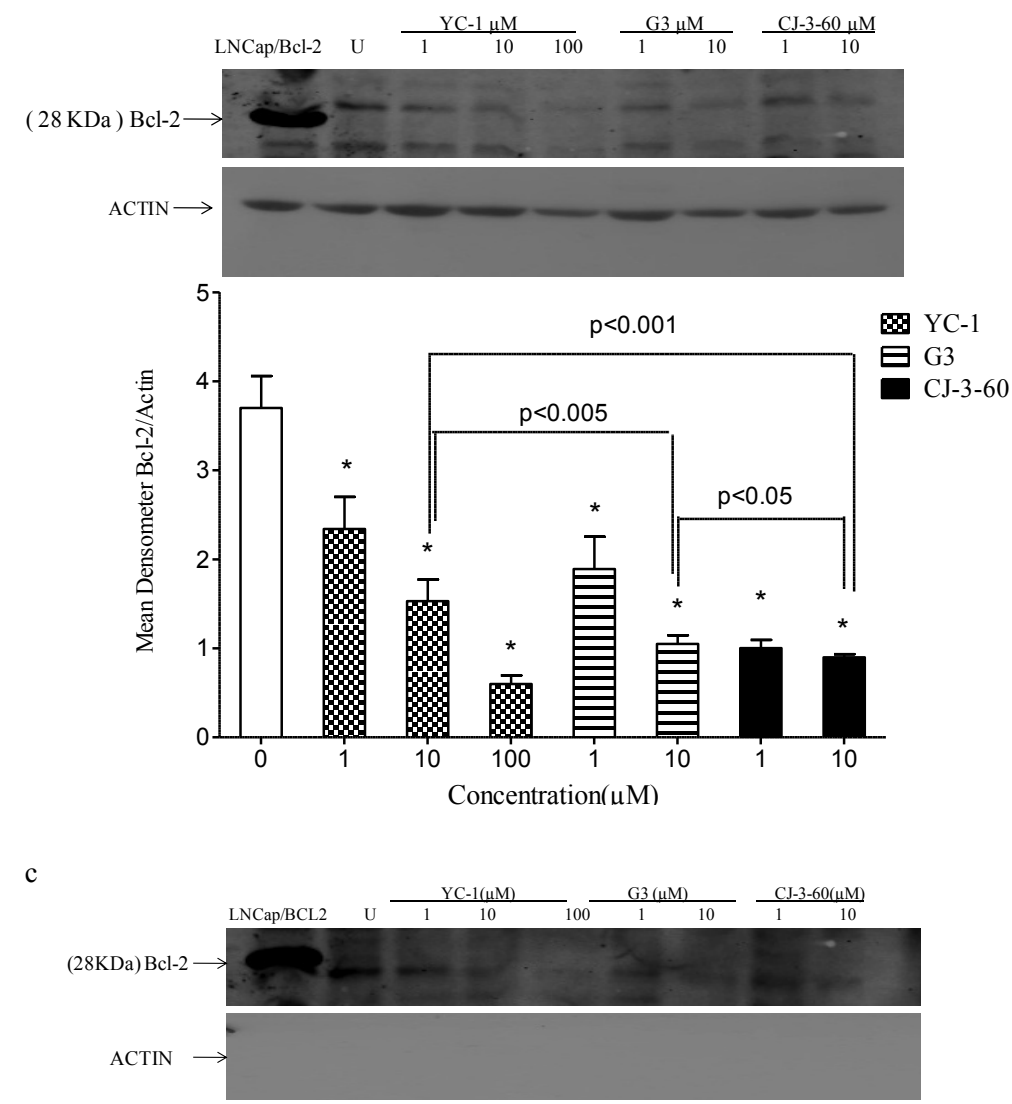

d

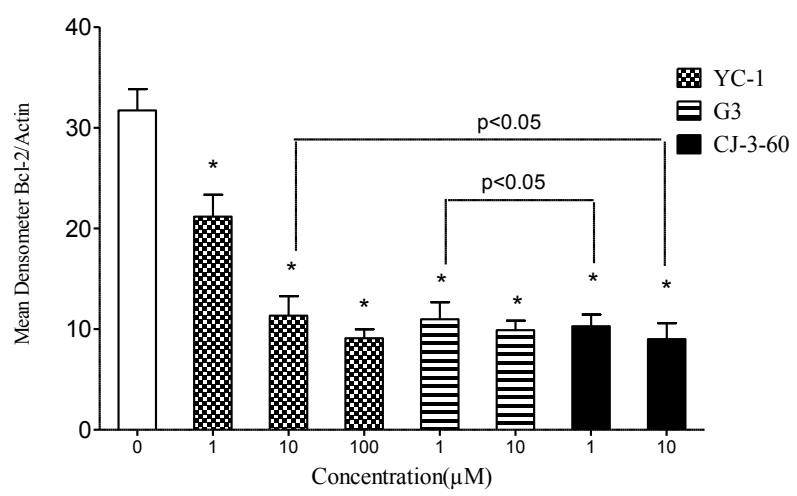

Figure 3-5. Effects of $\mathrm{YC}-1, \mathrm{G3}$, and $\mathrm{CJ}-3-60$ on Bcl-2 in MDA-MB-231 and $\operatorname{JygMC}(\mathrm{A})$ cells.

Cells were treated with $0,1,10$, and $100 \mu \mathrm{M} \mathrm{YC}-1, \mathrm{G} 3$, and CJ-3-60 for $72 \mathrm{hr}$ under normoxia and then $18 \mathrm{hr}$ under hypoxia. Cells were then harvested and subjected to western Blot. Protein extracts from $\mathrm{LNCaP} / \mathrm{Bcl}-2$ cells served as positive control in lane one for both western blot assays. Decreased levels of Bcl-2 were detected in both cell lines, and the most inhibition was observed in cell treated with CJ-3-60. (a and c) Western blots were subsequently quantified by scanning densitometry of Bcl-2 expression and normalized to that of $\beta$-actin ( $b$ and $d$ ). The means indicated with an asterisk were statistically different from the matched hypoxic control. * indicates $p<0.05$. 
one of the mechanisms by which these compounds acts as an anti-proliferative drug against these cancer cells.

\section{Conclusion}

Hypoxia greatly increases the protein level of HIF-1 $\alpha$, but these compounds inhibited the hypoxic accumulation of HIF-1 $\alpha$ in a dose dependent manner. The effect of YC-1, G3, and CJ-3-60 on HIF-1 $\alpha$ level was also examined in MDA-MB-231 and JygMC(A) cells to verify that YC-1, and examine the possibility that G3 and CJ-3-60 affects HIF-1 $\alpha$ protein under hypoxic conditions. The result confirms that $\mathrm{YC}-1$, and reveals that G3, and CJ-3-60 has an effect on HIF-1 $\alpha$ accumulation. In contrast, the density of HIF-1 $\beta$ protein band was unaltered by drug treatment, which suggests that the YC-1, G3, and CJ-3-60 effect is specific to HIF-1 $\alpha$.

One of the most described pathways for cell death involves the activation of caspase 3 or 7 [82]. Here we report that YC-1, G3, and CJ-3-60 directly induce cell death in breast cancer cells through caspases 3 and 7 . Several cellular steps are required to activate apoptosis. Among these steps, the Bcl-2 accumulation in cells is considered to be a key step in the induction of apoptosis; therefore we further characterized apoptosis triggered by YC-1, G3, and CJ-3-60 by examining levels of Bcl-2 protein. The results demonstrate that YC-1, G3, and CJ-3-60 exerts a dose-dependent inhibition of hypoxic-induced accumulation of Bcl-2 protein, which is manifested after $72 \mathrm{hr}$ of drug treatment and $18 \mathrm{hr}$ in hypoxia, leading to caspase-mediated cell death. 


\section{CHAPTER 4. NOVEL THERAPEUTIC COMPOUND INHIBITS TUMOR CELL-INDUCED ANGIOGENESIS}

\section{Introduction}

Numerous investigations have shown that primary tumors are incapable of growing beyond a volume of several $\mathrm{mm}^{3}$ in the absence of new vascularization meant to provide a fresh supply of oxygen, glucose and other nutrients [83, 84]. The inception of angiogenesis (and eventual vascularization of the tumor) allows the accelerated growth of the tumor, subsequently preparing the environment for the development of the invasive and metastatic properties that characterize the deadly cancer phenotype. Concurrently, as observed in many tumor types, there is a statistically significant correlation between tumor angiogenesis and patient survival [85].

Tumor angiogenesis occurs as a result of a tilt in balance between angiogenic and antiangiogenic factors. The most prominent angiogenic factor revealed to play a critical role in mediating blood vessel formation in response to developmental, physiological, or oncogenic stimuli, is vascular endothelial growth factor (VEGF) [15, 46, 47, 83, 84]. A strong parallel has been described between VEGF expression and clinical outcome in numerous types of tumor [86]. Whenever VEGF expression is inhibited or a binding of its receptor on endothelial cells occurs, a remarkable effect on tumor growth, invasion, and metastasis in animal models has been observed [65, 87-94]. HIF-1, in response to hypoxia, plays a prominent role in coordinating the transcription of a host of genes in the tumor cells, one of these being VEGF. The production of VEGF sequentially initiates and sustains new blood vessel development, essential for cellular proliferation and tumor development [95-99].

Furthermore, HIF-1 activates other pro-angiogenic agents like thymidine phosphorylase, and targets the gene encoding inducible nitric oxide synthase (iNOS), which plays a role in tumor vascularization. It has additionally been shown in animal xenograft studies that HIF-1/HIF-1 $\alpha$ enhances tumor growth and angiogenesis $[52,83$, $84,100]$. VEGF expression is not only induced by hypoxia, but also by exposure of both transformed and non-transformed cells to a variety of growth factors, like epidermal growth factor, basic fibroblast growth factor (FGF-2), insulin-like growth factor 1 (IGF-1), interleukin $1 \beta$, platelet-derived growth factor, and tumor necrosis factor $\alpha$ (TNF- $\alpha$ ) [101-105]. Interestingly, these growth factors also induce HIF-1 $\alpha$ protein expression and/or HIF-1 DNA binding activity [106-109]. HIF-1 $\alpha$ overexpression in tumor biopsies is linked with vascular density in ductal carcinoma in situ (the early pre invasive stage of breast cancer) [110], further substantiating that HIF-1 activity contributes to the angiogenic switch.

Based on these and other numerous observed upregulation of HIF in cancer, and its role in upregulating angiogenic growth factors (which ultimately increases tumor growth), one could hypothesize that an inhibition of the HIF pathway would reduce both angiogenesis and tumor growth. This has also been confirmed by a study using peptides 
that block the interaction between the HIF-1 $\alpha$ carboxyl terminus and the transcriptional co-activator p300, which reportedly leads to a reduction in growth and angiogenesis in tumors derived from breast and colon carcinoma cells [111].

\section{Materials and Methods}

\section{Western Blot Analysis of VEGF Proteins}

The protein levels of VEGF were analyzed in whole cell lysates by western blot analysis as described in previous sections of this report, using a monoclonal rabbit antihuman antibody against VEGF, and the protein concentration of each lane was normalized by $\beta$-actin.

\section{In vitro Network Formation Assay}

To determine whether potential therapeutic compound(s) inhibit tumor cell-induced angiogenesis, culture supernatants from MDA-MB-231 cells treated either with or without drug $(1-100 \mu \mathrm{M})$ under hypoxia or normoxia were used as conditioned medium for the network formation assay. 200 $\mu$ lice-cold matrigel (BD Bioscience) was added to coat each well of pre-chilled 48-well plate, and then incubated for $1 \mathrm{hr}$ at $37^{\circ} \mathrm{C}$ to become polymerized. Human microvascular endothelial cells (HMEC) $\left(3 \times 10^{4}\right.$

cells/well) were seeded with $300 \mu 1$ of culture supernatants from above. The network-like structure of the cells was photographed at $0,2,5,8,11$, and $24 \mathrm{hr}$ post HMEC plating on the matrigel. Five randomly selected fields at 5, 8, and $11 \mathrm{hr}$ were counted for the vessel crossing points in order to compare network connections (i.e. network formation) in a quantitative manner, and represented as mean $+\mathrm{SD}$.

\section{Result}

\section{Compounds Inhibit the Induction of VEGF Proteins in MDA-MB-231 Cell Line and Stimulation of Network Formation}

Given that HIF-1 is the main regulator of VEGF expression in hypoxia we analyzed the effect of these compounds on VEGF production in vitro, measured with an enzyme-linked immunosorbent assay (ELISA) (Figure 4-1). We showed by western blot (Figure 4-1b) that CJ-3-60 at $10 \mu \mathrm{M}$ almost completely blocked the hypoxic induction of secreted VEGF proteins $(p<0.05)$, when compared with the control, while G3 inhibited hypoxic induction of cellular and secreted VEGF proteins at the concentration of 100 $\mu \mathrm{M}$. 
$\mathrm{a}$
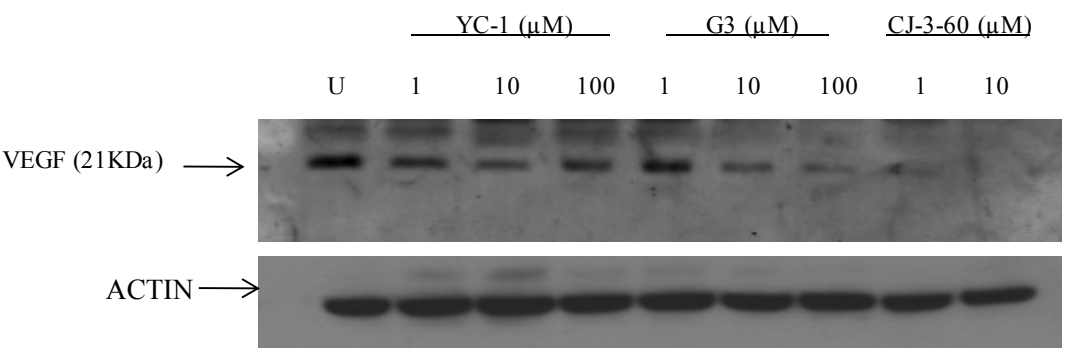

b

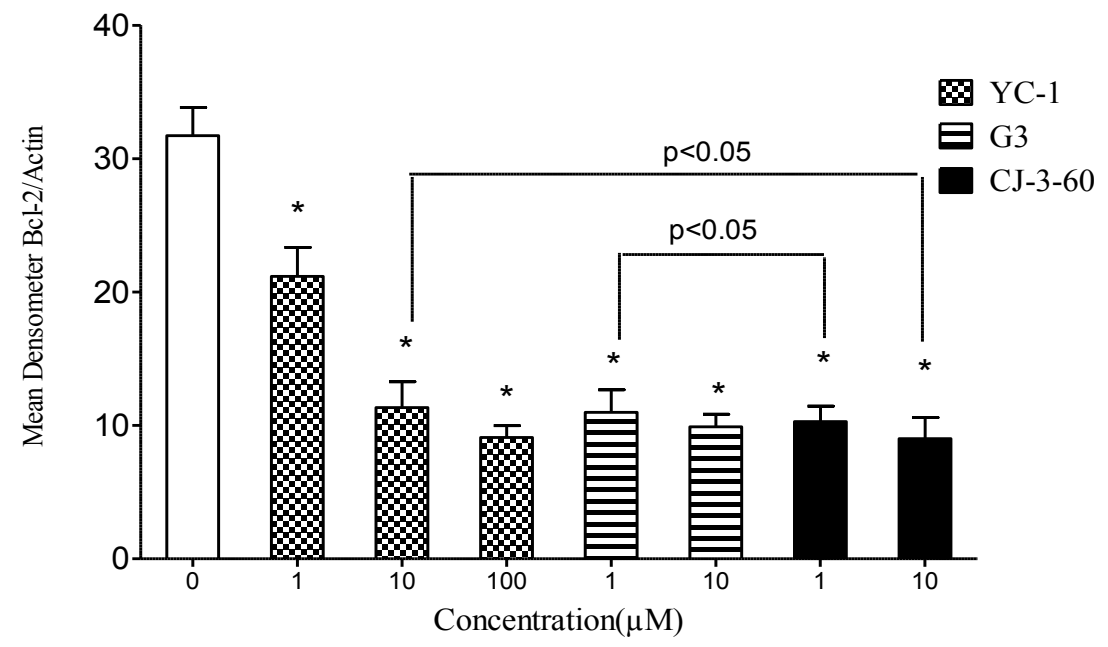

Figure 4-1. Compounds inhibit the induction of VEGF proteins in vitro.

Drugs inhibit VEGF expression in MDA-MB-231 cells. The protein levels of VEGF were analyzed in whole cell lysates by western blot analysis using a monoclonal rabbit anti-human VEGF antibody and the protein concentration of each lane was normalized by $\beta$-actin. (b) Quantified graphs based on densitometric analysis of ratio between VEGF and actin protein expression. The figure shows mean \pm SD of relative VEGF expression for each group. * indicates $p<0.05$ when compared to the control. 


\section{Compounds Inhibit the Stimulation of Network Formation}

A human microvascular endothelial cells (HMEC)-based in vitro angiogenesis assay was employed for further study to explore if the inhibition of VEGF protein production would parallel the inhibition of tumor angiogenesis. One common method used to quantify the degree of angiogenesis in the HMEC network formation assay is by counting the number of branching points formed by the networks. In the absence of required angiogenic factor, HMECs failed to form much significant network throughout the plate observed at eight hours after incubation (Figure 4-2a, Basal Media). However, the addition of the angiogenic factor (VEGF, $15 \mathrm{ng} / \mathrm{ml}$ ) stimulated the HMECs to form network-like structures (Figure 4-2a, Basal Media + VEGF, 15ng/ml).

Similar angiogenesis inducing activity was detected in HMECs cultured with conditioned media from hypoxic MDA-MB-231 cells at similar time point, which displayed a drastically enhanced angiogenesis stimulating activity (Figure 4-2b, Control Hypoxia) when compared to conditioned media collected from MDA-MB-231 cells cultured under normoxic conditions (Figure 4-2b, Control Normoxia).Invariably, we can reasonably conclude that hypoxia enhances the production of angiogenic factors (likely VEGF), essential for the formation of network. Both CJ-3-60 and G3 suppressed hypoxic MDA-MB-231 cell-induced angiogenesis at concentrations as low as $1 \mu \mathrm{M}$ (Figure 4-2b, bottom bar graph), more significantly than $\mathrm{YC}-1$, and less than that observed with untreated normoxic cells (Figure 4-2b, top bar graph). When the normoxia plus CJ-3-60 treatment was compared with the normoxia untreated control, CJ-3-60 completely blocked the hypoxic induction of secreted VEGF proteins.

In summary, of the three compounds assayed, CJ-3-60 demonstrated the greatest inhibition of the ability of hypoxic MDA-MB-231 cells to stimulate tumor angiogenesis in all condition and same time point (Figure $4-2 b$ ). These results compare concomitantly with the inhibitory actions exerted by the compounds on hypoxic induction of secreted VEGF proteins in MDA-MB-231 (Figure 4-1 a and b; Figure 2-15). In some related experiments performed separately, the angiogenesis activity was investigated in the presence of compound- treated HMECs with $15 \mathrm{ng} / \mathrm{ml}$ (Figure 4-2d) VEGF or condition cells cultured with the condition media used above with supplemented with $15 \mathrm{ng} / \mathrm{ml}$ VEGF. Significant network formation was observe (that thrived as well as that observed in the hypoxia control), indicating that the compounds do not act directly on HMECs to inhibit network formation in presence of VEGF (Figure 4-2d). Lastly, a cytotoxic assay conducted revealed that the compounds do not have a significant cytotoxic effect on HMECs (Figure 4-2e).

\section{Conclusion}

In fast growing tumors, local hypoxic conditions stimulate the expression of HIF-1 $\alpha$, which in turn induces the expression of VEGF in tumor cells. As a survival mechanism employed by these hypoxic tumor cells, the production of angiogenic factors such as VEGF is increased, which serves as a trigger to initiate the process of tumor 
Figure 4-2. Compounds inhibit the induction of VEGF proteins and tumor angiogenesis in vitro.

Secreted VEGF protein in the conditioned media from MDA-MB-231 cells exposed to various concentration of drug $-0,1,10,100 \mu \mathrm{M}$ for $72 \mathrm{hr}$ (in normoxia for $48 \mathrm{hr}$ and in hypoxia or $24 \mathrm{hr}$ ), were evaluated in a HMEC network formation assay. Representative pictures are shown and the negative (Basal Media) and positive (VEGF) controls are shown in two different panels. The extent of network formation in four fields selected randomly was quantified for condition from $10 \mu \mathrm{M}$ (a) and all concentrations for all compounds in normoxia and hypoxia (b), condition media enhanced with VEGF (c), and MTT assay done to examine cytotoxic effect of drugs on HMECs (d). The data shown are averages and the bars represent standard number of branching point. The $p$ values are provided where there is a statistically significant difference. ${ }^{*} p<0.05$ between the hypoxic control and the compound treated samples, between the negative and positive control, or between samples cultured in conditioned media with and withoiut VEGF. 

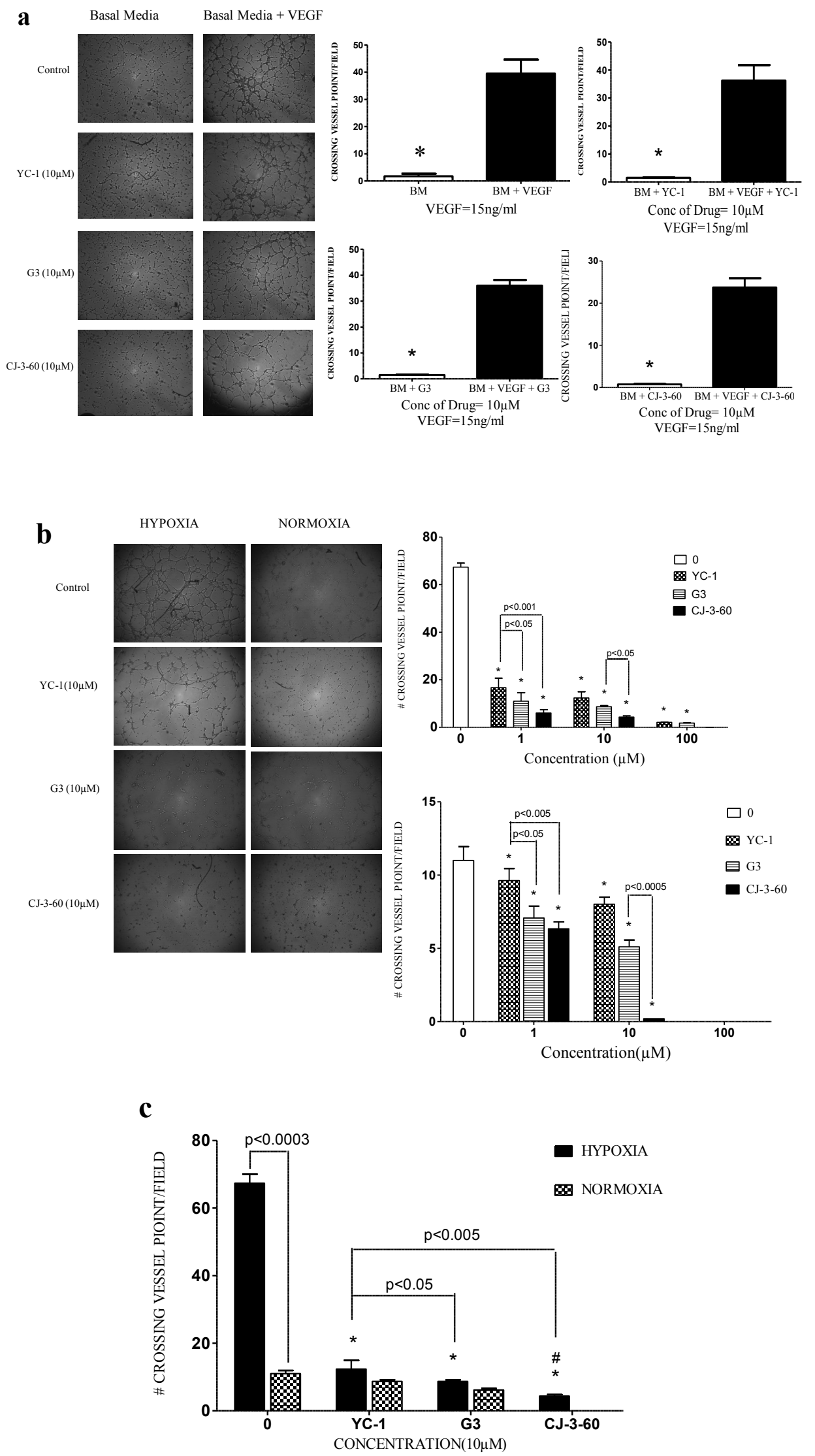


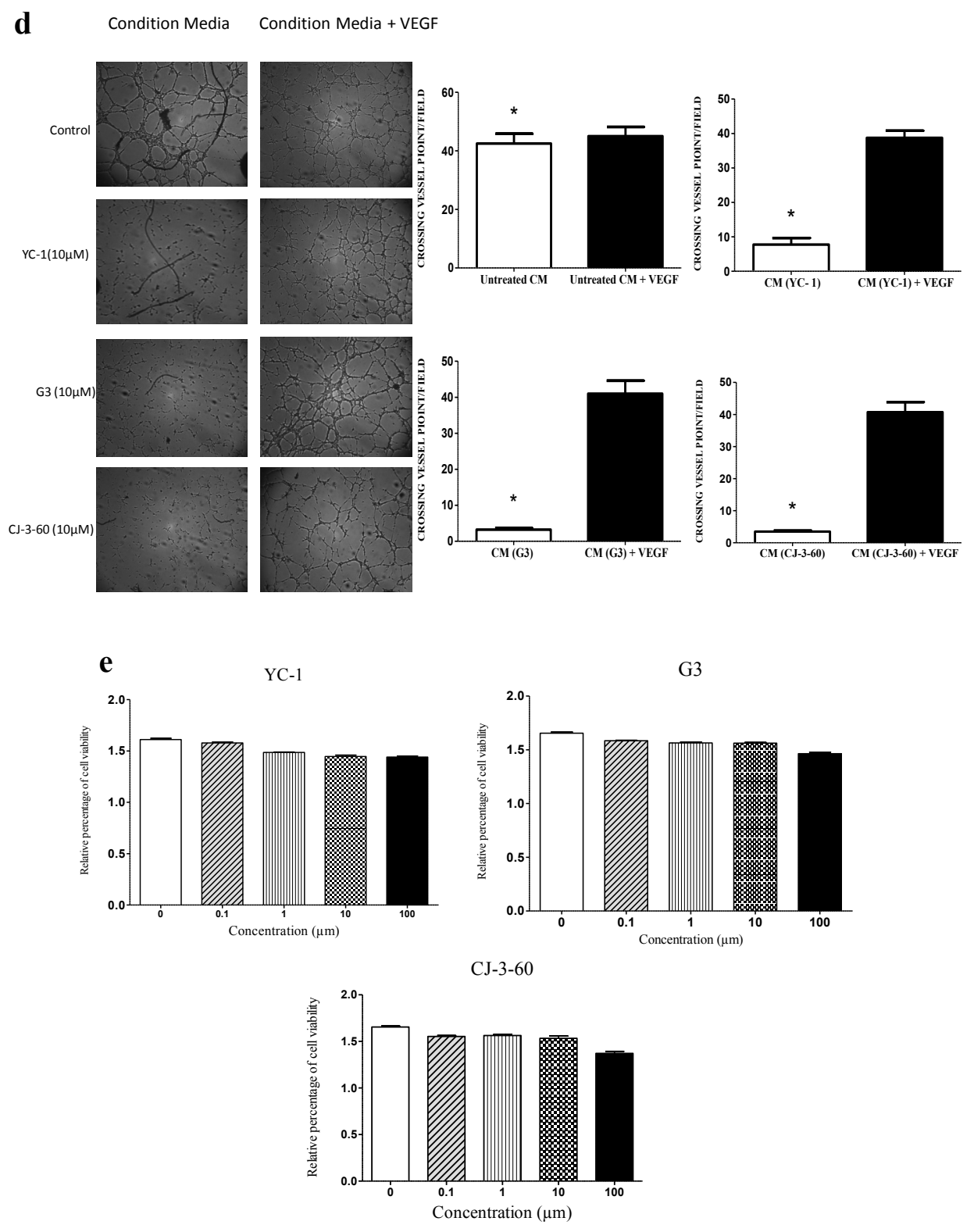

Figure 4-2. Continued. 
angiogenesis by binding to and activating the receptor on the surface of endothelial cells, leading to endothelial cell proliferation, migration, invasion, and eventually capillary tube formation.

It is essential to inhibit the expression of HIF-1 $\alpha$ and, subsequently, VEGF in these cells to repress the formation of new blood vessel in these tumors. Novel compound, CJ-3-60, was shown to inhibit hypoxic induction of secreted levels of VEGF protein in MDA-MB-231 cells, and we further reported the anti-angiogenic activity of compounds in HMECs cultured in media from $72 \mathrm{hr}$ drug-treated cells that were cultured for the last $24 \mathrm{hr}$ in hypoxia. Compounds decreased the secreted level of VEGF protein under hypoxia and normoxia conditions, which resulted in the disruption of in vitro capillary network formation in HMECs compared to untreated hypoxia control. Overall, this finding demonstrates that compounds hinder angiogenesis in hypoxic MDA-MB-231 breast cancer cells by inhibiting HIF-1 $\alpha$ accumulation. 


\section{CHAPTER 5. NOVEL THERAPEUTIC COMPOUND SUPPRESSES BREAST TUMOR METASTASIS}

\section{Introduction}

Two of the major biological characteristics of cancer cells are their unusual growth and metastasis, which combined is the major cause of morbidity and mortality in several patients with the disease [112]. Metastasis occurs in approximately half of the cases with apparently localized breast cancer, and death occurs in majority of the cases from the spreading of these cancer cells and their ultimate proliferation at secondary sites [113]. There are strong evidences that hypoxia represents a physiological stimulus for tumor cell invasion and metastasis and HIF-1 has been proven to regulate several stages throughout the complex metastatic process in many clinical and animal studies [36, 114-116]. Furthermore, based on immunohistochemical analyses, reasonable levels of HIF-1 $\alpha$ protein have been detected in benign tumors, high levels in primary malignant tumors, and a remarkable high amount in metastatic tumor, in sharp contrast to its absence in normal tissues [36, 117]. Likewise, angiogenesis has been widely implicated as critical to tumor growth, survival, and metastasis [118], a fact long established [46].

Since metastasis is one of the most critical factors associated with cancer therapeutic efficacy and prognostic survival, great effort is therefore warranted in development of new anticancer agents based on HIF-1 $\alpha$ inhibitors. Consequently, we sought out to investigate effect of these compounds on the migratory activity of these breast cancer cells (as a reasonably good predictor of in vivo metastatic activity) through Cell-Based Wound Healing assay and Soft Agar Colony Formation Assay.

\section{Materials and Methods}

\section{Cell-Based Wound Healing}

MDA-MB-231 or JygMC(A) cell lines were plated at the density of $8 \times 10^{6}$ cells/well into 12-well plates (Corning). After $24 \mathrm{hr}$, the cells were treated with each specific test compound $(0,1,10$, and $100 \mu \mathrm{M}$ of YC-1, G3, or CJ-3-60 respectively). The cells were washed twice with phosphate-buffered saline (PBS) solution after $24 \mathrm{hr}$ of drug treatment, followed by a short incubation $\left(1 \mathrm{hr}\right.$ at $\left.37^{\circ} \mathrm{C}\right)$ with $7-5 \mu \mathrm{g} / \mathrm{ml}$ of Mitomycin $\mathrm{C}$, a DNA intercalating agent known to inhibit cell proliferation (but allow migration), to MDA-MB-231 and JygMC(A) cell. A parallel wound was created inside each well by scratching the monolayer of confluent cells with a $200 \mu \mathrm{L}$ pipette tip at a $90^{\circ}$ angle. Each well with freshly made wound was then washed several times with PBS to remove cell debris, and then re-treated with their respective corresponding concentration of drug to investigate its effect on the cells migration during wound healing under both normoxic ( $95 \%$ air) and hypoxic $\left(0.5 \% \mathrm{O}_{2}\right)$ conditions. Cell migration into the wound surface was determined by the average distance of migrating cells under an 
inverted microscopy at various times. Serial images of selected fields were acquired every $24 \mathrm{hr}$ by a cell imaging workstation (Olympus CK2 Japan), coupled to a brightfield microscope at 40x. The scratched area was measured using the Scope photo 3.0 software and the width was calculated as a difference between the width of the wound at $0 \mathrm{hr}$ and each subsequent time period for each drug and concentration.

\section{Soft Agar Colony Formation Assay}

To test for contact-independent growth in soft agar, a 24-well Petri dish was first coated with $375 \mu \mathrm{l}$ base agrose consisting of $0.8 \%$ agrose in the culture medium RPMI 1640(MDA-MB-231 cells); DMEM 11995(JygMC(A) cells). Cells were counted, and resuspended at a density of 100 cells/ $125 \mu \mathrm{l}$ (JygMC(A) cells; 500 cells/ $125 \mu 1$ (MDA-MB-231 cells) in $0.4 \%$ agrose mixed in culture medium (treated and untreated). After introducing the mixture of cells, agrose with respective concentration of drugtreated media (or untreated) into the respective 24 well plate containing the base agrose, the immobilized cells were grown and fed with growth media $(100 \mu 1 /$ well) twice for 13 days in a humidified chamber at $37{ }^{\circ} \mathrm{C}$ with $21 \% \mathrm{O}_{2}, 5 \% \mathrm{CO}_{2}$. Plates were then stained with $0.05 \%$ crystal violet in PBS for $1 \mathrm{hr}$, and the colonies photographed and counted. The experiments were performed in duplicate, twice.

\section{Results}

\section{Compounds Inhibit in vitro Migration of MDA-MB-231 and JygMC(A) Cell Lines under Both Normoxia and Hypoxia Conditions}

Having shown that these compounds inhibited hypoxia-induced HIF-1 activation in these cell lines, we then studied their effects on MDA-MB-231 and JygMC(A) cell migration in a wound-healing assay as an in vitro model for this study as described under the materials and methods. Over a $72 \mathrm{hr}$ period, MDA-MB-231 cells migrated into the wounded area and resulted in closure of the wound (Figure 5-1a-d). All compounds at $100 \mu \mathrm{M}$ suppressed MDA-MB-231 cell migration under both normoxic and hypoxic conditions after $72 \mathrm{hr}$ (results not shown). YC-1 only modestly inhibited MDA-MB-231 cell migration at a concentration of $10 \mu \mathrm{M}$, while $\mathrm{G} 3$ and CJ-3-60 potently inhibited the cell migration of MDA-MB-231 cells at $10 \mu \mathrm{M}$ after 24, 48, and $72 \mathrm{hr}$ (Figure 5-1a-d); and also in JygMC(A) (results not shown). Meanwhile, CJ-3-60 more potently inhibited cell migration more significantly than G3.

In conclusion, while the untreated cells migrated and closed the wound in approximately $48 \mathrm{hr}$, cells treated with YC-1, G3 and CJ-3-60 did not. YC-1, though presenting delay versus the control, showed a lesser effect on wound-healing time than the other two inhibitors tested at the same concentration and duration. CJ-3-60 produced the most significant inhibition in both cell lines compared to the two other compounds. However, while the reduction was approximately half that of the control, the reduction in 
Figure 5-1. Cell migration capability was determined with a wound healing assay.

A confluent monolayer of MDA-MB-231 cells or JygMC(A) cells after a $24 \mathrm{hr}$ exposure to different concentrations of drug or blank control was wounded. Cells were then incubated for $72 \mathrm{hr}$ in hypoxia. Photographs were taken immediately (0 hr) and at $24 \mathrm{hr}$, $48 \mathrm{hr}$, and $72 \mathrm{hr}$ after wounding (a). The data (b-d) represent the cell migration to the wound areadetermined by the mean width (as a percentage compared to initial width at 0 $\mathrm{hr}$ ) at stated time point $(24,48$, and $72 \mathrm{hr}$ respectively) after wounding in two independent wound sites per group. * indicates $p<0.05$ when compared to the control. 
a
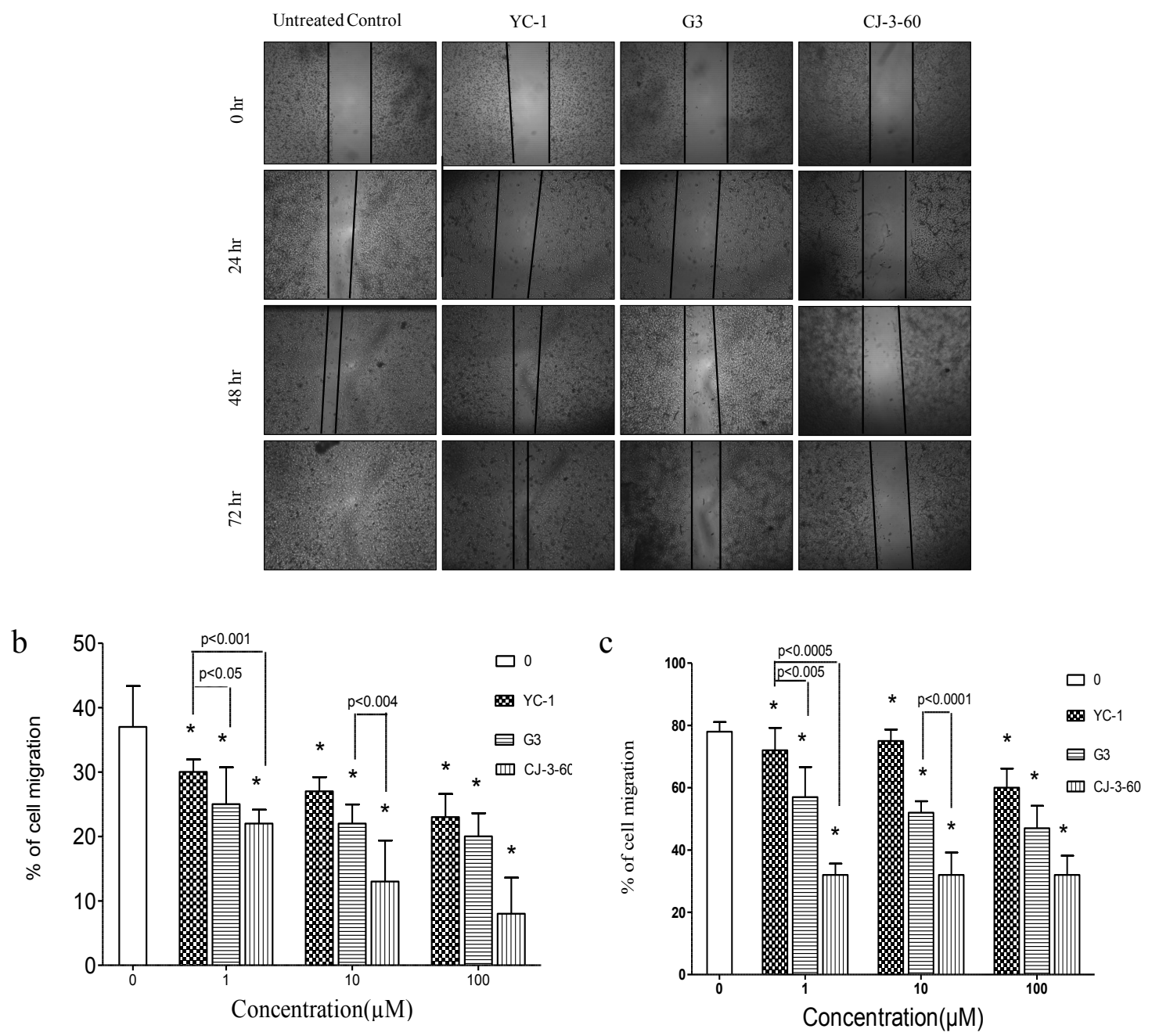

d

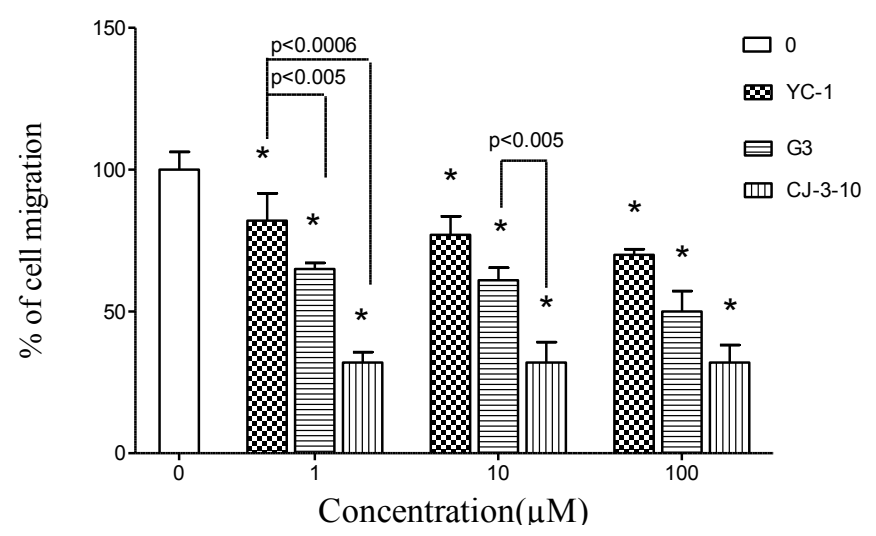


normoxia was only moderate or very slight compared to hypoxia for all cell lines and all drugs (Figure not shown). This lessening of wound-healing capability (or migration) of cells treated with G3 and CJ-3-60 is demonstrated as a near inhibition in the narrowing of the width of the wound compared to when they were observe at $0 \mathrm{hr}$, and an approximately $20-80 \%$ wider than that of the control in the treated cell lines.

\section{CJ-3-60 and G3 Significantly Blocked Colony Formation}

To determine whether YC-1, G3, and CJ-3-60 inhibited anchorage-independent colony formation, we cultured the cells either in the absence or presence of YC-1, G3, and CJ-3-60 for 13 days. The cells were incubated in a soft agar culture system, and colony formation was counted 13 days later. The results show a significant decrease in colony formation in drug-treated culture compared with untreated (Figure 5-2a-j). This data demonstrate that $\mathrm{YC}-1, \mathrm{G} 3$, and CJ-3-60 decreased in vitro colony formation by MDA-MB-231 and JygMC(A) breast cancer cells in a dose dependent manner (0.1 to 10 $\mu \mathrm{M})$ in all assays, and that CJ-3-60 had a more potent effect on inhibiting cell colony formation than $\mathrm{YC}-1$ and $\mathrm{G} 3$.

\section{Conclusion}

In the current study we reported that G3, and CJ-3-60 blocked migration of MDA-MB-231 and JygMC(A) cells. Cell migration plays a key role in both normal physiological and pathological conditions. Wound healing assay was used in investigating cell migration, and the inhibition exerted by $\mathrm{YC}-1, \mathrm{G} 3$, and CJ-3-60 was determined. Although the mechanism by which hypoxia amplifies the metastatic potential is still being studied, it is suggested that HIF-1 drives expression of a set of downstream genes that control processes implicated in migration and invasion $[115,116]$.

Finally, we determined whether YC-1, G3, and CJ-3-60 inhibited anchorage-independent colony formation. Anchorage independent growth is one of the characteristics of tumor-cell transformation, and is regarded as one of the most precise and stringent in vitro assay for identifying malignant transformation of cells. It has been revealed that tumor cells that can form colonies in the anchorage-independent growth assay will be tumorogenic in vivo [52]. Therefore, since YC-1, G3, and CJ-3-60 inhibited colony formation (in vitro tumorigenesis) of MDA-MB-231 and JygMC(A) cells in a dose-dependent manner, it indicates that these compounds will likely inhibit the cell incursion of these breast cancer cell lines. More importantly, the soft agar colony formation assay demonstrated that G3 and CJ-3-60 almost completely blocked colony formation, in contrast, YC-1 showed less significant effect on the cells. 
Figure 5-2. Effects of YC-1, G3, and CJ-3-60 on soft agar colony formation.

(a) Colony formation in MDA-MB- 231 cells and (e) JygMC(A) cells treated with YC-1, G3, and CJ-3-60 compounds. The number of colonies $>0.2,>0.5$, and $>1.0 \mathrm{~mm}$ was counted and data shown are the mean values from three separate experiments for each group (b-e for MDA-MB-231 and g-j for JygMC(A) cells). In the absence of all compounds, both cell lines formed colonies after 13 days. The addition of YC-1, G3, and CJ-3-60 $(0.1-10 \mu \mathrm{M})$ to the culture medium significantly inhibited colony formation of MDA MB 231 and JygMC(A). * indicates $p<0.05$ when compared to the control. 
a

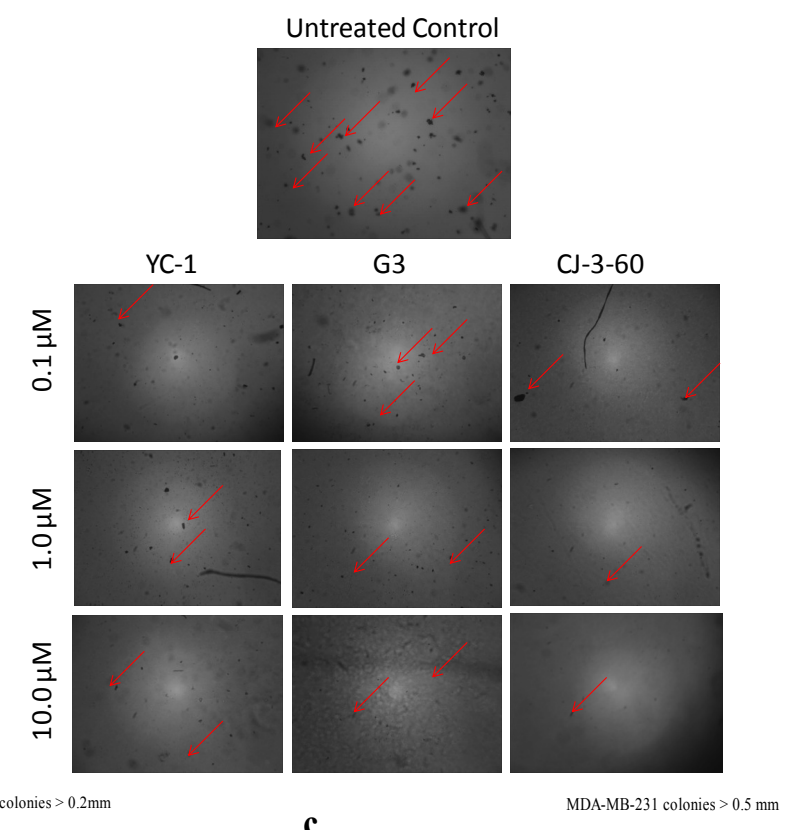

b
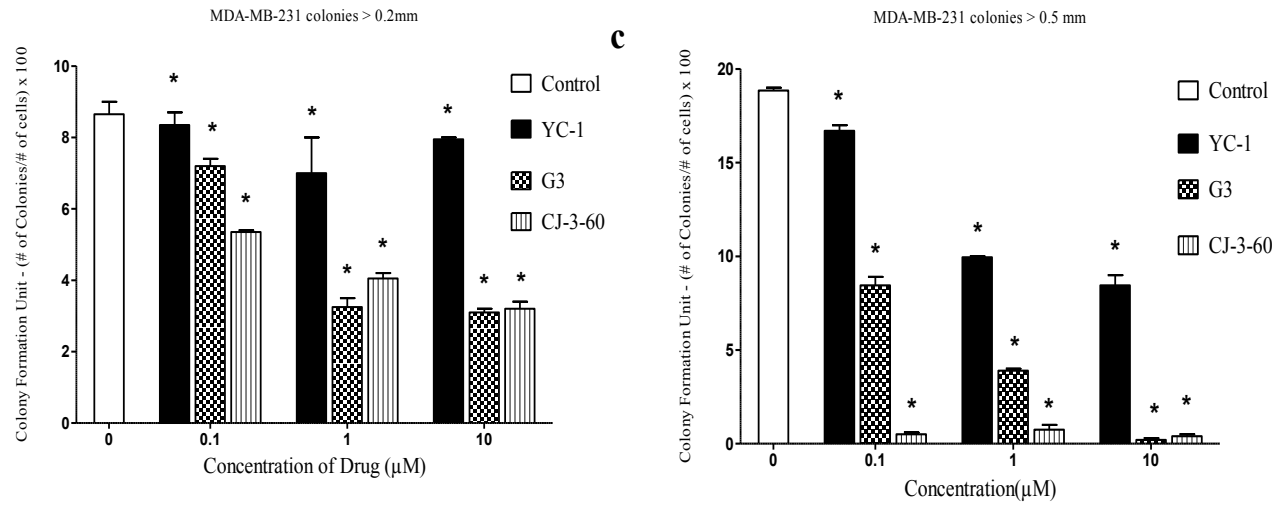

d

e

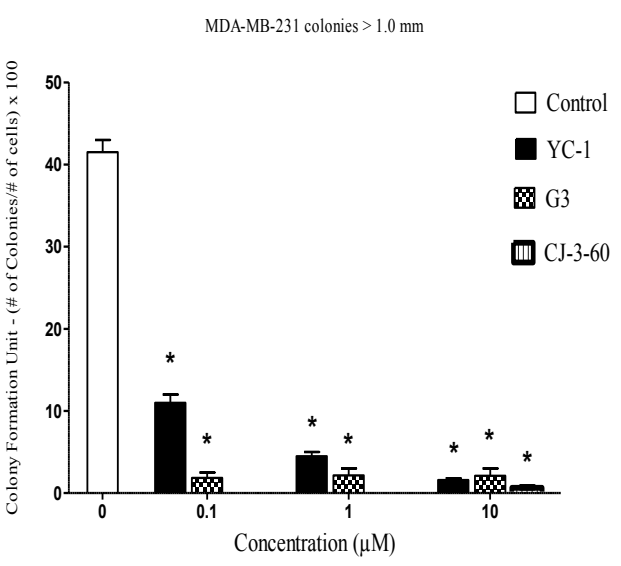

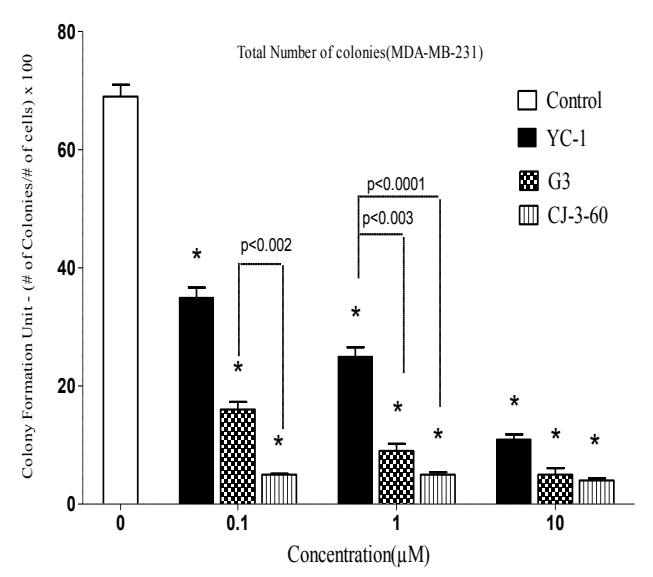


f

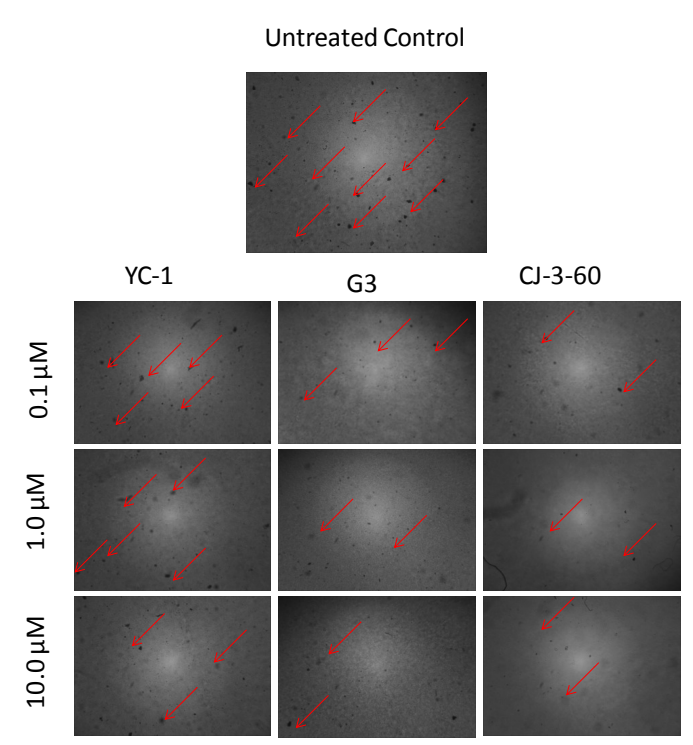

g
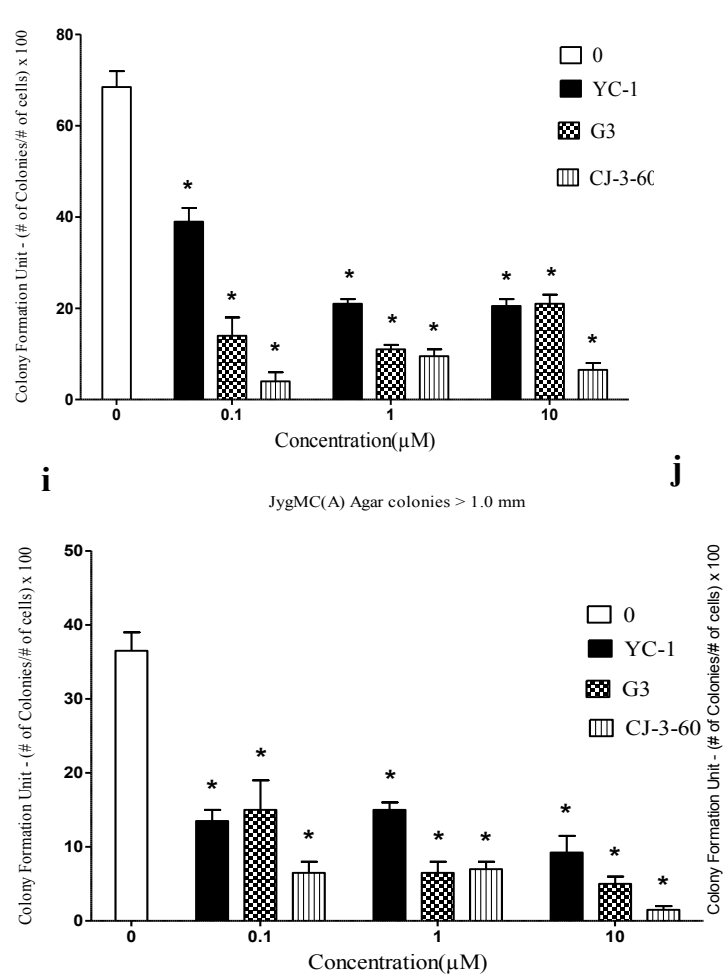

h

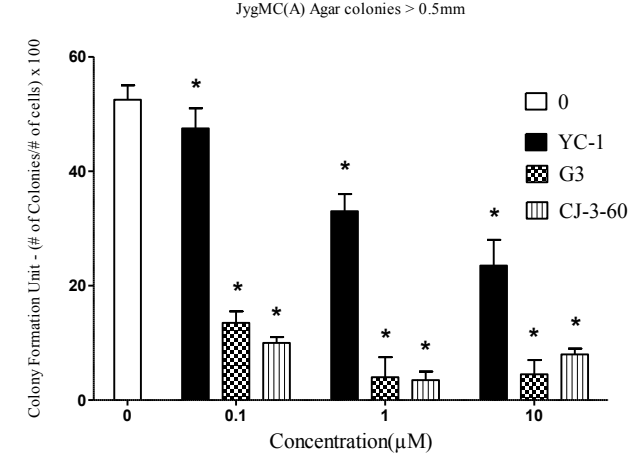

Total Number of colonies-JygMC(A)

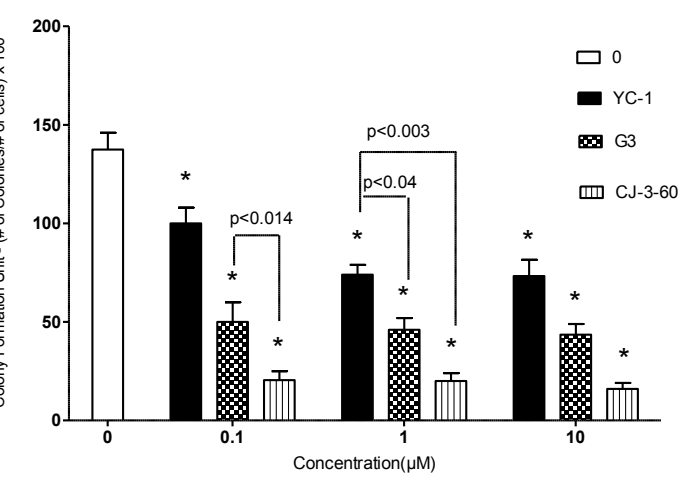

Figure 5-2. Continued. 


\section{CHAPTER 6. POSSIBLE MECHANISM OF ANTI-HIF-1 $\alpha$ ACTION OF NOVEL THERAPEUTIC COMPOUND IN VITRO}

\section{Introduction}

A significant effort has been invested by researchers in identifying and developing compounds that inhibit HIF- $1 \alpha$ and ascertaining their mechanisms of action. None however, at the time of writing this, has been reported that directly and specifically targets HIF-1. Although numerous drugs were developed to primarily target signal transduction proteins, these drugs were later discovered to inhibit HIF-1 either in conjunction with, or as a consequence of inhibiting their primary target [19, 20, 118-122]. It has been therefore difficult for researchers to attribute any anti-cancer effects of these compounds specifically to the inhibition of HIF-1 $\alpha$ due to this lack of specificity. Nevertheless, this should not exclude such compounds as potential anticancer agents, because the fact that they target multiple pathways makes them very essential if these other targets are also implicated in tumourigenesis.

For these studies, we evaluated the molecular mechanism of action of the G3 and CJ-3-60. The low levels of HIF-1 $\alpha$ observed in the preceding studies may be due to impairment in protein translation or an increase in its degradation. Since hypoxia is associated with decreased degradation of HIF-1 $\alpha$, and YC-1 in part facilitates in HIF-1 $\alpha$ degradation, it therefore makes degradation primarily the first possible mechanism of action by these analogues to be investigated. Furthermore, since HIF-1 regulation characteristically occurs at the protein level, we investigated by western blotting whether the compounds had a direct effect on the rate of HIF-1 $\alpha$ protein degradation.

Protein hydroxylation induces the proteasomal degradation of HIF-1 $\alpha$ on proline residues 402 and 564 by specific HIF-prolyl hydroxylases in the presence of iron and oxygen [18]. To test whether protein hydroxylation is involved in G3 and CJ-3-60-induced inhibition of HIF-1 $\alpha$, a prolyl hydroxylase (PHD) inhibitor Dimethyloxalylglycine (DMOG) was used in G3 and CJ-3-60-treated cells under normoxia. The protein level of HIF-1 $\alpha$ subunit is post-transcriptionally regulated by prolyl and asparaginyl hydroxylase (PAH), and suppression of $\mathrm{PAH}$ activity increases endogenous HIF-1 $\alpha$ levels. DMOG is an ester of N-oxalylglycine that penetrates cells readily, inhibits all prolyl-4-hydroxylase domain 1-3 factor-inhibiting HIF enzymes, thereby upregulating HIF [123,124].

\section{Materials and Methods}

MDA-MB-231 cells were incubated under hypoxia condition for $18 \mathrm{hr}$ in the absence or presence or absence of G3 and CJ-3-60 $(20 \mu \mathrm{M})$ and then treated with cycloheximide $(30 \mu \mathrm{M})(\mathrm{CHX})$-a protein translation inhibitor- for 15 or $30 \mathrm{mins}$ to prevent de novo HIF-1 $\alpha$ protein synthesis in cells. Western blotting for HIF-1 $\alpha$ protein was performed as described earlier. 
In a follow up experiment, cells were pretreated with DMOG $(1000 \mu \mathrm{M})$ and treated either with or without drug $(50 \mu \mathrm{M})$ for $24 \mathrm{hr}$ under normoxia condition. Cell lysates were prepared and subjected to western blotting for HIF-1 $\alpha$.

\section{Result}

The protein level of HIF-1 $\alpha$ was decreased in G3 and CJ-3-60-treated cells in comparison with untreated control (Figure 6-1), indicating that G3 and CJ-3-60 accelerates the degradation process of HIF-1 $\alpha$ under hypoxia condition in MDA-MB-231 cells.

Prior to these experiments, we confirmed that DMOG treatment resulted in a stable increase of functionally active HIF-1 $\alpha$ proteins in vitro (result not shown). A treatment for $24 \mathrm{hr}$ with $1000 \mu \mathrm{M}$ DMOG resulted in $\sim 10.5$-fold increase of HIF-1 $\alpha$ protein levels and similar to results obtained with cells exposed to hypoxia $\left(0.5 \% \mathrm{O}_{2}\right)$ for the same period of time. Subsequently, we then examined the effect of DMOG, a competitive inhibitor for HIF-1 $\alpha$ prolyl-hydroxylase (Figure 6-2).

While treatment of the cells with DMOG induced accumulation of HIF-1 $\alpha$ under normoxic conditions, the induction of HIF- $1 \alpha$ was not observed in the presence of either G3 or CJ-3-60 without DMOG under normoxia. However, DMOG recovered HIF-1 $\alpha$ accumulation suppressed by G3 and CJ-3-60 in MDA-MB-231cells under normoxia (Figure 6-2). Thus, these results suggest that the inhibition of HIF-1 $\alpha$ protein expression is caused by degradation of HIF- $1 \alpha$ protein and since DMOG recovered HIF- $1 \alpha$ accumulation inhibited by G3 and CJ-3-60, prolyl hydroxylation is involved in inhibition of HIF-1 $\alpha$.

\section{Conclusion}

In these assays, the inhibitory mechanism of CJ-3-60 was investigated on HIF-1 $\alpha$ stability in MDA-MB-231 cells. All compounds promoted hypoxia-induced HIF-1 $\alpha$ degradation and cycloheximide (CHX) blocked de novo protein synthesis in MDA-MB231 cells. Also, as anticipated, CJ-3-60 had more potency in causing the rapid degradation of hypoxia-induced HIF-1 $\alpha$ expression than YC-1 and G3.

Degradation occurs when HIF-1 $\alpha$ is hydroxylated at Pro 564 and Pro 402 located at its oxygen-dependent degradation domain (ODDD). This process is facilitated by a family of prolyl hydroxylases (PHDs) that require oxygen, iron, and 2-oxoglutarate as the co substrate to hydroxylate the specific amino acid residues [125-127]. PHD proteins are inhibited in hypoxic conditions, leading to a gradual increase in HIF-1 $\alpha$ protein levels and formation of the active HIF-1 [128, 129].

A prolyl hydroxylase (PHD) inhibitor dimethyloxalylglycine (DMOG) is usually utilized to examine whether prolyl hydroxylation is involved in inhibition of HIF-1 $\alpha$ 
a

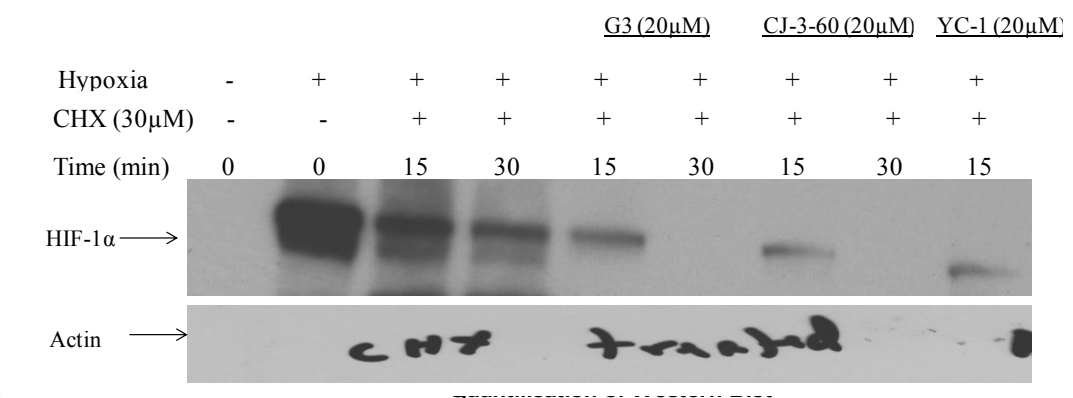

b

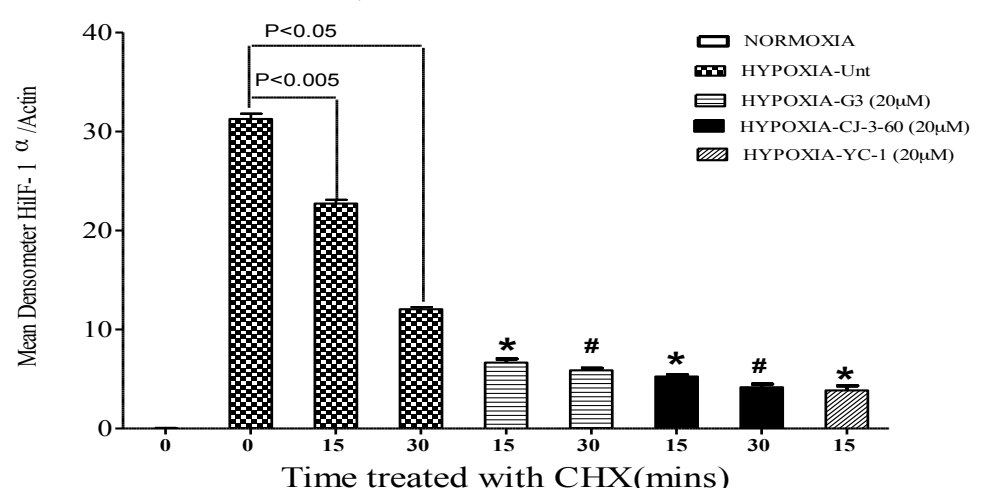

\section{Figure 6-1. Effect of drugs on hypoxia-induced HIF-1 $\alpha$ protein stability by post-translational modification in MDA-MB-231 cells.}

Cells were incubated under hypoxia condition for $18 \mathrm{~h}$ in the absence or presence of YC1, G3, and CJ-3-60 $(20 \mu \mathrm{M})$ and then treated with cycloheximide (CHX) $(30 \mu \mathrm{M})$ for 15 or $30 \mathrm{~min}$. Cell lysates were prepared and subjected to western blotting for HIF-1 $\alpha$ (a). Quantified graphs of HIF- $1 \alpha$ normalize with levels of actin (b). * indicates $p<0.05$ when compared to untreated hypoxia sample and \# indicates $p<0.05$ when compared to 15 mins respective reoxygenated samples and untreated hypoxia 
$\mathrm{a}$

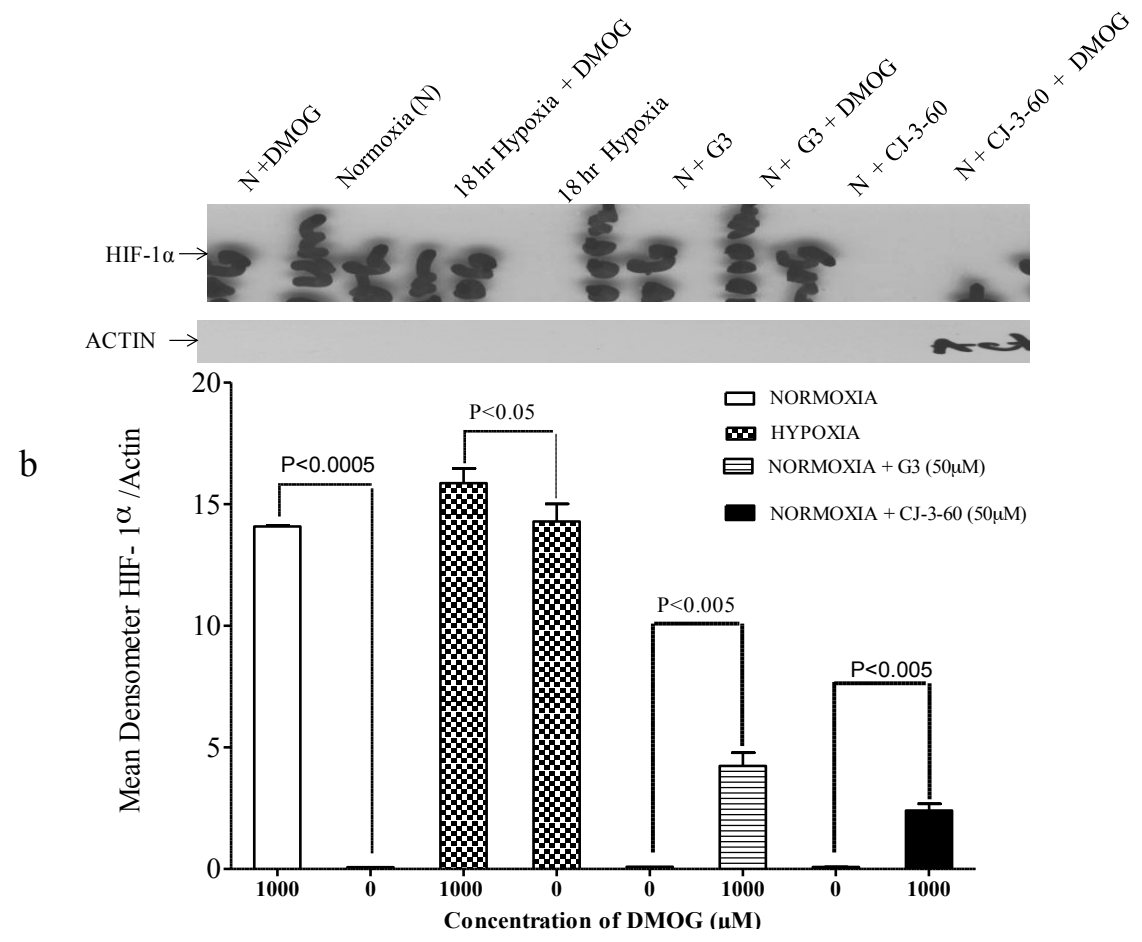

Figure 6-2. Inhibitory effect of G3 and CJ-3-60 on HIF-1 $\alpha$ accumulation via prolyl hydroxylation under normoxia.

Cells were pretreated with DMOG $(1000 \mu \mathrm{M})$ and treated either with or without respective drug $(50 \mu \mathrm{M})$ for $18 \mathrm{hr}$ under normoxia or hypoxia condition. Cell lysates were prepared and subjected to western blotting for HIF-1 $\alpha$. (a) Western blot analysis. (b) quantified graphs. 
accumulation. Here, DMOG recovered HIF-1 $\alpha$ accumulation suppressed by these drugs in MDA-MB-231 cells under normoxia, which indicates that these drugs may be acting as agonists of the enzymes (prolyl hydroxylases) involved in physiologic degradation of HIF-1 $\alpha$. In vitro screenings of chemical libraries conducted for such agonists of the enzymes implicated in HIF-1 $\alpha$ degradation (three prolyl hydroxylases, PHD1-3 and acetyltransferase, ARD1), have suggested that, alternatively, such drugs may activate PHDS by reversing fumerate or succinate-mediated inhibition of PHDS [130, 131]. 


\section{CHAPTER 7. POSSIBLE MECHANISM OF ANTI-METASTATIC ACTION OF NOVEL THERAPEUTIC COMPOUND IN VITRO}

\section{Introduction}

\section{Effect of Compounds on the Expression of Hypoxia-Induced HEF1 Expression}

Hypoxia in the tumor microenvironment enhances cancer progression by triggering adaptive programs that promote cell survival, motility, and tumor angiogenesis. Many cellular responses to hypoxia are mediated through changes in gene expression. Human Enhancer of Filamentation protein 1 (HEF1), also known as Neural precursor cell Expressed Developmentally Down-regulated protein 9 (NEDD9), is part of the Cas family of proteins, which include HEF1/NEDD9, p130Cas and Efs. HEF1 is a docking protein that plays a central coordinating role related to cell adhesion, motility, growth and apoptosis $[132,133]$. It is believed to be one of the chief regulator of cancer metastasis, essential for the invasive activity of certain cancer cells [134] and is linked to the promotion of metastasis in some others [135].Studies have suggested that HEF1 is an essential regulator for metastasis of melanoma and glioblastoma [133, 134], and overexpression of HEF1 advances cancer cell growth, migration, and invasion through the activation of various signal transduction pathways [136-139].

\section{Effect of Compounds on the Expression of MMP-9 in MDA-MB-231 Cells}

Hypoxia is widely being proposed as another regulator of HEF1 expression. In one study, HEF1 was upregulated after transient global ischemia in rats [140], and in cultured mesenchymal stem cells in response to hypoxia [141]. However, the molecular basis for regulation and function of HEF1 in cancer tissues under hypoxic conditions remains largely unknown [140]. HIF-1 $\alpha$ has been shown to stimulate HEF1 transcription when colon carcinoma cells were exposed to hypoxia. Inhibition of HEF1 expression has been reported to be linked to reduced levels of hypoxia-inducible genes, including those that regulate cell motility. Furthermore, inhibition of HIF-1 $\alpha$ by its siRNA blocked hypoxia-induced HEF1 expression at both the protein and mRNA levels. Treatment of $\mathrm{CoCl} 2$, a chemical inducer of HIF-1 $\alpha$, increased HEF1 protein levels [142].

Various studies have suggested that HIF-1 $\alpha$ stimulates tumor cell invasiveness under hypoxic conditions in vitro by regulating genes including those involved in extracellular matrix metabolism (MMPs) [144,145]. Matrix Metallo-Proteinases (MMPs) are a family of enzymes involved in degradation of extracellular matrix (gelatinases, collagenases) and are vital in tissue remodeling during tumor invasion, metastasis, and angiogenesis. The MMP-9 (a member of the MMP family) is a known mediator of tumor cell invasion [146] and has recently been shown to be critical for the invasive steps of 
metastasis [147-148], the fact that its expression correlates with HIF-1 $\alpha$ expression suggests that HIF-1 $\alpha$ is involved in promoting MMP-9-dependent metastasis. As a result of this, we tested whether compounds could inhibit the expression of MMP-9 in MDAMB-231 cells by western blot assay.

\section{Materials and Methods}

\section{Luciferase Assay}

For dual luciferase reporter assays, $6 \times 10^{4}$ MDA-MB-231 cells were plated on 24-well tissue culture plate. The following day, they were co-transfected with $0.5455 \mu \mathrm{g}$ firefly luciferase reporter constructs pHEF1-Luc and $0.0545 \mu \mathrm{g}$ of the control Renilla luciferase reporter phRluc-TK using the nonliposomal transfection reagent, Fugene 6(Promega). After treatment, cells were lysed with cell lysis buffer provided by the dualluciferase reporter assay kit (Promega). Luciferase activity was then measured according to the manufacture's instruction.

\section{Western Blot Analysis}

MDA-MB-231 cells were treated for $24 \mathrm{hr}$ with various concentrations of $\mathrm{YC}-1$, G3, and CJ-3-60 (1, and $10 \mu \mathrm{M})$ and collected. The cells were then lysed as described earlier for western blot assay The blots were incubated with specific antibodies against MMP-9 (1:1000, Santa Cruz) overnight at $4^{\circ} \mathrm{C}$ followed by Li-COR conjugated secondary anti mouse antibody for $1 \mathrm{hr}$ at $37^{\circ} \mathrm{C}$. Detection was performed by the Odyssey Infrared Imaging System (Li-COR Inc., Lincoln, Massachusetts). The blot was reprobed with polyclonal anti-actin antibody to ascertain equal loading of proteins.

\section{Result}

\section{Novel Compound Inhibits Hypoxia-Induced HEF1 Expression}

Studies have revealed the relevance of HEF1 in metastasis, although the precise mechanism of action requires further investigation. Furthermore, no serious attempt has as yet been made to target HEF1 for drug development; therefore since HIF-1 $\alpha$ is a critical transcription factor in regulating the cellular transcriptional response to hypoxia [143], we examined whether compounds inhibits cell migration by inhibiting the hypoxia-induced expression of HEF, which is mediated by HIF-1 $\alpha$. As shown in Figure 7-1, MDA-MB-231 cells treated with novel compounds and a known HIF-1 $\alpha$ inhibitor, YC-1, inhibits hypoxia-induced HEF1 expression. 


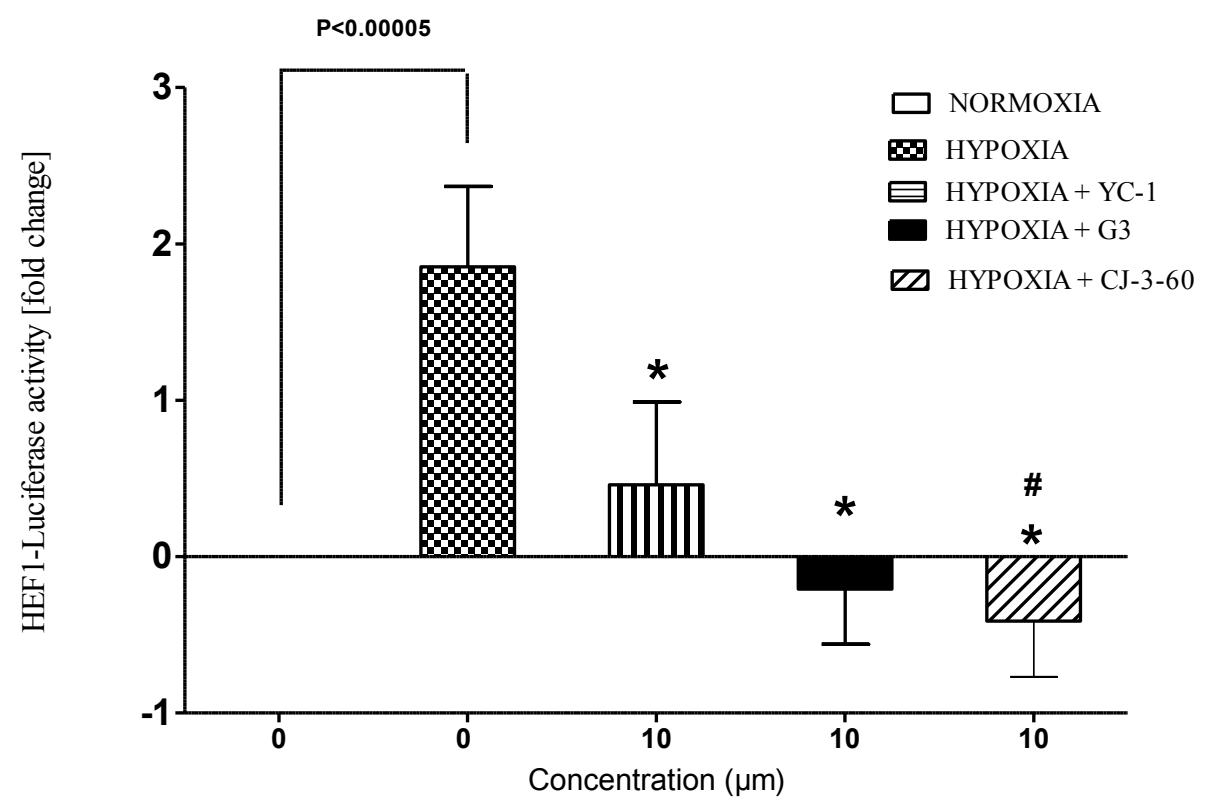

Figure 7-1. Compounds inhibit hypoxia-induced HEF1 expression.

MDA-MB-231 cells were transiently co-transfected with pHEF1-Luc and phRluc-TK plasmids for $48 \mathrm{hr}$ while under drug treatment, and exposed to hypoxia for the last $18 \mathrm{hr}$. The luciferase activity was then determined. Luciferase activity represents data that have been normalized into cotransfected Renilla luciferase activity, then quantified as a ratio of expression levels from normoxia samples. * indicates $p<0.05$ when compared to the hypoxia untreated control. \# indicates $p<0.05$ when compared to $\mathrm{YC}-1$ at the same concentration. 


\section{Compound Suppresses the Activity and Expression of MMP-9 in MDA-MB-231 Cells}

Breast cancer cells produce MMPs, and its increased expression is associated with disease progression [149]. The activity and expression of MMP-9 in MDA-MB-231cells exposed to different concentrations of YC-1, G3, and CJ-3-60 were examined to explore the possible anti invasive mechanism of the compounds. Western blotting analysis was carried out to examine the expression of MMP-9 in MDA-MB-231 cells. YC-1, G3, and CJ-3-60 exerted inhibitive effect on the expression of MMP-9 in a concentration-dependent manner compared with the control group (Figure 7-2a). Quantification analysis indicated that MMP-9 activity reduced by $42 \%, 52 \%$ and $76 \%$ when cells were treated with $10 \mu \mathrm{M}$ of YC-1, G3, and CJ-3-60 (Figure 7-2b).

\section{Conclusion}

Over the years, our understanding of metastasis has progressed considerably. However, a lot still needs to be elucidated about this significant process for the advancement of cancer treatment. Alterations in expression of HEF1/CAS-L/NEDD9 protein, have been established over the past decade to be a strong pro-metastatic stimulus in numerous cancers, and reportedly important in regulating genes that are fundamentally involved in cell motility such as MMP9 [150, 151], and apoptosis [152-155]. CJ-3-60 inhibited, in MDA-MB- 231 cancer cells, the expression and secretion of, MMP-9, which is involved in the degradation of extracellular matrix and play vital roles in cancer cell migration and invasion [156-158]. The complex multistep process of metastasis of cancer cells involves cell adhesion, invasion and motility, therefore interruption of one or more of these steps can be considered as one approach for anti-metastatic therapy [124]. 
a

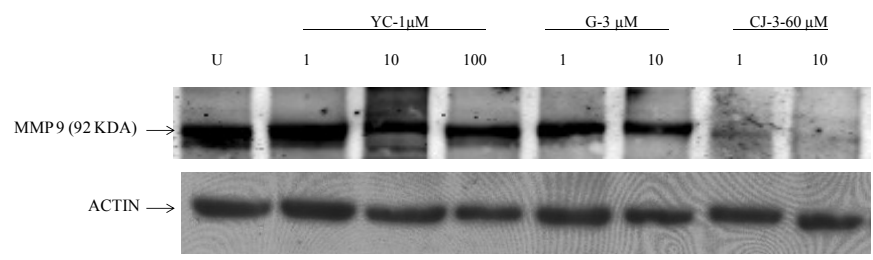

$\mathrm{b}$

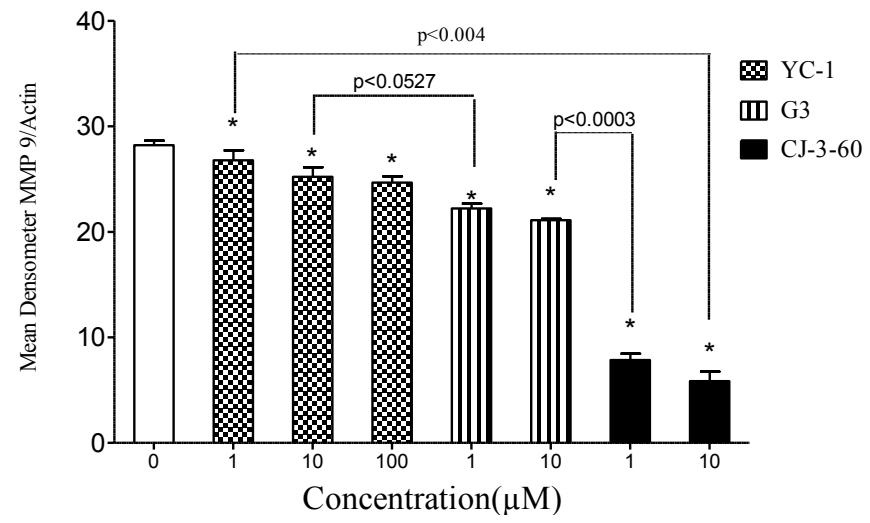

Figure 7-2. CJ-3-60 reduced the protein levels of MMP 9 in MDA-MB-231 under hypoxic conditions in a dose-dependent manner.

Western blot analysis of YC-1, G3, and CJ-3-60 in the downregulation of MMP-9 expression in MDA-MB-231 cells shows that all compounds could inhibit the MMP-9 expression in a concentration-dependent manner (a). Quantification of the western blot assay with protein levels of MMP-9 normalized with levels of actin (b). ${ }^{*} P<0.05$ compared with control. Data are presented as the mean $\pm \mathrm{SE}$ of two separate experiments. 


\section{CHAPTER 8. FUTURE PRECLINICAL STUDIES}

In order to survive and proliferate, cancer cells must adapt to the hypoxic environment [159]. Hypoxic tumors cells undertake several morphological and genetic alterations including angiogenesis, anaerobic glycolysis, and production of stress proteins associated with their survival or death $[20,160,161]$. The heterogeneity of the human cancer observed in any particular individual over time, and between individuals with the same type of cancer is the greatest impediment to the establishment of potent therapies for this disease. Despite the discovery of numerous genetic and epigenetic alterations in cancer cells, understanding which of these alterations represent critical therapeutic targets in a particular patient still proves to be a major challenge. The central role of HIF-1 $\alpha$ in the adaptive response to hypoxia and in the activation of numerous pathways responsible for tumor progression, positions it as a viable target for anticancer drug development. The potential of HIF-1 $\alpha$ as a target for cancer therapy, therefore, lies in the development of small molecule inhibitors of HIF-1 [160-162].

The recognition that HIF-1 plays a key role in cancer biology and the improved understanding of the roles and regulatory mechanisms induced by this transcription factor will open the gate to novel, potentially effective and selective therapies against a variety of pathologic conditions, such as ischemic/hypoxic injuries, tumor growth, and cardiovascular remodeling. Based on the rapidly growing interest in therapeutic strategies targeting hypoxia/HIF, more active compounds of potential interest for preclinical trial will undoubtedly be generated. However, one issue pertinent to the development of anti-HIF compounds is that HIF-1 inhibition alone may be insufficient in arresting angiogenesis and tumor growth, because HIF independent pathways may circumvent or overcome HIF inhibition [162-164]. Therefore, due to the possibility that HIF-1 inhibitors may have limited activity when used as single agents, combining HIF inhibitors with conventional therapies or prospective molecular targeted agents may be necessary.

We set out, using various experimental methods, to discover of HIF-1 inhibitors through a cell-based HTS, which has provided some information regarding novel compounds that impede some pathways involved in HIF-1 regulation. In our quest for finding potential therapeutics, we choose $\mathrm{YC}-1$ as a basic scaffold. Based on the premise that the synthesis of YC-1 derivatives should be an active area of research, hundreds of small molecule compounds were screened, and several showed positive and potent anti-HIF-1 $\alpha$ activity at the initial screening round. We discovered that G3, an existing analogue of YC-1, affects the hypoxic accumulation of HIF-1 $\alpha$ protein more potently when compared to $\mathrm{YC}-1 \mathrm{We}$ further validated the potency of the newly discovered compound and performed comparison analyses. This was therefore selected as a structural scaffold to design novel compounds, one of which, CJ-3-60, displayed an impressive result. Also after selecting the most potent drug moieties, we examined their effect on other members of the HIF family and other genes with functional roles similar or complementary to HIF-1. 
The in vitro studies showed that $\mathrm{G} 3$ and CJ-3-60 was able to decrease the accumulation of hypoxia-inducible factor (HIF-1 $\alpha$ ) and the expression of downstream HIF-1 target genes, including those for vascular endothelial growth factor. Although HIF-1 $\alpha$ down-regulation may be insufficient for HIF-1 inhibition, we propose developing G3 and CJ-3-60 as a novel attractive therapeutic agent aimed to inhibit angiogenesis and breast cancer therapeutic agent for cancer cells.

While the compounds are designed to target a specific biological molecule (HIF $1 \alpha$ ), we elucidated important mechanisms of the anticancer activity of G3 and CJ-3-60, related to cell survival and angiogenesis, which are essential for the adaptation of cancer cells to micro environmental hypoxia and hence for tumor progression. These mechanisms may in part explain the broad spectrum of the novel compound's anticancer effects, and provide a rationale for its development as an anticancer drug. Any anti HIF-1 compound may disrupt the HIF-1 signaling pathway through a variety of mechanisms. Therefore in terms of the anti-HIF mechanism of G3 and CJ-3-60, some mechanisms may still need to be explored, since the HTSS does not reveal mechanisms of action of antiHIF- $1 \alpha$ compounds. Hence, more studies on the mechanism of action of G3 and CJ-3-60 will likely provide new insights into its validity/applicability for the pharmacologic targeting of HIF- $1 \alpha$ for therapeutic purposes.

We anticipate that some of these compounds identified in this approach will progress through the preclinical models, and tested for further clinical development. Preclinical efficacy of the therapy will eventually be evaluated with the primary end point of overall survival and safety, while the secondary end points will include tumor size decline and inhibition or reduction in metastasis. Further work is ongoing in our lab to identify more selective HIF-1 inhibitors, to determine their mechanism of action and to translate these developments into clinical trials. The most potent drug candidates with the highest HIF-1 $\alpha$ specificity and selectivity and minimal side effect will be used for subsequent studies. We envisage that results from these screens will lead to an increase in the number of HIF inhibitors over in the near future, and likely reveal novel targets involved in the regulation of HIF activity. The further investigation of these positive "hits" in significant preclinical models and the modified early clinical trials is crucial for maximizing the results of this exciting area of drug development. 


\section{LIST OF REFERENCES}

1. Jemal A, et al. (2009). Cancer statistics. CA Cancer J. Clin 59: 225-249.

2. Society AC (2008). Breast Cancer Facts and Figures: 2007-2008. American Cancer Society, Inc. : Atlanta, GA. Available from

http://www.cancer.org/Research/CancerFactsFigures/BreastCancerFactsFigures/bre ast-cancer-facts--figures-2007-2008.

3. National Cancer institute (2007).Cancer Trends Progress. National Institutes of Health, Department of Health and Human Services: Bethesda, MD. Available from http://progressreport.cancer.gov.

4. Hutchinson L (2010). Breast cancer: Challenges, controversies, breakthroughs. Nat Rev Clin Oncol 7: 669-670.

5. Bombonati, A, Sgroi DC (2011). The molecular pathology of breast cancer progression. J Pathol 223: 307-317.

6. Alvarez RH (2010). Present and future evolution of advanced breast cancer therapy. Breast Cancer Res 12 Suppl 2: S1.

7. Longatto Filho A, Lopes JM, Schmitt FC (2010). Angiogenesis and breast cancer. J Oncol pii: 576384.

8. Melillo G (2007). Targeting hypoxia cell signaling for cancer therapy. Cancer Metastasis Rev 26: 341-352.

9. Hockel M, Schlenger K, Hockel S, Aral B, Schaffer U, Vaupel P (1998). Tumor hypoxia in pelvic recurrences of cervical cancer. Int J Cancer 79: 365-369.

10. Stadler P et al. (1999). Influence of the hypoxic subvolume on the survival of patients with head and neck cancer. Int J Radiat Oncol Biol Phys 44: 749-754.

11. Greijer AE, Van der Wall E (2004). The role of hypoxia inducible factor 1 (HIF-1) in hypoxia induced apoptosis. J Clin Pathol 57: 1009-1014.

12. Lee JY et al. (2008). Rare variant of hypoxia-inducible factor-1 $\alpha$ (HIF-1 $\alpha)$ and breast cancer risk in Korean women. Clin Chim Acta 391: 131.

13. Bunn HF, Poyton RO (1996). Oxygen sensing and molecular adaptation to hypoxia. Physiol Rev 76: 839-885.

14. Chun YS, Adusumilli PS, Fong Y (2005). Employing tumor hypoxia for oncolytic therapy in breast cancer. J Mammary Gland Biol Neoplasia 10: 311-318. 
15. Hanahan D, Folkman J (1996). Patterns and emerging mechanisms of the angiogenic switch during tumorigenesis. Cell 86: 353-364.

16. Semenza GL. (2007). Life with oxygen. Science 318: 62-64.

17. Brown JM, Wilson WR (2004). Exploiting tumor hypoxia in cancer treatment. Nat Rev Cancer 4: 437-447.

18. Melillo G. (2006). Inhibiting hypoxia-inducible factor 1 for cancer therapy. Mol Cancer Res 4: 601-605.

19. Semenza GL (2003). Targeting HIF-1 for cancer therapy. Nat Rev Cancer 3: 721732 .

20. Giaccia A, Siim BG, Johnson RS (2003). HIF-1 as a target for drug development. Nat Rev Drug Discov 2: 803-811.

21. Wang GL, Semenza GL (1995). Purification and characterization of hypoxiainducible factor 1. J Biol Chem 270: 1230-1237.

22. Ema M et al. (1997). A novel bHLH-PAS factor with close sequence similarity to hypoxia- inducible factor $1 \alpha$ regulates the VEGF expression and is potentially involved in lung and vascular development. Proc Natl Acad Sci USA 94: 42734282 .

23. Tian H, McKnight SL, Russell DW (1997). Endothelial PAS domain protein 1 (EPAS1), a transcription factor selectively expressed in endothelial cells. Genes Dev 11: 72-82.

24. Gu YZ, Moran SM, Hogenesch JB, Wartman L, Bradfield CA (1998). Molecular characterization and chromosomal localization of a third $\alpha$-class hypoxia inducible factor subunit, HIF-3 $\alpha$. Gene Exp 7: 205-213.

25. Hara S, Hamada J, Kobayashi C, Kondo Y, Imura N (2001). Expression and characterization of hypoxia-inducible factor (HIF-3 $\alpha$ ) in human kidney: suppression of HIF-mediated gene expression by HIF-3 $\alpha$. Biochem Biophys Res Commun 287: 808-813.

26. Semenza GL, et al. (1997). Structural and functional analysis of hypoxia-inducible factor 1. Kidney Int 51: 553-55.

27. Wang GL, Jiang BH, Rue EA, Semenza GL (1995). Hypoxia-inducible factor 1 is a basic-helix-loop-helix-PAS heterodimer regulated by cellular $\mathrm{O}_{2}$ tension. Proc Natl Acad Sci U S A 92: 5510-5514. 
28. Rankin EB, Giaccia AJ (2008). The role of hypoxia-inducible factors in tumorigenesis. Cell Death Differ 4: 678-685.

29. Beck I, Ramirez S, Weinmann R, Caro J (1991). Enhancer element at the 3'flanking region controls transcriptional response to hypoxia in the human erythropoietin gene. J Biol Chem 266: 15563-15566.

30. Burbach KM, Poland A, Bradfield, CA (1992). Cloning of the Ah-receptor cDNA reveals a distinctive ligand-activated transcription factor. Proc Natl Acad Sci U S A 89: $8185-8189$.

31. Melillo G. (2004). HIF-1: A target for cancer, ischemia and inflammation-Too good to be true? Cell Cycle 3: 154-155.

32. Kaufman B, et al. (2004). Proceedings of the oxygen homeostasis/hypoxia meeting. Cancer Res 64: 3350-3356.

33. Melillo G, Semenza GL (2006). Meeting report: Exploiting the tumor microenvironment for therapeutics. Cancer Res 66: 4558-4560.

34. Kallio PJ (1998). Signal transduction in hypoxic cells: Inducible nuclear translocation and recruitment of the $\mathrm{CBP} / \mathrm{p} 300$ coactivator by the hypoxia-inducible factor-1 $\alpha$. EMBO J 16: 6573-6586.

35. Chun YS, Kim MS, Park JW (2002).Oxygen-dependent and -independent regulation of HIF-1 $\alpha$. J Korean Med Sci 17: 581-588.

36. Zhong H, et al. (1999). Overexpression of hypoxia-inducible factor 1alpha in common human cancers and their metastases. Cancer Res 59: 5830-5835.

37. Stebbins CE, Kaelin WG Jr, Pavletich NP (1999). Structure of the VHL-elongin-Celongin-B complex: implications for VHL tumor suppressor function. Science 284: 455-461.

38. Okuda H, et al. (1999). Direct interaction of the $\beta$-domain of VHL tumor suppressor protein with the regulatory domain of atypical PKC isotypes. Biochem Biophys Res Commun 263: 491-497.

39. Kamura T, Conrad MN, Yan Q, Conaway RC, Conaway JW (1999). The Rbx1 subunit of SCF and VHL E3 ubiquitin ligase activates Rub1 modification of cullins Cde53 and Cul2. Genes Dev 13: 2928-2933.

40. Yamashita K, Discher DJ, Hu J, Bishopric NH, Webster KA (2001). Molecular regulation of the endothelin-1 gene by hypoxia. Contributions of hypoxia-inducible factor-1, activator protein-1, GATA-2, and p300/CBP. J Biol Chem 276: 1264512653. 
41. Maxwell PH, Pugh CW, Ratcliffe PJ (2001). Activation of the HIF pathway in cancer. Curr Opin Genet Dev 11: 293-299.

42. Spirig R, et al. (2010).Effects of TLR agonists on the hypoxia-regulated transcription factor HIF-1 $\alpha$ and dendritic cell maturation under normoxic conditions. PLoS One 5: e0010983.

43. Czyzyk-Krzeska MF (1997). Molecular aspects of oxygen sensing in physiological adaptation to hypoxia. Respir Physiol 110: 99-111.

44. Semenza GL (2000). Hypoxia, clonal selection, and the role of HIF-1 in tumor progression. Crit Rev Biochem Mol Biol 35: 71-103.

45. Dang CV, Semenza GL (1999). Oncogenic alterations of metabolism. Trends Biochem Sci 24: 68-72.

46. Folkman J (1971).Tumor angiogenesis: therapeutic implications. N Engl J Med 285: $1182-1186$.

47. Ferrara N, Henzel WJ.(1989). Pituitary follicular cells secrete a novel heparinbinding growth factor specific for vascular endothelial cells. Biochem Biophys Res Commun. 161:851-58.

48. Griffioen AW, Barendsz-Janson AF, Mayo KH, Hillen HF (1998). Angiogenesis, a target for tumor therapy. J Lab Clin Med 132: 363-368.

49. Semenza GL, Roth PH, Fang HM, Wang GL (1994). Transcriptional regulation of genes encoding glycolytic enzymes by hypoxia-inducible factor 1 . J Biol Chem 269: 23757-23763.

50. Ryan HE, et al. (2000). Hypoxia-inducible factor-1 $\alpha$ is a positive factor in solid tumor growth. Cancer Res 60: 4010-4015.

51. Ryan HE, Lo J, Johnson RS (1998).HIF-1 $\alpha$ is required for solid tumor formation and embryonic vascularization. EMBO J 17: 3005-3015.

52. Blagosklonny MV (2001). Hypoxia-inducible factor: Achilles' heel of antiangiogenic cancer therapy. Int J Oncol 19: 257-262.

53. Rodríguez-Dévora JI, Shi ZD, Xu T (2011). doi: 10.1002/biot.201100100. Direct assembling methodologies for high-throughput bioscreening. J Biotechnol 6 (Pt 12): $1454-1465$.

54. Rapisarda A, et al. (2002). Identification of small molecule inhibitors of hypoxiainducible factor 1 transcriptional activation pathway. Cancer Res 62: 4316-4324. 
55. Wang GL, Semenza GL (1993). Desferrioxamine induces erythropoietin gene expression and hypoxia-inducible factor 1 DNA-binding activity: Implications for models of hypoxia signal transduction. Blood 82: 3610-3615.

56. Jiang BH, Rue E, Wang GL, Roe R, Semenza GL (1996). Dimerization, DNA binding, and transactivation properties of hypoxia-inducible factor 1. J Biol Chem 271: $17771-17778$.

57. Shoemaker RH, et al. (2002). Application of highthroughput, molecular-targeted screening to anticancer drug discovery. Curr Top Med Chem 2: 229-246.

58. Wang GL, Semenza GL (1993). General involvement of hypoxia-inducible factor 1 in transcriptional response to hypoxia. Proc Natl Acad Sci U S A 90: 4304-4308.

59. Ko FN, Wu CC, Kuo SC, Lee FY, Teng CM (1994). YC-1, a novel activator of platelet guanylate cyclase. Blood 84: 4226-4233.

60. Chun YS, Choi E, Yeo EJ, Lee JH, Kim MS, Park JW (2001). A new HIF-1 alpha variant induced by zinc ion suppresses HIF-1-mediated hypoxic responses. J Cell Sci 114: 4051-4061.

61. Chun YS, et al. (2001). Inhibitory effect of YC-1 on the hypoxic induction of erythropoietin and vascular endothelial growth factor in Hep3B cells. Biochem Pharmacol 61: 947-954.

62. Yeo EJ, et al. (2003).YC-1: a potential anticancer drug targeting hypoxia-inducible factor 1. J Natl Cancer Inst 95: 516-525.

63. Pan SL, et al. (2005). YC-1 [3-(5'-hydroxymethyl-2'-furyl)-1-benzyl indazole] inhibits endothelial cell functions induced by angiogenic factors in vitro and angiogenesis in vivo models. J Pharmacol Exp Ther 314: 35-42.

64. Forsythe JA, et al. (1996). Activation of vascular endothelial growth factor gene transcription by hypoxia-inducible factor 1. Mol Cell Biol 16: 4604-4613.

65. Grunstein J, Roberts WG, Mathieu-Costello O, Hanahan D, Johnson RS (1999). Tumor-derived expression of vascular endothelial growth factor is a critical factor in tumor expansion and vascular function. Cancer Res 59: 1592-1598.

66. Michel G, et al. (2002). Site-directed mutagenesis studies of the hypoxia-inducible factor-1alpha DNA-binding domain. Biochim Biophys Acta 1578: 73-83.

67. Burroughs KD, Oh J, Barrett JC, DiAugustine RP (2003). Phosphatidylinositol 3kinase and mek $1 / 2$ are necessary for insulin-like growth factor-I-induced vascular endothelial growth factor synthesis in prostate epithelial cells: a role for hypoxiainducible factor-1? Mol Cancer Res 1: 312-322. 
68. Li L, Madu CO, Lu A, Lu Y(2010). HIF-1 $\alpha$ promotes a Hypoxia-Independent Cell Migration. Open Biol J 3: 8-14.

69. Hockel M, Schlenger K, Aral B, Mitze M, Schaffer U, Vaupel P (1996).

Association between tumor hypoxia and malignant progression in advanced cancer of the uterine cervix. Cancer Res 56: 4509-4515.

70. Piret JP, Mottet DRM, Michiels C (2002). Is HIF-1alpha a pro- or an anti-apoptotic protein? Biochem Pharmacol 64: 889-892.

71. Graeber TG, Peterson JF, Tsai M, Monica K, Fornace AJ, Giaccia AJ (1994). Hypoxia induces accumulation of p53 protein, but activation of a G1- phase checkpoint by low-oxygen conditions is independent of p53 status. Mol Cell Biol 14: 6264-6277.

72. An WG, Kanekal M, Simon MC, Maltepe E, Blagosklonny MV, Neckers LM (1998). Stabilization of wild-type p53 by hypoxia-inducible factor 1alpha. Nature 392: 405-408.

73. Woods DB, Vousden KH(2001). Regulation of p53 function. Exp Cell Res 264: 56-66.

74. Blagosklonny MV, An WG, Romanova LY, Trepel J, Fojo T, Neckers LM (1998). p53 inhibits hypoxia-inducible factor-stimulated transcription. J Biol Chem 273: 11995-11998.

75. Ravi R, et al. (2000). Regulation of tumor angiogenesis by p53-induced degradation of hypoxia-inducible factor 1alpha. Genes Dev 14: 34-44.

76. Unruh A, et al. (2003). The hypoxia inducible factor $1 \alpha$ is a negative factor for tumour therapy. Oncogene 22: 3213-3220.

77. Costa A, Coradini D, Carassi A, Erdas R, Sardella A, Daidon MG (2001). Re: Levels of hypoxia inducible factor $1 \alpha$ during breast carcinogenesis. J Natl Cancer Inst 93: 1175-1177.

78. Pidgeon GP, Barr MP, Harmey JH, Foley DA, Bouchier-Hayes DJ (2001).Vascular endothelial growth factor (VEGF) up-regulates Bcl-2 and inhibits apoptosis in human and murine mammary adenocarcinoma cells. Br J Cancer 85: 273-278.

79. Suzuki H, Tomida A, Tsuruo T (2001). Dephosphorylated hypoxia-inducible factor 1alpha as a mediator of p53- dependent apoptosis during hypoxia.Oncogene. 20: 5779-5788. 
80. Yeo EJ, Ryu JH, Chun YS, Cho YS, Jang IJ, Cho H, Kim J, Kim MS, Park JW (2006).YC-1 induces $\mathrm{S}$ cell cycle arrest and apoptosis by activating checkpoint kinases. Cancer Res 66: 6345-6352.

81. Feng Y, Zhu H, Ling T, Hao B, Zhang G, Shi R (2011). Effects of YC-1 targeting hypoxia-inducible factor 1 alpha in oesophageal squamous carcinoma cell line Eca109 cells. Cell Biol Int 35: 491-497.

82. Boatright KM, Salvesen GS (2003). Mechanisms of caspase activation. Curr Opin Cell Biol 15: 725-731.

83. Folkmann J, D’Amore PA (1996).Blood vessel formation: what is its molecular basis? Cell 87: 1153-1155.

84. Fidler IJ, Ellis LM (1994). The implication of angiogenesis for the biology and therapy of cancer metastasis. Cell 79: 185-188.

85. Fox SB (1997). Tumor angiogenesis and prognosis. Histopathology 30: 294-301.

86. Ferrara N, Davis-Smyth T (1997). The biology of vascular endothelial growth factor. Endocr Rev 18: 4-25.

87. Benjamin LE, Keshet E (1997). Conditional switching of vascular endothelialgrowth factor (VEGF) expression in tumors: induction of endothelial cell shedding and regression of hemangioblastoma like vessels by VEGF withdrawal. Proc Natl Acad Sci U S A 94: 8761-8766.

88. Benjamin LE, Golijanin D, Itin A, Pode D, Keshet E (1999). Selective ablation of immature blood vessels in establishedtumors follows vascular endothelial growth factor withdrawal. J Clin Invest 103: 159-165.

89. Borgstrom P, Hillan KJ, Sriramarao P, Ferrara N (1996). Complete inhibition of angiogenesis and growth of microtumors by anti-vascular endothelial growth factor neutralizing antibody: novel concepts of angiostatic therapy from intravital video microscopy. Cancer Res 56: 4032-4039.

90. Cheng SY, et al. (1996). Suppression of glioblastoma angiogenicity and tumorigenicity by inhibition of endogenous expression of vascular endothelial growth factor. Proc Natl Acad Sci U S A 93: 8502-8507.

91. Im SA, et al. (1999). Antiangiogenesis treatment for gliomas: transfer of antisensevascular endothelial growth factor inhibits tumor growth in vivo. Cancer Res 59: 895-900. 
92. Jain RK, et al. (1998). Endothelial cell death, angiogenesis, and microvascular function after castration in an androgen-dependent tumor: role of vascular endothelial growth factor. Proc Natl Acad Sci U S A 95: 10820-10825.

93. Kim KJ, et al. (1993). Inhibition of vascular endothelial growth factor-induced angiogenesis suppresses tumor growth in vivo. Nature 362: 841-844.

94. Millauer B, Shawver LK, Plate KH, Risau W, Ullrich A (1994). Glioblastoma growth inhibited in vivo by a dominantnegative Flk-1 mutant. Nature 367: 576-579.

95. Millauer B, et al. (1996). Dominant-negative inhibition of Flk-1 suppresses the growth of many tumor types in vivo. Cancer Res 56: 1615-1620.

96. Skobe M, Rockwell P, Goldstein N, Vosseler S, Fusenig NE (1997). Halting angiogenesis suppresses carcinoma cell invasion. Nat Med 3: 1222-1227.

97. Shaheen RM, et al. (1999). Antiangiogenic therapy targeting the tyrosine kinase receptor for vascular endothelial growth factor inhibits the growth of colon cancer liver metastases and induces tumor and endothelial cell apoptosis. Cancer Res 59: 5412-5416.

98. Saleh M, Stacker SA, Wilks AF (1996). Inhibition of growth of C6 glioma cells in vivo by expression of antisense vascular endothelial growth factor sequence. Cancer Res 56: 393-401.

99. Yuan F, Chen Y, Dellian M, Safabakhsh N, Ferrara N, Jain RK. (1996). Timedependent vascular regression and permeability changes in established tumor xenografts induced by an anti-vascular endothelial growth factor/vascular permeability permeability factor antibody. Proc Natl Acad Sci U S A 93: $14765-$ 14770 .

100. Maxwell PH, et al. (1997).Hypoxiainducible factor-1 modulates gene expression in solid tumors and influences both angiogenesis and tumor growth. Proc Natl Acad Sci U S A 94: 8104-8109.

101. Jackson JR, Minton JAL, Ho ML, Wei N, Winkler JD (1997). Expression of vascular endothelial growth factor in synovial fibroblasts is induced by hypoxia and interleukin 1 $\beta$. J. Rheumatol 24:1253-1259.

102. Ryuto M, et al. (1996). Induction of vascular endothelial growth factor by tumor necrosis factor $\alpha$ in human glioma cells. J Biol Chem 271: 28220-28228.

103. Stavri GT, et al. (1995). Hypoxia and platelet-derived growth factor-BB synergistically upregulate the expression of vascular endothelial growth factor in vascular smooth muscle cells. FEBS Lett 358: 311-315. 
104. Stavri GT, Zachary IC, Baskerville PA, Martin JF, Erusalimsky JD (1995). Basic fibroblast growth factor upregulates the expression of vascular endothelial growth factor in vascular smooth muscle cells. Circulation 92: 11-14.

105. Warren RS, Yuan H, Matli MR, Ferrara N, Donner DB (1996). Induction of vascular endothelial growth factor by insulin- like growth factor 1 in colorectal carcinoma. J Biol Chem 271: 29483-29488.

106. Feldser D, et al. (1999). Reciprocal postive regulation of hypoxiainducible factor $1 \alpha$ and insulin-like growth factor 2. Cancer Res 59: 3915-3918.

107. Hellwig-Burgel T, Rutkowsk K, Metzen E, Fandrey J, Jelkmann W (1999). Interleukin- $1 \beta$ and tumor necrosis factor- $\alpha$ stimulate DNA binding of hypoxiainducible factor 1. Blood. 94: 1561-1567.

108. Zelzer E, et al. (1998). Insulin induces transcription of target genes through the hypoxia-inducible factor HIF-1 $\alpha /$ ARNT. EMBO J 17: 5085-5094.

109. Zhong H, et al. (2000). Modulation of HIF-1 $\alpha$ expression by the epidermal growth factor/ phosphatidylinositol 3-kinase/PTEN/AKT/ FRAP pathway in human prostate cancer cells: implications for tumor angiogenesis and therapeutics. Cancer Res 60: 1541-1545.

110. Bos R, et al. (2001).Levels of hypoxia-inducible factor-1 $\alpha$ during breast carcinogenesis. J Natl Cancer Inst 93: 309-314.

111. Kung AL, Wang S, Klco JM, Kaelin WG, Livingston DM (2000). Suppression of tumor growth through disruption of hypoxia-inducible transcription. Nat Med. 6: 1335-1340.

112. S. Wang, Q. Liu, Y. Zhang, et al. (2009). Suppression of growth, migration and invasion of highly-metastatic human breast cancer cells by berbamine and its molecular mechanisms of action. Mol Cancer 8: 81 .

113. M Lacroix (2006). Significance, detection and markers of disseminated breast cancer cells. Endocr Relat Cancer 13 (Pt 4): 1033-1067.

114. Zagzag D, et al. (2000). Expression of hypoxia-inducible factor $1 \alpha$ in brain tumors: association with angiogenesis, invasion, and progression. Cancer 88: 2606-2618.

115. Liao D, Corle C, Seagroves, TN, Johnson RS (2007). Hypoxia-inducible factor1alpha is a key regulator of metastasis in a transgenic model of cancer initiation and progression. Cancer Res 67: 563-572.

116. Gordan JD, Simon MC (2007). Hypoxia-inducible factors: central regulators of the tumor phenotype. Curr Opin Genet Dev 17: 71-77. 
117. Harris AL (2002). Hypoxia - a key regulatory factor in tumour growth. Nat Rev Cancer 2: 38-47.

118. Semenza GL (2006). Development of novel therapeutic strategies that target HIF-1. Expert Opin on Ther Targets 10: $267-280$.

119. Powis G, Kirkpatrick L (2004). Hypoxia inducible factor-1alpha as a cancer drug target. Mol Cancer Ther 3: 647-654.

120. Escuin D, Kline ER, Giannakakou P (2005). Both microtubule-stabilizing and microtubule-destabilizing drugs inhibit hypoxia-inducible factor-1alpha accumulation and activity by disrupting microtubule function. Cancer Res 65: 9021-9028.

121. Wiedmann MW, Caca K (2005). Molecularly targeted therapy for gastrointestinal cancer. Curr Cancer Drug Targets 5: 171-193.

122. Generali D, Fox SB, Berruti A (2006). Hypoxia-inducible factor (HIF) 1-alpha expression predicts a poor response to primary chemo-endocrine therapy and disease free survival in primari human breast cancer. Clin Cancer Res. Clin Cancer Res. (15): 4562-4568.

123. Duffy MJ (2004). The urokinase plasminogen activator system: role in malignancy. Curr Pharm Des. (1):39-49

124. Jaakkola P, Mole DR, Tian YM, et al. (2001). Targeting of HIF-alpha to the von Hippel-Lindau ubiquitylation complex by O2-regulated prolyl hydroxylation. Science 292: 468-472.

125. Kaelin WG Jr, Ratcliffe PJ (2008). Oxygen sensing by metazoans: the central role of the HIF hydroxylase pathway. Mol Cell 30 (Pt 4): 393-402.

126. Kaluz S, Kaluzova M, Stanbridge EJ (2008). Does inhibition of degradation of hypoxia-inducible factor (HIF) alpha always lead to activation of HIF? Lessons learnt from the effect of proteasomal inhibition on HIF activity. J Cell Biochem 104 (Pt 2): 536-544.

127. Ohh M, et al. (2000). Ubiquitination of hypoxia-inducible factor requires direct binding to the beta-domain of the von Hippel-Lindau protein. Nat Cell Biol 2 (Pt 7): $423-427$.

128. Furuta GT, et al. (2001). Hypoxia-inducible factor 1-dependent induction of intestinal trefoil factor protects barrier function during hypoxia. J Exp Med 193: $1027-1034$. 
129. Karhausen J, et al. (2004). Epithelial hypoxia-inducible factor-1 is protective in murine experimental colitis. J Clin Invest 114: 1098-1106.

130. Xia Y, Choi HK, Lee K (2012). Recent advances in hypoxia-inducible factor (HIF1) inhibitors. Eur J Med Chem 49: 24-40.

131. Kroemer G, Pouyssegur J (2008). Tumor cell metabolism: cancer's Achilles' heel. Cancer Cell 13 (Pt 6): 472-482.

132. O'Neill GM, et al. (2007). A new central scaffold for metastasis: parsing HEF1/Cas-L/NEDD9.Cancer Res 67: 8975-8979.

133. Law SF, et al. (1998). Cell cycle-regulated processing of HEF1 to multiple protein forms differentially targeted to multiple subcellular compartments. Mol Cell Biol 18: $3540-3551$.

134. Natarajan M, et al. (2006). HEF1 is a necessary and specific downstream effector of FAK that promotes the migration of glioblastoma cells. Oncogene 25: 1721-1732.

135. Kim M, et al. (2006). Comparative oncogenomics identifies NEDD9 as a melanoma metastasis gene. Cell 125: 1269-1281.

136. Singh M, Cowell L, Seo S, O'Neill G, Golemis E (2007). Molecular basis for HEF1/NEDD9/Cas-L action as a multifunctional co-ordinator of invasion, apoptosis and cell cycle. Cell Biochem Biophys 48: 54-72.

137. Pugacheva EN, Golemis EA (2005). The focal adhesion scaffolding protein HEF1 regulates activation of the Aurora-A and Nek2 kinases at the centrosome. Nat Cell Biol 7: 937-946.

138. Dadke D, Jarnik M, Pugacheva EN, Singh MK, Golemis EA (2006). Deregulation of HEF1 impairs M-phase progression by disrupting the RhoA activation cycle. Mol Biol Cell 17: 1204-1217.

139. Xia D, Holla VR, Wang D, Menter DG, DuBois RN (2010). HEF1 is a crucial mediator of the proliferative effects of prostaglandin $\mathrm{E}(2)$ on colon cancer cells. Cancer Res 70: 824-831.

140. Sasaki T, et al. (2005). Nedd9 protein, a Cas-L homologue, is upregulated after transient global ischemia in rats: possible involvement of Nedd9 in the differentiation of neurons after ischemia. Stroke 36: 2457-2462.

141. Martin-Rendon E, et al. (2007). Transcriptional profiling of human cord blood $\mathrm{CD} 133+$ and cultured bone marrow mesenchymal stem cells in response to hypoxia. Stem Cells 25: 1003-1012. 
142. Sun-Hee Kim, Dianren Xia, Sang-Wook Kim, Vijaykumar Holla, David G. Menter, and Raymond N (2010). DuBois. Human enhancer of filamentation 1 is a mediator of hypoxia-inducible factor- $1 \alpha$-mediated migration in colorectal carcinoma cells. Cancer Res 70 (Pt 10): 4054-4063.

143. Giatromanolaki A, Harris AL (2001). Tumour hypoxia, hypoxia signaling pathways and hypoxia inducible factor expression in human cancer. Anticancer Res 21: 4317-4324.

144. Victor N, Ivy A, Jiang BH, Agani FH (2003). Involvement of HIF-1 in invasion of Mum2B uveal melanoma cells. Cancer Res 63 (Pt 5): 1138-1143.

145. Krishnamachary B et al, (2003). Regulation of colon carcinoma cell invasion by hypoxia-inducible factor 1. Cancer Res. 63(5):1138-1143.

146. Björklund M, Koivunen E (2005). Gelatinase-mediated migration and invasion of cancer cells. Biochim Biophys Acta 1755 (Pt 1): 37-69.

147. Gerg M, et al. (2008). Distinct functionality of tumor cell-derived gelatinases during formation of liver metastases. Mol Cancer Res 6 (Pt 3): 341-351.

148. Gorden DL, Fingleton B, Crawford HC, Jansen DE, Lepage M, Matrisian LM (2007). Resident stromal cell-derived MMP-9 promotes the growth of colorectal metastases in the liver microenvironment. Int J Cancer. 121 (Pt 3):495-500.

149. Bachmeier BE, et al. (2001). Matrix metalloproteinases (MMPs) in breast cancer cell lines of different tumorigenicity. Anticancer Res 21 (Pt 6A): 3821-3828.

150. Sun-Hee K, Dianren X, Sang-Wook K, Vijaykumar H, David GM, Raymond ND (2010). Human enhancer of filamentation 1 is a mediator of hypoxia-inducible factor-1 $\alpha$-mediated migration in colorectal carcinoma cells. Cancer Res. 70 (Pt 10): 4054-4063.

151. Gans JD, et al. (2006). Comparative oncogenomics identifies NEDD9 as a melanoma metastasis gene. Cell 125:1269-1281.

152. Fashena SJ, Einarson MB, O'Neill GM, Patriotis C, Golemis E A (2002) Dissection of HEF1-dependent functions in motility and transcriptional regulation. J Cell Sci 115: 99-111.

153. Van Seventer GA, et al. (2001). Focal adhesion kinase regulates beta1 integrindependent T cell migration through an HEF1 effector pathway. Eur. J. Immunol. 31:1417-1427. 
154. Law SF, O'Neill GM, Fashena SJ, Einarson MB, Golemis EA (2000). The docking protein HEF1 is an apoptotic mediator at focal adhesion sites. Mol Cell Biol 20:5184-5195.

155. Ohashi Y, Iwata S, Kamiguchi K, Morimoto C (1999). Tyrosine phosphorylation of Crk-associated substrate lymphocyte-type is a critical element in TCR- and beta 1 integrin-induced T lymphocyte migration. J Immunol 163:3727-3734.

156. Duffy MJ, McGowan PM, Gallagher WM (2008). Cancer invasion and metastasis: changing views. J Pathol 214 (Pt 3): 283-293.

157. Overall CM, Kleifeld O (2006). Tumour microenvironment - opinion: validating matrix metalloproteinases as drug targets and anti-targets for cancer therapy. Nat Rev Cancer 6 (Pt 3): 227-239.

158. Vaupel P, Mayer A (2007). Hypoxia in cancer: significance and impact on clinical outcome. Cancer Metastasis Rev 26: 225-239.

159. Sartorelli AC (1988). Therapeutic attack of hypoxic cells of solid tumors: presidential address. Cancer Res 48: 775-778.

160. Chen J, et al. (2003). Dominant-negative hypoxia-inducible factor-1 alpha reduces tumorigenicity of pancreatic cancer cells through the suppression of glucose metabolism. Am J Pathol162: 1283-1291.

161. Williams KJ, et al. (2002). A protective role for HIF-1 in response to redox manipulation and glucose deprivation: implications for tumorigenesis. Oncogene 21(Pt 2): 282-290.

162. Brizel DM, et al. (1996). Tumor oxygenation predicts for the likelihood of distant metastases in human soft tissue sarcoma. Cancer Res 56: 941-943.

163. Nam KS, Shon YH (2009). Suppression of metastasis of human breast cancer cells by chitosan oligosaccharides. J Microbiol Biotechnol 19 (Pt 6): 629-633.

164. Kroemer G, Pouyssegur J (2008). Tumor cell metabolism: cancer's Achilles' heel. Cancer Cell 13 (Pt 6): 472-482. 


\section{VITA}

Chikezie Okoro Madu was born in 1972. He obtained a Bachelor degree in Biochemistry from the University of Uyo, Nigeria, and shortly following his graduation, he started teaching in a military high school in Nigeria, and continued this profession in the Memphis city schools for six years after obtaining a Masters degree in Education.

He began his graduate studies in the Integrated Program in Biomedical Sciences at the University of Tennessee Health Science Center in 2007, and plans to continue residing in Memphis, Tennessee with his wife, Pamela, and two children, Chinua and Elechi. 